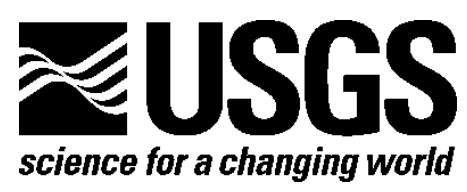

\title{
Economic Analysis of the 2010 U.S. Geological Survey Assessment of Undiscovered Oil and Gas in the National Petroleum Reserve in Alaska
}

By Emil D. Attanasi and Philip A. Freeman

Open-File Report 2011-1103

U.S. Department of the Interior U.S. Geological Survey 


\section{U.S. Department of the Interior \\ KEN SALAZAR, Secretary}

\section{U.S. Geological Survey \\ Marcia K. McNutt, Director}

U.S. Geological Survey, Reston, Virginia: 2011

For product and ordering information:

World Wide Web: http://www.usgs.gov/pubprod

Telephone: 1-888-ASK-USGS

For more information on the USGS—-the Federal source for science about the Earth, its natural and living resources, natural hazards, and the environment-

World Wide Web: http://www.usgs.gov

Telephone: 1-888-ASK-USGS

Suggested citation:

Attanasi, E.D., and Freeman, P.A., 2011, Economic analysis of the 2010 U.S. Geological Survey assessment of undiscovered oil and gas in the National Petroleum Reserve in Alaska: U.S. Geological Survey Open-File Report 2011-1103, 64 p., available only online.

Any use of trade, product, or firm names is for descriptive purposes only and does not imply endorsement by the U.S. Government.

Although this report is in the public domain, permission must be secured from the individual copyright owners to reproduce any copyrighted material contained within this report. 


\section{Contents}

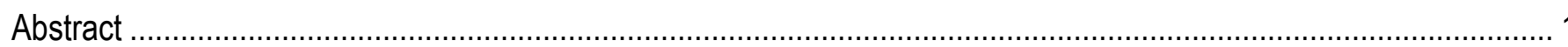

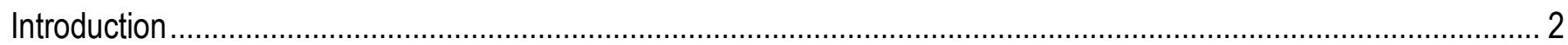

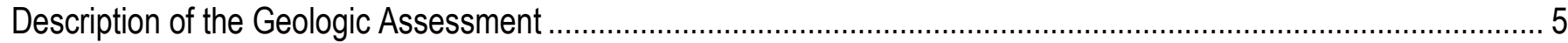

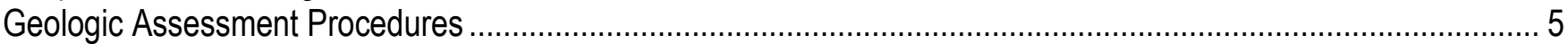

Characteristics of Assessed Technically Recoverable Resources ..................................................................

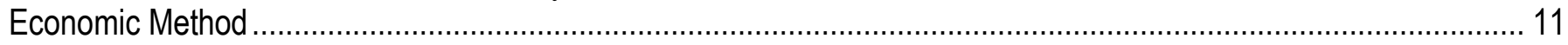

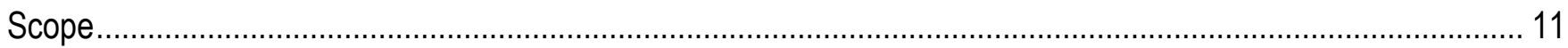

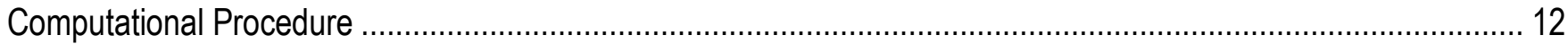

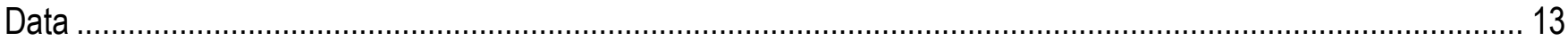

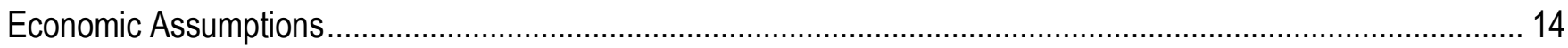

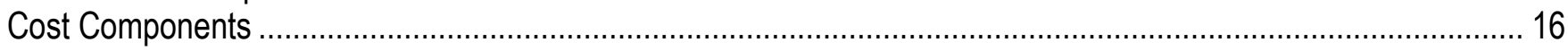

Transportation, Infrastructure, and Location Assumptions ………………………….............................. 16

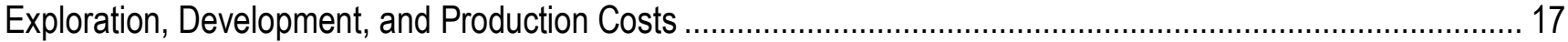

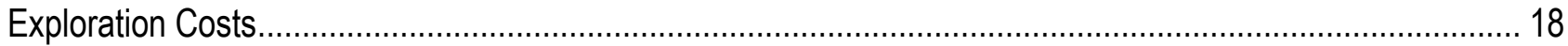

Development Costs for Crude Oil Accumulations .............................................................................. 18

Production Profiles and Operating Costs for Crude Oil Accumulations......................................................... 19

Development Costs for Gas Accumulations.................................................................................. 19

Production Profiles and Operating Costs for Gas Accumulations .............................................................. 20

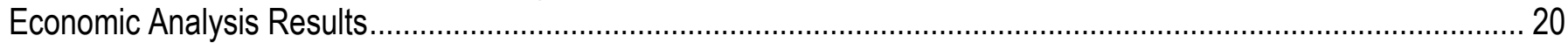

Estimated Economic Gas in Undiscovered Gas Accumulations................................................................... 21

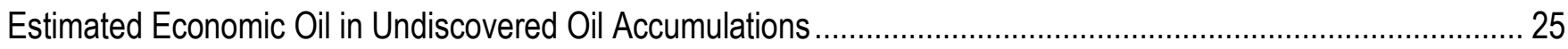

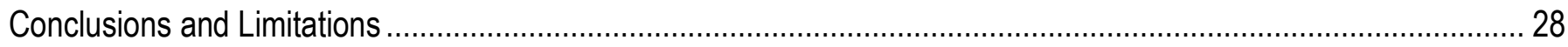

Acknowledgments

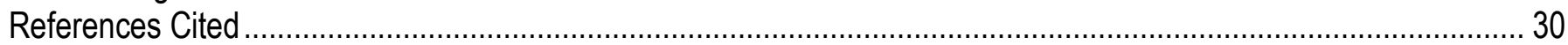

Appendix 1. Play Maps and Mean Estimates of Undiscovered Technically Recoverable Volumes of Oil, Gas,

and Natural Gas Liquids for Each Play in the NPRA Study Area............................................................. 35

Appendix 2. Allocation of Play Resources to Economic Zones ........................................................................ 40

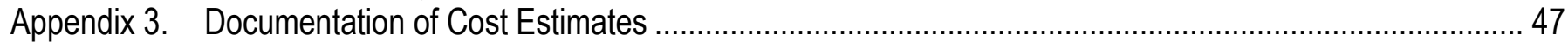

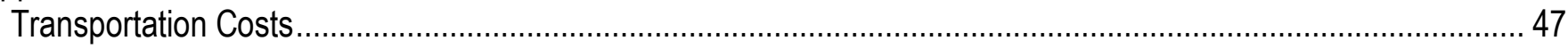

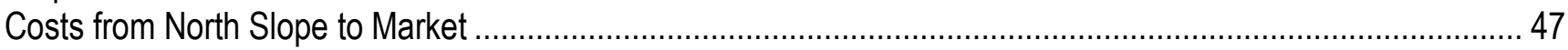

Feeder and Regional Pipeline Assumptions ...................................................................................... 47

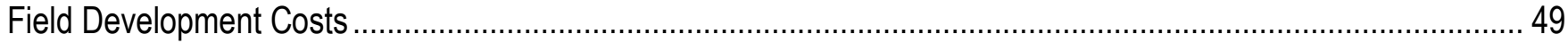

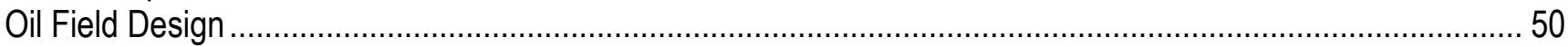

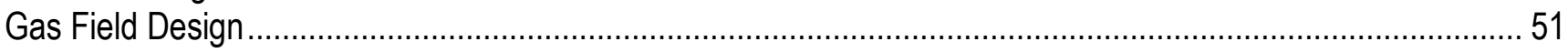

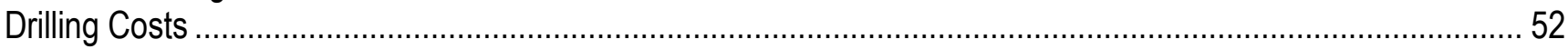

Facilities Costs—Oil and Gas Development......................................................................................... 53

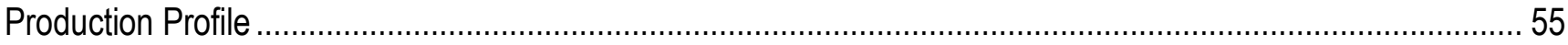

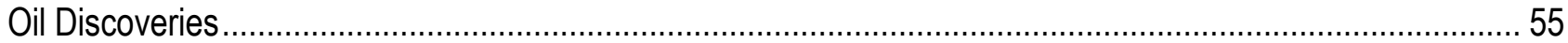

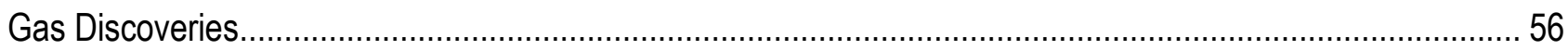

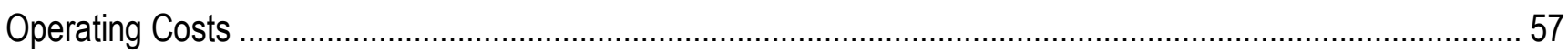

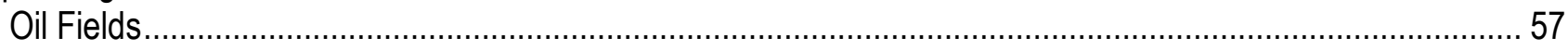

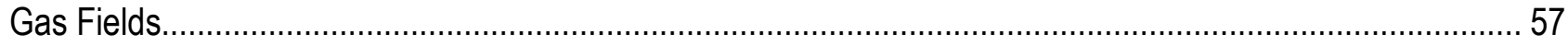

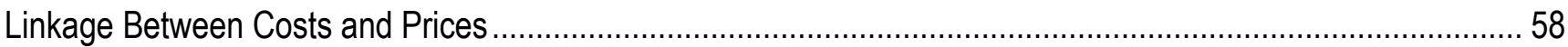

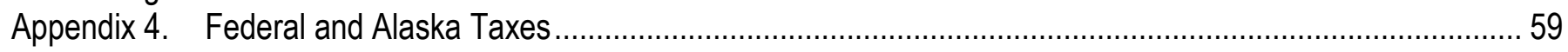




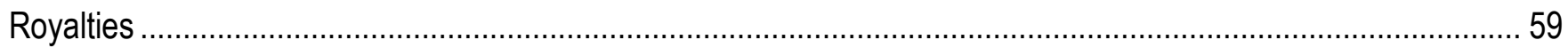

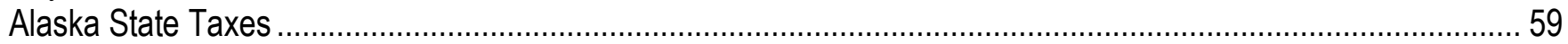

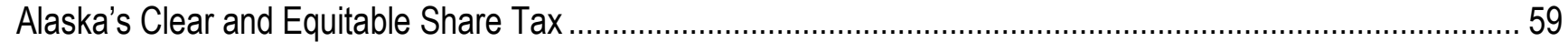

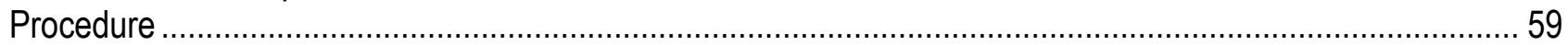

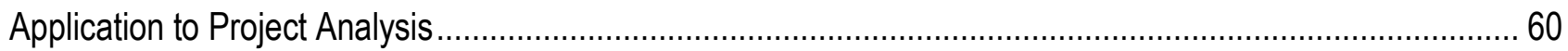

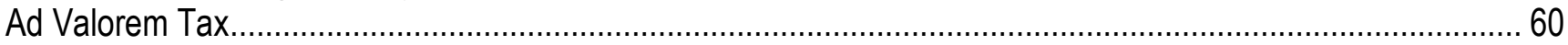

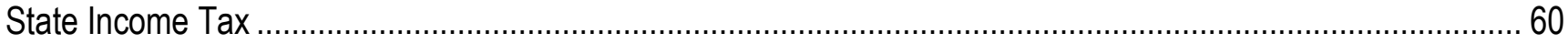

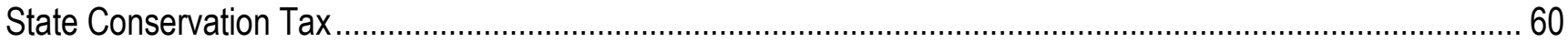

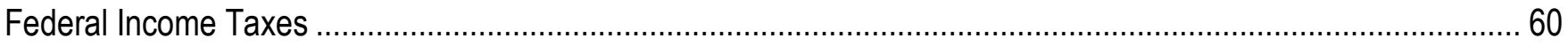

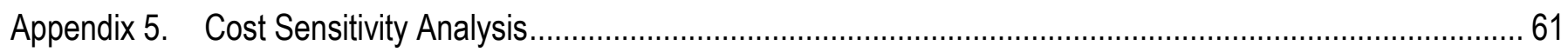

\section{Figures}

1. Map showing the National Petroleum Reserve in Alaska (NPRA), the 1002 Area of the Arctic National Wildlife Refuge, and oil-producing units near Prudhoe Bay in the central North Slope......

2. Graphs of size-frequency distributions of the estimated number of accumulations of undiscovered technically recoverable oil $(A)$ and nonassociated gas $(B)$ corresponding to the 95 th-fractile (F95), mean, and 5th-fractile (F5) volume resource estimates for the National Petroleum Reserve in Alaska study area..... 8

3. Map showing economic zones of the National Petroleum Reserve in Alaska (NPRA) study area................. 11

4. Summary graph of undiscovered economic nonassociated gas resources in the National Petroleum

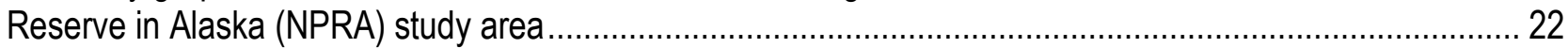

5. Summary graph of undiscovered economic oil resources in the National Petroleum Reserve in Alaska

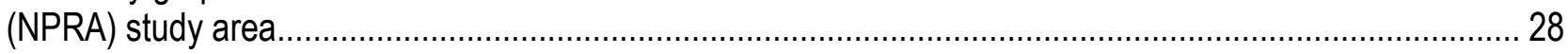

A1-1. Play boundary maps for the 20 plays in the 2010 assessment (Houseknecht and others, 2010) showing the National Petroleum Reserve in Alaska (NPRA), the coastline, and play extents

A3-1. Graph showing percentage of water in oil production stream as a function of reservoir depletion for Kuparuk-type reservoirs...

A3-2. Graph showing percentage of water in oil production stream as a function of reservoir depletion for Alpine-type reservoirs in the National Petroleum Reserve in Alaska

A5-1. Graphs showing percentage changes in economic volumes of gas in undiscovered gas accumulations at different market prices based on the mean estimate for the NPRA study area with either a 33-percent increase or a 33-percent reduction in investment costs of drilling and facilities from the base case and with either $(A)$ a 20-year delay or $(B)$ a 10-year delay between discovery and availability of an export pipeline to market

A5-2. Graphs showing percentage changes in economic volumes of gas in undiscovered gas accumulations at different market prices based on the mean estimate for the NPRA study area with either a 33-percent increase or a 33-percent reduction in transportation costs from the base case and with either $(A)$ a 20-year delay or $(B)$ a 10-year delay between discovery and availability of an export pipeline to market...

A5-3. Graphs showing percentage changes in economic volumes of gas in undiscovered gas accumulations at different market prices based on the mean estimate for the NPRA study area with either a 33-percent increase or a 33-percent reduction in investment costs of drilling, facilities, and pipelines (within the North Slope) from the base case and with either $(A)$ a 20-year delay or $(B)$ a 10-year delay between discovery and availability of an export pipeline to market. 


\section{Tables}

1. Volumes of the aggregated undiscovered technically recoverable oil, gas, and natural gas liquids (NGL) related to the mean, 95 th-fractile, and 5th-fractile estimates by the U.S. Geological Survey in 2010 of oil and nonassociated gas, associated gas byproduct volume, and concomitant resource volumes, that is nonassociated gas volumes corresponding to the oil fractile estimates and concomitant oil volumes corresponding to the nonassociated gas fractile estimates, respectively, for the National Petroleum Reserve in Alaska study area....................................................................................................

2. Cumulative percentage distribution of estimated undiscovered technically recoverable oil in oil accumulations and nonassociated (NA) gas in gas accumulations by size class for the National Petroleum Reserve in Alaska study area...

3. Volumes of nonassociated gas and natural gas liquids (NGL) from undiscovered gas accumulations, estimated for the National Petroleum Reserve in Alaska study area, available as a function of specified market prices that offset costs of finding, developing, producing, and transporting the gas to market

4. Volumes of oil and natural gas liquids (NGL) from undiscovered oil accumulations, estimated for the National Petroleum Reserve in Alaska study area, available as a function of specified market prices that offset costs of finding, developing, producing, and transporting the oil to market.......

A1-1. Mean estimates by the U.S. Geological Survey in 2010 of undiscovered technically recoverable volumes of conventional oil and gas by play for the National Petroleum Reserve in Alaska study area...... 36

A2-1. Percentage allocations to economic zones of undiscovered technically recoverable oil in oil accumulations and gas in gas accumulations for plays of the National Petroleum Reserve in Alaska study area......

A2-2. Volume of the aggregated undiscovered technically recoverable oil, gas, and natural gas liquids (NGL) related to the mean, 95 th-fractile, and 5th-fractile estimates by the U.S. Geological Survey in 2010 of oil and nonassociated gas, associated gas byproduct volume and concomitant resource volumes, that is nonassociated gas volumes corresponding to the oil fractile estimates and concomitant oil volumes corresponding to the nonassociated gas fractile estimates, respectively, for each economic zone of the National Petroleum Reserve in Alaska (NPRA) study area

A2-3. Distribution of mean estimates of undiscovered technically recoverable oil in oil accumulations and nonassociated gas in gas accumulations by size class for each economic zone in the National Petroleum Reserve in Alaska study area..

A3-1. Distances and regional pipeline capacity by economic zone of a hypothetical pipeline system for the National Petroleum Reserve in Alaska study area.....

A3-2. Estimated recovery per production well, in millions of barrels of oil (MMBO), for oil accumulations in any economic zone of the National Petroleum Reserve in Alaska study area.

A3-3. Estimated recovery per production well, in billions of cubic feet of gas (BCF), for gas accumulations in any economic zone of the National Petroleum Reserve in Alaska study area.

A3-4. Estimates of oil field facilities investment costs per barrel of oil recovered by accumulation size class for facilities located in economic zone 110 of the National Petroleum Reserve in Alaska study area..

A3-5. Estimates of gas field facilities investment costs per thousand cubic feet of gas recovered by accumulation size class for facilities located in economic zone 110 of the National Petroleum Reserve in Alaska study area.

A3-6. Oil discovery production profiles used in the economic analysis .......................................................... 55

A3-7. Gas discovery production profiles used in the economic analysis ..........................................................5 57

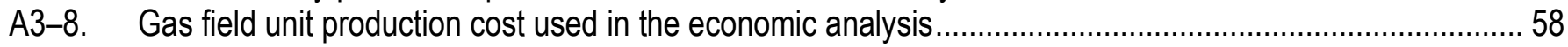




\section{Conversion Factors}

\begin{tabular}{|c|c|c|}
\hline Multiply & By & To obtain \\
\hline \multicolumn{3}{|c|}{ Length } \\
\hline inch (in.) & 2.54 & centimeter $(\mathrm{cm})$ \\
\hline foot $(\mathrm{ft})$ & 0.3048 & meter $(\mathrm{m})$ \\
\hline mile (mi) & 1.609 & kilometer (km) \\
\hline \multicolumn{3}{|c|}{ Area } \\
\hline square foot $\left(\mathrm{ft}^{2}\right)$ & 0.09290 & square meter $\left(\mathrm{m}^{2}\right)$ \\
\hline acre & & square meter $\left(\mathrm{m}^{2}\right)$ \\
\hline acre & 0.4047 & hectare (ha) \\
\hline square mile (640 acres) & 2.590 & square kilometer \\
\hline \multicolumn{3}{|c|}{ Volume } \\
\hline barrel (bbl) (petroleum, 1 barrel=42 gallons) & 0.1590 & cubic meter $\left(\mathrm{m}^{3}\right)$ \\
\hline cubic foot $\left(\mathrm{ft}^{3}\right)$ & 0.02832 & cubic meter $\left(\mathrm{m}^{3}\right)$ \\
\hline
\end{tabular}

\section{Unit Abbreviations}

$\begin{array}{ll}\text { bbl } & \text { barrel of crude oil } \\ \text { BBL } & \text { billion barrels of liquids } \\ \text { BBO } & \text { billion barrels of oil } \\ \text { BCF } & \text { billion cubic feet } \\ \text { Btu } & \text { British thermal unit } \\ \text { MCF } & \text { thousand cubic feet } \\ \text { MMBL } & \text { million barrels of liquids } \\ \text { MMBO } & \text { million barrels of oil } \\ \text { TCF } & \text { trillion cubic feet }\end{array}$




\title{
Economic Analysis of the 2010 U.S. Geological Survey Assessment of Undiscovered Oil and Gas in the National Petroleum Reserve in Alaska
}

\author{
By Emil D. Attanasi and Philip A. Freeman
}

\begin{abstract}
This report summarizes the economic analysis of the U.S. Geological Survey's 2010 assessment of oil and gas in undiscovered accumulations in the National Petroleum Reserve in Alaska (NPRA); the assessment results were released by D.W. Houseknecht and others in October 2010 in USGS Fact Sheet 2010-3102. The assessment study area includes Federal, State, and Native lands within the NPRA boundary plus State offshore areas on the landward side of the State-Federal offshore boundary.

Estimates of technically recoverable oil in undiscovered oil accumulations range from 336 to 1,707 million barrels of oil (MMBO) with a mean of $895 \mathrm{MMBO}{ }^{1}$ The endpoints of the range in estimated volumes correspond to the 95-percent probability level (that is, a 19-in-20 chance that the actual volume will exceed the 95th-fractile volume) and the 5-percent probability level (1-in-20 chance that the actual volume will exceed the 5th-fractile volume), respectively. Similarly, the 95th- and 5thfractile estimates of technically recoverable gas volumes in undiscovered gas accumulations range from 31.0 to 77.5 trillion cubic feet (TCF) of gas with a mean value of $52.8 \mathrm{TCF}$.

Characteristics of the assessment important to the commercial development of oil and gas discoveries are the size-frequency distributions, general geographic locations, and depths of the posited undiscovered oil and gas accumulations. At the mean estimate, the assessed distribution of undiscovered oil accumulations has 87 percent of the assessed oil in accumulations smaller than $256 \mathrm{MMBO}$. At the 95th-fractile estimate, all of the undiscovered oil was assigned to accumulations smaller than 128 MMBO, and at the 5th-fractile estimate, 64 percent of the assessed oil was assigned to accumulations smaller than $256 \mathrm{MMBO}$. At the mean estimate, 17 percent of the gas (8.74 TCF) assessed was in undiscovered accumulations containing at least 3 TCF (500 million barrels of oil equivalent.) At the 95th-fractile estimate, only 6 percent $(1.71 \mathrm{TCF})$ of the undiscovered natural gas was assigned to accumulations containing at least $3 \mathrm{TCF}$, and at the 5th-fractile estimate, 27 percent $(21.2 \mathrm{TCF})$ was assigned to accumulations containing at least $3 \mathrm{TCF}$. Although the sizes of undiscovered gas accumulations are modest, the posited numbers of gas accumulations lead to the expectation that joint development of accumulations containing between 250 and 768 billion cubic feet (BCF) will be possible and may become the norm.

Results of the economic analysis are presented as separate cost functions associated with the mean, 95th-, and 5th-fractile estimates of undiscovered technically recoverable oil and gas. An after-tax 12-percent rate of return, or hurdle rate, was assumed. The calculations used 2010 costs and current
\end{abstract}

\footnotetext{
${ }^{1}$ Houseknecht and others (2010) show a total mean oil volume of 896 million barrels, which is the sum if each play mean is rounded to an integer. The mean estimate of 895 million barrels used in this report represents the sum of the actual unrounded (decimal-valued) play estimates.
} 
technology, and the results of the analysis are stated in constant 2010 dollars. Cost functions include the cost of finding, developing, producing, and transporting the resource to market. The transportation costs from the field to the market were included in the analysis so that the prices and costs are at the market rather than the wellhead.

There is currently no pipeline to transport gas from the North Slope to the other markets in North America. Therefore, the economic analysis of nonassociated natural gas was based on the assumption that there would be either a 10-year or a 20-year delay between the expenditures for discovery of gas accumulations and their development and production that would access a gas pipeline to market. At a market price in the conterminous United States of $\$ 8$ per thousand cubic feet (MCF) and with the assumption of a 10-year delay, the economic nonassociated gas resources at the 95th-fractile, mean, and 5th-fractile estimates are predicted to be 4.5 TCF, 17.5 TCF, and 39.4 TCF, respectively. Similarly, for a 20-year delay, the economic gas resources at the 95th-fractile, mean, and 5th-fractile estimates are predicted to be 0.9 TCF, 7.3 TCF, and 24.5 TCF, respectively. Results illustrate the importance of access to pipeline capacity for the timely development of new discoveries as an incentive for exploration.

In the process of gas exploration, oil accumulations are expected to be found, and some will be commercially developed. At an oil price of $\$ 90$ per barrel ( $\$ 10.00$ per MCF gas price) at the mean estimate of $895 \mathrm{MMBO}$, the economically recoverable oil resources are predicted to be $502 \mathrm{MMBO}$ according to the gas scenario of a 10-year delay for gas pipeline capacity and $358 \mathrm{MMBO}$ according to a 20 -year-delay assumption.

\section{Introduction}

The U.S. Geological Survey's 2010 assessment (Houseknecht and others, 2010) of the National Petroleum Reserve in Alaska (NPRA) posits a set of scientifically based estimates of undiscovered inplace and technically recoverable ${ }^{2}$ quantities of oil and gas in conventional accumulations. ${ }^{3}$ The 2010 assessment is an update of the U.S. Geological Survey's 2002 assessment of the NPRA (Bird and Houseknecht, 2002). The NPRA assessment study area is depicted in figure 1; the area includes the 23.2 million acres of Federal, State, and Native lands within the NPRA boundary plus 1.0 million acres of State waters on the landward side of the State-Federal offshore boundary.

\footnotetext{
${ }^{2}$ Technically recoverable resources are producible using recovery technology that is currently available; estimates of technically recoverable resources are made without reference to economic viability. Accumulations assessed by geologists outside of known fields were considered for the purposes of the economic analysis as separate and discrete new fields.

${ }^{3}$ Conventional oil and gas accumulations are discrete accumulations typically bounded by an oil-water or gas-water contact.
} 


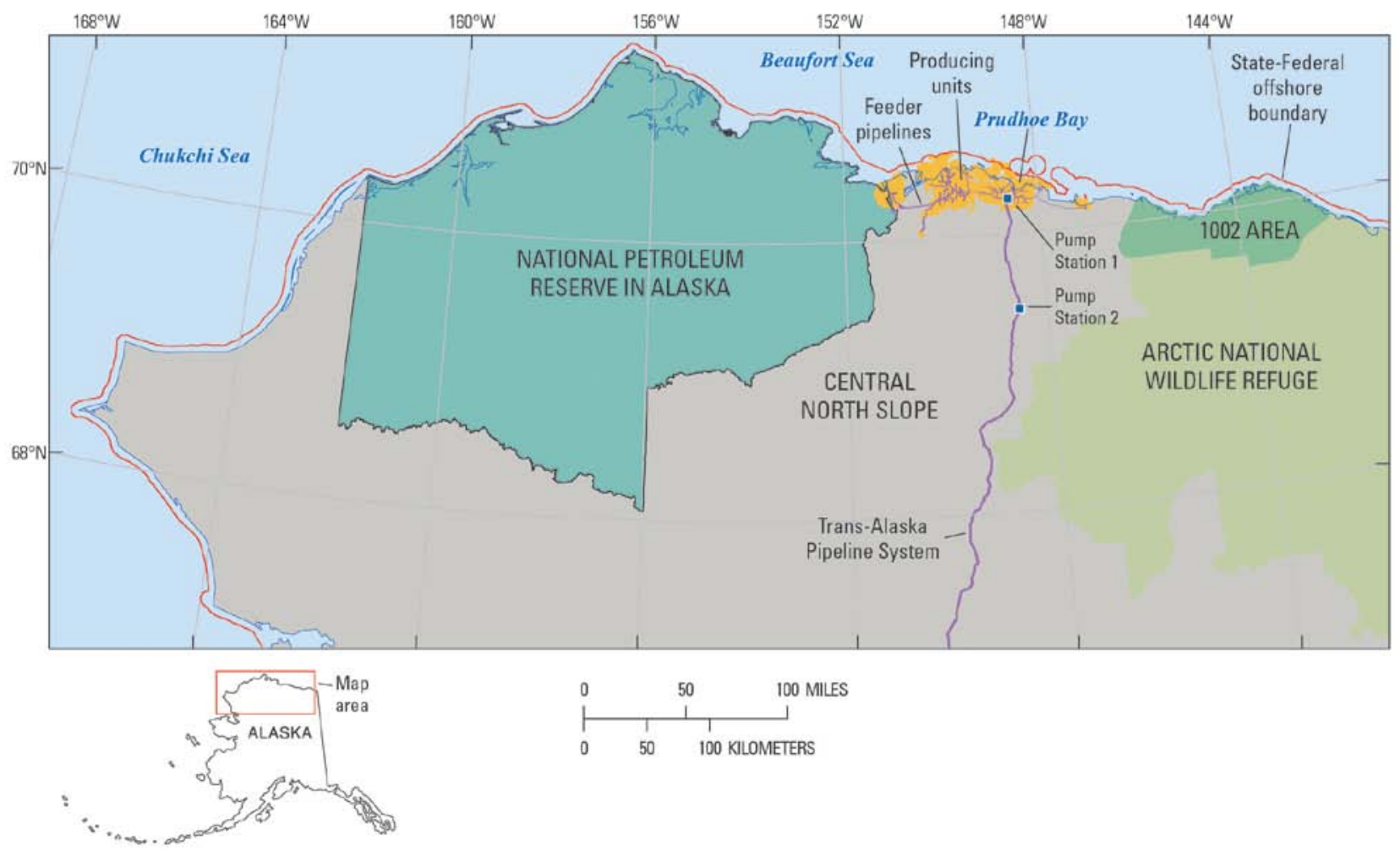

Figure 1. Map showing the National Petroleum Reserve in Alaska (NPRA), the 1002 Area of the Arctic National Wildlife Refuge, and oil-producing units near Prudhoe Bay in the central North Slope. The NPRA study area is the NPRA, including Federal, State, and Native lands, and the State waters on the landward side of the State-Federal offshore boundary.

Since the time of the 2002 assessment, six Federal lease sales have taken place, and an additional 30 exploration wells have been drilled on Federal and Native lands. U.S. Geological Survey (USGS) geologists have interpreted results of exploratory drilling to show that formations thought to be oil prone are actually gas prone. The new data have also indicated that actual reservoir quality is inferior to the reservoir quality inferred in the 2002 assessment (Houseknecht and others, 2010). The change in paradigm results in a decline in the estimated mean value of undiscovered oil from 10.6 billion barrels of oil (BBO) to 895 million barrels of oil (MMBO). The mean estimate of nonassociated natural gas (gas in gas fields) was revised from 61.4 trillion cubic feet (TCF) of gas in 2002 to 52.8 TCF in 2010. Table 1 shows 2010 estimates of undiscovered volumes of (1) oil, associated gas, and natural gas liquids (NGL) in oil accumulations and (2) nonassociated gas and NGL in gas accumulations. 
Table 1. Volumes of the aggregated undiscovered technically recoverable oil, gas, and natural gas liquids (NGL) related to the mean, 95th-fractile, and 5th-fractile estimates by the U.S. Geological Survey in 2010 of oil and nonassociated gas, associated gas byproduct volume, and concomitant resource volumes, that is nonassociated gas volumes corresponding to the oil fractile estimates and concomitant oil volumes corresponding to the nonassociated gas fractile estimates, respectively, for the National Petroleum Reserve in Alaska study area.

[MMBO, millions of barrels of oil; BCF, billions of cubic feet of gas; MMBL, millions of barrels of liquids. Data are from sources described in appendix 1]

\begin{tabular}{|c|c|c|c|c|}
\hline \multicolumn{3}{|c|}{ Oil accumulations } & \multicolumn{2}{|c|}{ Gas accumulations } \\
\hline $\begin{array}{c}\text { Oil } \\
\text { (MMBO) }\end{array}$ & $\begin{array}{l}\text { Associated gas } \\
\text { (BCF) }\end{array}$ & $\begin{array}{c}\text { NGL } \\
\text { (MMBL) }\end{array}$ & $\begin{array}{c}\text { Nonassociated gas } \\
\text { (BCF) }\end{array}$ & $\begin{array}{c}\text { NGL } \\
\text { (MMBL) }\end{array}$ \\
\hline \multicolumn{5}{|c|}{ Mean value estimate } \\
\hline${ }^{1} 895$ & 840 & 16 & 52,821 & 826 \\
\hline \multicolumn{5}{|c|}{ 95th-fractile oil estimate for study area } \\
\hline 336 & 348 & 6 & 43,042 & 712 \\
\hline \multicolumn{5}{|c|}{ 5th-fractile oil estimate for study area } \\
\hline 1,707 & 1,327 & 25 & 61,985 & 966 \\
\hline \multicolumn{5}{|c|}{ 95th-fractile gas estimate for study area } \\
\hline 640 & 625 & 12 & 30,984 & 478 \\
\hline \multicolumn{5}{|c|}{ 5th-fractile gas estimate for study area } \\
\hline 995 & 868 & 16 & 77,513 & 1,186 \\
\hline
\end{tabular}

\footnotetext{
${ }^{1}$ Houseknecht and others (2010) show a total mean oil volume of 896 million barrels, which is the sum if each play mean is rounded to an integer. The mean estimate of 895 million barrels used in this report represents the sum of the actual unrounded (decimal-valued) play estimates.
}

This report provides an economic analysis to estimate how much of the assessed undiscovered resource can be commercially developed at a range of market prices. The analysis estimates the cost of finding, developing, producing, and transporting the assessed resource to market. The resource cost functions show cost-resource recovery possibilities, but they are not supply functions as strictly defined by economists. These possibilities are in competition with other resource development projects throughout the world, and some of these other projects may be more attractive to investors. This analysis does not predict the revenue or bonus payment for leases in the study area, nor does it attempt to estimate regional or national secondary economic benefits that may result as a consequence of development of the resource.

This economic analysis is intended to place the geologic resource analysis into an economic context that is informative and easily understood by policymakers and decisionmakers. The geologic assessment might best be described as a regional reconnaissance appraisal. The geologists assigned subjective probabilities to the occurrence of hydrocarbon accumulations that capture play and prospect risk. They also formulated subjective probability distributions for reservoir attributes for such accumulations, using data from available field studies, exploration well cores in the public domain, regional geophysical studies, knowledge about regional trends, and postulated regional geologic history. The reservoir attribute distributions are used to predict size, depth, and production characteristics of these hypothetical accumulations.

The scope of the economic analysis is general rather than site or prospect specific. Consequently, the complete economic and technical impact of particular detailed regulations that currently govern development on Federal lands in the study area could not be included. This economic analysis is 
restricted to the evaluation of general finding costs, development costs (including costs of primary recovery and some aspects of secondary recovery), and costs of transporting the product to market.

Undiscovered technically recoverable conventional oil and gas resources are resources posited by the assessment geologists to exist, on the basis of broad geologic knowledge and theory, in undiscovered accumulations outside of known fields. Economically recoverable resources are that part of the assessed technically recoverable resources for which the costs of finding, developing, producing, and transporting to market, including a return on capital, can be recovered by production revenues at a particular price. There is currently no infrastructure to transport produced gas to markets located outside of the North Slope. There is, however, a large inventory, in excess of 25 TCF of relatively low cost stranded gas in rapidly depleting oil fields, which may have priority access to a gas product pipeline when it is built. This study gaged, by scenario analysis, the potential valuations associated with undiscovered nonassociated gas resources.

The discussion briefly reviews the revised geologic assessment for the NPRA and then summarizes the characteristics of the technically recoverable resource important for understanding the economic analysis. The assumptions about technical relationships, costs, markets, and pricing used in the computations of the resource cost functions are discussed. Results and interpretations of the economic analysis are presented in the concluding sections.

\section{Description of the Geologic Assessment}

The geologic assessment method (Schuenemeyer, 2003) and results (Houseknecht and others, 2010) are briefly reviewed here. The commercial value of newly discovered oil and gas accumulations depends on the expected size, hydrocarbon type (oil or gas ${ }^{4}$ ), depth, location, and reservoir attributes. These properties and the probability distributions used to describe them are fundamental to understanding the results of the economic analysis.

\section{Geologic Assessment Procedures}

The geologic assessment used a play analysis paradigm. A play is a set of known or postulated oil and (or) gas accumulations sharing similar geologic, geographic, and temporal properties, such as source rock, migration patterns, timing, trapping mechanism, and hydrocarbon type (Baker and others, 1984). Originally, the geologists had defined 24 plays to be assessed (Bird and Houseknecht, 2002; Schuenemeyer, 2003). Across all plays, the uniform minimum accumulation size for oil accumulations assessed was set at $50 \mathrm{MMBO}$ of oil in place, and the minimum accumulation size for natural gas accumulations assessed was 250 billion cubic feet (BCF) of recoverable nonassociated natural gas (Schuenemeyer, 2003).

For each play, the assessment geologists assigned subjective probabilities to the occurrence of hydrocarbon accumulations to capture play and prospect risk. The play probability (commonly called play risk) was the probability of occurrence of at least one accumulation of minimum size (50 MMBO oil in place or $250 \mathrm{BCF}$ recoverable gas). For hypothetical plays where the assessor was not confident of

\footnotetext{
${ }^{4}$ Accumulations were defined as either oil or nonassociated gas on the basis of their gas-to-oil ratios. Those having at least 20,000 cubic feet of gas per barrel of crude oil were classified as nonassociated gas; otherwise, the accumulations were classified as oil. Oil accumulations may have associated natural gas, and gas accumulations may have natural gas liquids. There is no distinction made in the assessment except via the assessed gas-to-oil ratio between associated gas and gas that is in a gas cap in the assessed undiscovered oil accumulations. The assessed natural gas liquids in gas accumulations include condensate as well as plant liquids. For this report, 1 barrel of oil $=1$ barrel of oil equivalent $=6,000$ cubic feet of gas $=1.5$ barrels of natural gas liquids.
} 
the occurrence of at least one accumulation as large as the threshold size, the play probability was the product of the occurrence probability of the three play attributes of charge, trap, and timing.

A prospect probability was also assigned to each play. The prospect probability was the probability that any randomly chosen oil or gas prospect contained resources of at least $50 \mathrm{MMBO}$ of oil in place or $250 \mathrm{BCF}$ of technically recoverable gas. There was no attempt to assign different probabilities to individual prospects that might have been identified. The prospect probability may be computed as the product of the occurrence probabilities assigned by the geologists to the prospect attributes of charge, trap, and timing. The geologists also specified separate distributions for the number of oil prospects and the number of gas prospects, as well as reservoir depth. The number of posited accumulations (meeting the threshold size) was then the product of the number of prospects, the play probability, and the prospect probabilities.

Data from available field studies, regional geophysical studies, knowledge about regional trends, and postulated regional geologic history allowed the assessment geologists to specify probability distributions for the reservoir attributes of (1) net reservoir thickness, (2) area of closure, (3) porosity, (4) trap fill, and (5) reservoir depth. Numerically simulated values from these distributions were combined with the engineering-based reservoir equation ${ }^{5}$ to predict size, depth, and characteristics of the undiscovered accumulations. These simulations, which were conditioned on the play and prospect probabilities, constituted the assessment results (see Schuenemeyer, 2003).

In order to properly aggregate play results, which were expressed as probability distributions, to the larger study-area level, the covariance among plays had to be specified. Pairwise dependencies between plays of the hydrocarbon charge, trap, and timing play attributes were assigned by the assessment geologists to all plays. The ranked dependencies (high, medium, low) were assigned correlation values, and the values were averaged so that the pairwise dependency between plays was reduced to one correlation value. The resulting correlation matrix was transformed to a covariance matrix that was used in the aggregation of play results to the study-area level. Details of the aggregation procedure were discussed in Schuenemeyer (2003).

For the updated assessment, the geologists started with the same plays as described in the 2002 NPRA assessment (Bird and Houseknecht, 2002; Schuenemeyer, 2003). However, four plays ${ }^{6}$ were not assessed because results of recent drilling indicate that reservoir quality is insufficient for recovery of the resource using methods typically applied to conventional deposits (Houseknecht and others, 2010). Assessments for 9 plays were unchanged. The new data resulted in revised assessments for 11 plays (see table A1-1 in appendix 1).

\footnotetext{
${ }^{5}$ For each oil accumulation, for example, the simulated reservoir attribute values included the following: (1) net reservoir thickness, $t$, in feet, (2) area of closure, $a c$, in thousands of acres, (3) porosity, $p$, as a decimal fraction, (4) trap fill, $f$, as a decimal fraction, and (5) hydrocarbon pore space, $h p s$, as a function of $p$ and $S_{W}$, where $S_{W}$ is water saturation as a decimal fraction. The assessors provided estimates of the oil recovery factor, $r f_{o}$, as a fraction of the in-place resources that are recoverable, and the formation volume factor, $f v f_{o}$, was calculated as a function of trap depth and API gravity. Oil accumulation size, szo, in millions of barrels was calculated with the following equation:

where $h p s=p\left(1-S_{W}\right)$. szo $=7.758(t)(h p s)(f)\left(r f_{o}\right)(a c) /\left(f v f_{o}\right)$

For gas accumulations, the size, szg, in billions of cubic feet was computed as: $\mathrm{szg}=4.356(t)(\mathrm{hps})(f)\left(r f_{g}\right)(a c)\left(f v f_{g}\right) \times 10^{-8}$

where the recovery factor and formation volume factor were specifically defined for gas accumulations.

${ }^{6}$ These unassessed plays are the Beaufortian Cretaceous Topset South, Beaufortian Upper Jurassic Topset Southeast, Beaufortian Upper Jurassic Topset Southwest, and Beaufortian Clinoform.
} 


\section{Characteristics of Assessed Technically Recoverable Resources}

Results of the updated assessment show a mean estimate for oil of 895 MMBO contained in 16 undiscovered oil accumulations and a mean estimate for nonassociated gas of 52.8 TCF in 70 undiscovered gas accumulations. The results of the aggregation method described in Schuenemeyer (2003) yield confidence intervals at the 95th-fractile (19-in-20 chance of at least that volume of either oil or gas) and 5th-fractile (1-in-20 chance of at least that amount) estimates for the respective resource type. For oil in undiscovered oil accumulations, the mean estimate of $895 \mathrm{MMBO}$ is bracketed by the 95th-fractile estimate of $336 \mathrm{MMBO}$ and the 5 th-fractile estimate of 1,707 MMBO. ${ }^{7}$ For gas in undiscovered gas accumulations, the mean estimate of $52.8 \mathrm{TCF}$ is bracketed by the 95th-fractile estimate of $31.0 \mathrm{TCF}$ and the 5 th-fractile estimate of $77.5 \mathrm{TCF}^{8}$ (see table 1). The estimates are predicated on the geologic interpretation described in Houseknecht and others (2010).

Figure 2 shows the underlying accumulation size-frequency distributions corresponding to the fractile estimates ${ }^{9}$ and mean estimates described above for oil (fig. $2 A$ ) and nonassociated gas (fig. 2B). The accumulation size distribution is of interest because unit production costs typically vary inversely with accumulation size. Table 2 shows by size class the number of deposits, the volume of oil or gas, and the cumulative percentage of the total volume of oil or gas at that estimate. The oil accumulation sizes are small by North Slope standards, with the average size for the mean estimate at $56 \mathrm{MMBO}$ and with $36 \mathrm{MMBO}$ and $76 \mathrm{MMBO}$ for the 95th- and 5th-fractile estimates, respectively. If these accumulations occur in clusters, commercial development is possible, depending on location.

\footnotetext{
${ }^{7}$ At the 95 th-fractile oil estimate, there are 9 oil accumulations, and at the 5 th-fractile oil estimate, there are 22 oil accumulations.

${ }^{8}$ At the 95 th-fractile nonassociated gas estimate, there are 51 gas accumulations, and at the 5 th-fractile nonassociated gas estimate, there are 86 gas accumulations.

${ }^{9}$ The calculations of the fractile estimates were based on the deposit/play simulations as provided by the aggregation computation. Rather than using a single aggregation combination of the simulated plays to represent a fractile, the fractile volume estimate and associated accumulation distribution were based on an average of the play results (10 combinations greater and 10 combinations smaller) around the single-point fractile estimate and its associated accumulation distribution. This averaging to obtain a robust fractile accumulation distribution resulted in fractional accumulations in the corresponding size-frequency distributions (Schuenemeyer, 2003).
} 
A
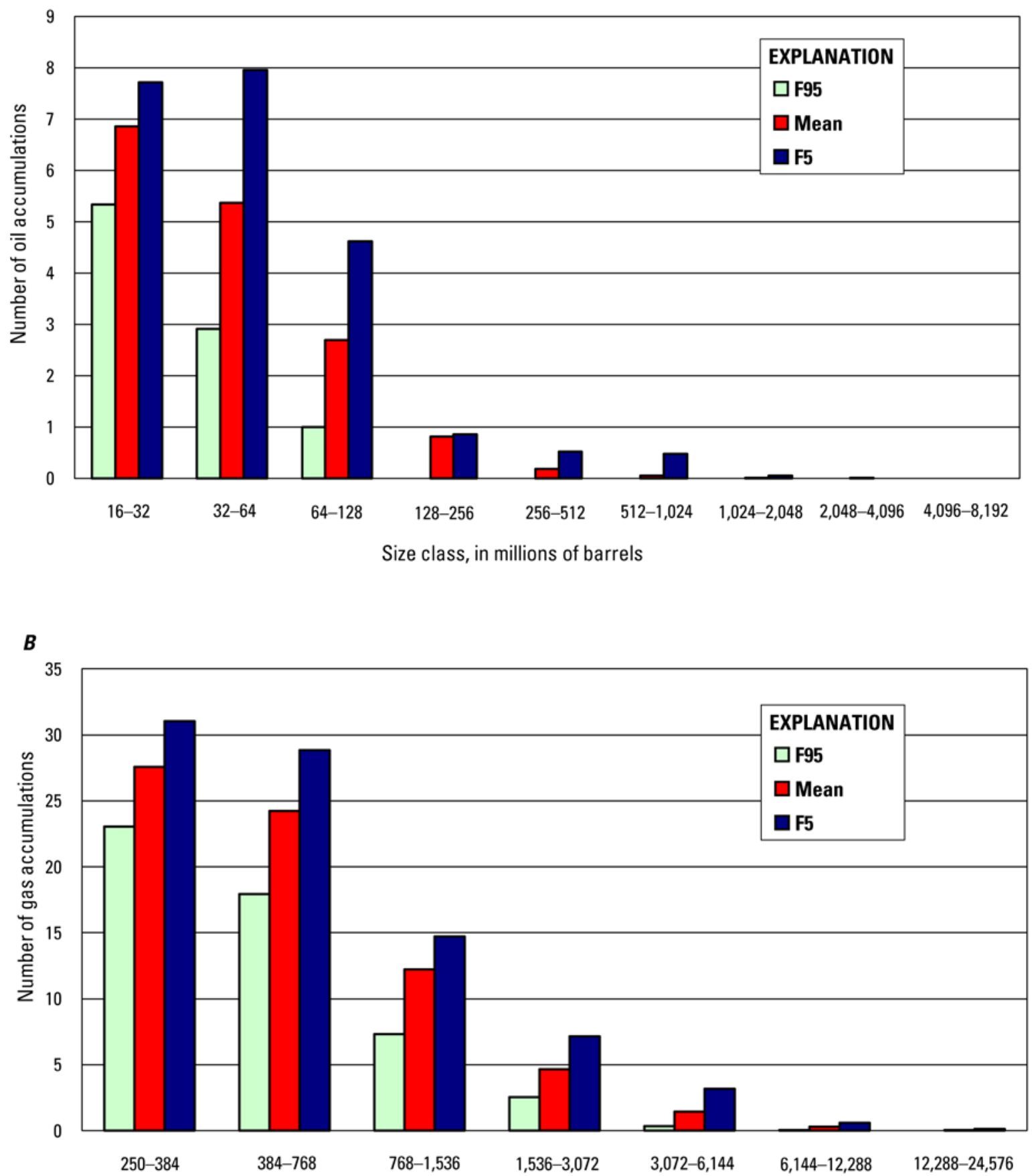

Size class, in billions of cubic feet

Figure 2. Graphs of size-frequency distributions of the estimated number of accumulations of undiscovered technically recoverable oil $(A)$ and nonassociated gas $(B)$ corresponding to the 95th-fractile (F95), mean, and 5thfractile (F5) volume resource estimates for the National Petroleum Reserve in Alaska study area. Details are in table 2. 
Table 2. Cumulative percentage distribution of estimated undiscovered technically recoverable oil in oil accumulations and nonassociated (NA) gas in gas accumulations by size class for the National Petroleum Reserve in Alaska study area.

[MMBO, millions of barrels of oil; BCF, billions of cubic feet of gas. Entries of "0" indicate zero amount]

\begin{tabular}{|c|c|c|c|c|c|c|c|c|c|}
\hline \multicolumn{10}{|c|}{ Oil accumulations } \\
\hline \multirow[b]{2}{*}{$\begin{array}{l}\text { Size class } \\
\text { (MMBO) }\end{array}$} & \multicolumn{3}{|c|}{ 95th-fractile estimate } & \multicolumn{3}{|c|}{ Mean estimate } & \multicolumn{3}{|c|}{ 5th-fractile estimate } \\
\hline & $\begin{array}{c}\text { Number of } \\
\text { accumulations }\end{array}$ & $\begin{array}{l}\text { Oil in } \\
\text { class } \\
\text { (MMBO) }\end{array}$ & $\begin{array}{c}\text { Oil volume } \\
\text { cumulative } \\
\text { percent }\end{array}$ & $\begin{array}{c}\text { Number of } \\
\text { accumulations }\end{array}$ & $\begin{array}{l}\text { Oil in } \\
\text { class } \\
\text { (MMBO) }\end{array}$ & $\begin{array}{c}\text { Oil volume } \\
\text { cumulative } \\
\text { percent }\end{array}$ & $\begin{array}{c}\text { Number of } \\
\text { accumulations }\end{array}$ & $\begin{array}{c}\text { Oil in } \\
\text { class } \\
\text { (MMBO) }\end{array}$ & $\begin{array}{c}\text { Oil volume } \\
\text { cumulative } \\
\text { percent }\end{array}$ \\
\hline $4,096-8,192$ & 0 & 0 & 0 & 0 & 0 & 0 & 0 & 0 & 0 \\
\hline $2,048-4,096$ & 0 & 0 & 0 & 0.001 & 2 & 0 & 0 & 0 & 0 \\
\hline $1,024-2,048$ & 0 & 0 & 0 & 0.01 & 18 & 2 & 0.05 & 53 & 3 \\
\hline $512-1,024$ & 0 & 0 & 0 & 0.1 & 38 & 6 & 0.5 & 370 & 25 \\
\hline $256-512$ & 0 & 0 & 0 & 0.2 & 61 & 13 & 0.5 & 195 & 36 \\
\hline $128-256$ & 0 & 0 & 0 & 0.8 & 137 & 29 & 0.9 & 150 & 45 \\
\hline $64-128$ & 1.0 & 85 & 25 & 2.7 & 236 & 55 & 4.6 & 403 & 69 \\
\hline $32-64$ & 2.9 & 127 & 63 & 5.4 & 241 & 82 & 8.0 & 349 & 89 \\
\hline $16-32$ & 5.3 & 124 & 100 & 6.9 & 163 & 100 & 7.7 & 186 & 100 \\
\hline \multicolumn{10}{|c|}{ Nonassociated (NA) gas accumulations } \\
\hline & \multicolumn{3}{|c|}{ 95th-fractile estimate } & \multicolumn{3}{|c|}{ Mean estimate } & \multicolumn{3}{|c|}{ 5th-fractile estimate } \\
\hline $\begin{array}{l}\text { Size class } \\
\text { (BCF) }\end{array}$ & $\begin{array}{c}\text { Number of } \\
\text { accumulations }\end{array}$ & $\begin{array}{l}\text { NA gas } \\
\text { in } \\
\text { class } \\
\text { (BCF) }\end{array}$ & $\begin{array}{c}\text { Gas } \\
\text { volume } \\
\text { cumulative } \\
\text { percent } \\
\end{array}$ & $\begin{array}{c}\text { Number of } \\
\text { accumulations }\end{array}$ & $\begin{array}{l}\text { NA gas } \\
\text { in } \\
\text { class } \\
\text { (BCF) }\end{array}$ & $\begin{array}{c}\text { Gas } \\
\text { volume } \\
\text { cumulative } \\
\text { percent } \\
\end{array}$ & $\begin{array}{c}\text { Number of } \\
\text { accumulations }\end{array}$ & $\begin{array}{c}\text { NA gas } \\
\text { in } \\
\text { class } \\
\text { (BCF) } \\
\end{array}$ & $\begin{array}{c}\text { Gas } \\
\text { volume } \\
\text { cumulative } \\
\text { percent } \\
\end{array}$ \\
\hline $24,576-49,152$ & 0 & 0 & 0 & 0 & 0 & 0 & 0 & 0 & 0 \\
\hline $12,288-24,576$ & 0 & 0 & 0 & 0.03 & 363 & 1 & 0.1 & 2,054 & 3 \\
\hline $6,144-12,288$ & 0.05 & 356 & 1 & 0.3 & 2,448 & 5 & 0.6 & 5,637 & 10 \\
\hline $3,072-6,144$ & 0.3 & 1,351 & 6 & 1.4 & 5,932 & 17 & 3.2 & 13,540 & 27 \\
\hline $1,536-3,072$ & 2.6 & 4,984 & 22 & 4.7 & 9,721 & 35 & 7.1 & 15,058 & 47 \\
\hline $768-1,536$ & 7.3 & 7,755 & 47 & 12.2 & 12,978 & 60 & 14.7 & 16,038 & 68 \\
\hline 384-768 & 18.0 & 9,462 & 77 & 24.3 & 12,922 & 84 & 28.9 & 15,561 & 88 \\
\hline $250-384$ & 23.0 & 7,075 & 100 & 27.6 & 8,457 & 100 & 31.1 & 9,626 & 100 \\
\hline
\end{tabular}


The gas accumulation distributions shown in table 2 imply average accumulation of sizes of 750 $\mathrm{BCF}$ for the mean estimate and $600 \mathrm{BCF}$ and $900 \mathrm{BCF}$ for the 95th- and 5th-fractile estimates of gas, respectively. Accumulations with at least 3 TCF of gas (500 million barrels of oil equivalent) account for only 6 percent of the assessed nonassociated gas at the 95th-fractile estimates, 17 percent of the gas at the mean estimate, and 27 percent of the gas at the 5th-fractile estimate. For the mean and 5th-fractile estimates, most of the assessed gas is in accumulations at least as large as $768 \mathrm{BCF}$ (128 million barrels of oil equivalent). For accumulations in size classes smaller than $768 \mathrm{BCF}$, the comparatively large volume of gas in such accumulations and the large numbers of accumulations will undoubtedly allow joint development opportunities.

Table A1-1 in appendix 1 shows the mean estimates of oil, gas, and NGL for each play. Play maps are shown in figure A1-1. Prospective areas for the oil plays are in the northern and eastern part of the study area. Although the API gravity ranged from $23^{\circ}$ API to $40^{\circ}$ API, 87 percent of oil assessed was assigned gravity values between $32^{\circ}$ and $37^{\circ} \mathrm{API}$. At the mean estimate, the depth distribution of the volume of assessed oil is the following: 0 to 5,000 feet, 23 percent; 5,000 to 10,000 feet, 56 percent; and 10,000 to 15,000 feet, 22 percent.

Table A1-1 in appendix 1 also identifies the Brookian Topset Structural play and the Torok Structural play as having the largest assessed volumes of undiscovered nonassociated natural gas. These two plays are located in the southern part of the study area. Together they account for almost 54 percent of the gas by volume. For these plays, the NGL-to-gas ratios, at the mean estimates, were about 11.1 and 14.7 barrels per million cubic feet gas. ${ }^{10}$ Across all plays shown in table A1-1, the weighted average NGL-to-gas ratio for nonassociated gas was 15.6 barrels per million cubic feet. At the mean estimate, the depth distribution of the volume of assessed nonassociated gas is the following: 0 to 5,000 feet, 19 percent; 5,000 to 10,000 feet, 39 percent; 10,000 to 15,000 feet, 25 percent; and greater than 15,000 feet, 17 percent.

In order to prepare an economic analysis of the undiscovered resources, the NPRA study area was partitioned into the economic zones shown in figure 3. For each play shown in table A1-1 in appendix 1, the assessment geologists allocated the oil in oil accumulations to each economic zone. Likewise for each play, the gas volume in assessed undiscovered gas accumulations was allocated to economic zones (see table A2-1 in appendix 2 for the percentage allocations). The aggregation procedure used the play simulation data (of play realizations) for its basic data (Schuenemeyer, 2003), and so the individual play realizations for each of the (volume) fractiles along with the appropriately allocated size-frequency accumulation distributions were assigned to each economic zone. The economic zones and resource allocations provide the conceptual basis for developing the costs associated with a proposed product transportation system. See table A2-2 in appendix 2 for assessed volumes by economic zone. Table A2-3 shows numbers of accumulations and volumes by size class for each economic zone.

\footnotetext{
${ }^{10}$ These values are not particularly rich in liquids. A 4.5-TCF field, even with the NGL-to-gas ratio of 14.7 barrels per million cubic feet, would contain only 66.2 million barrels of liquids. It is unlikely that a gas accumulation of this size would be developed for its liquids.
} 


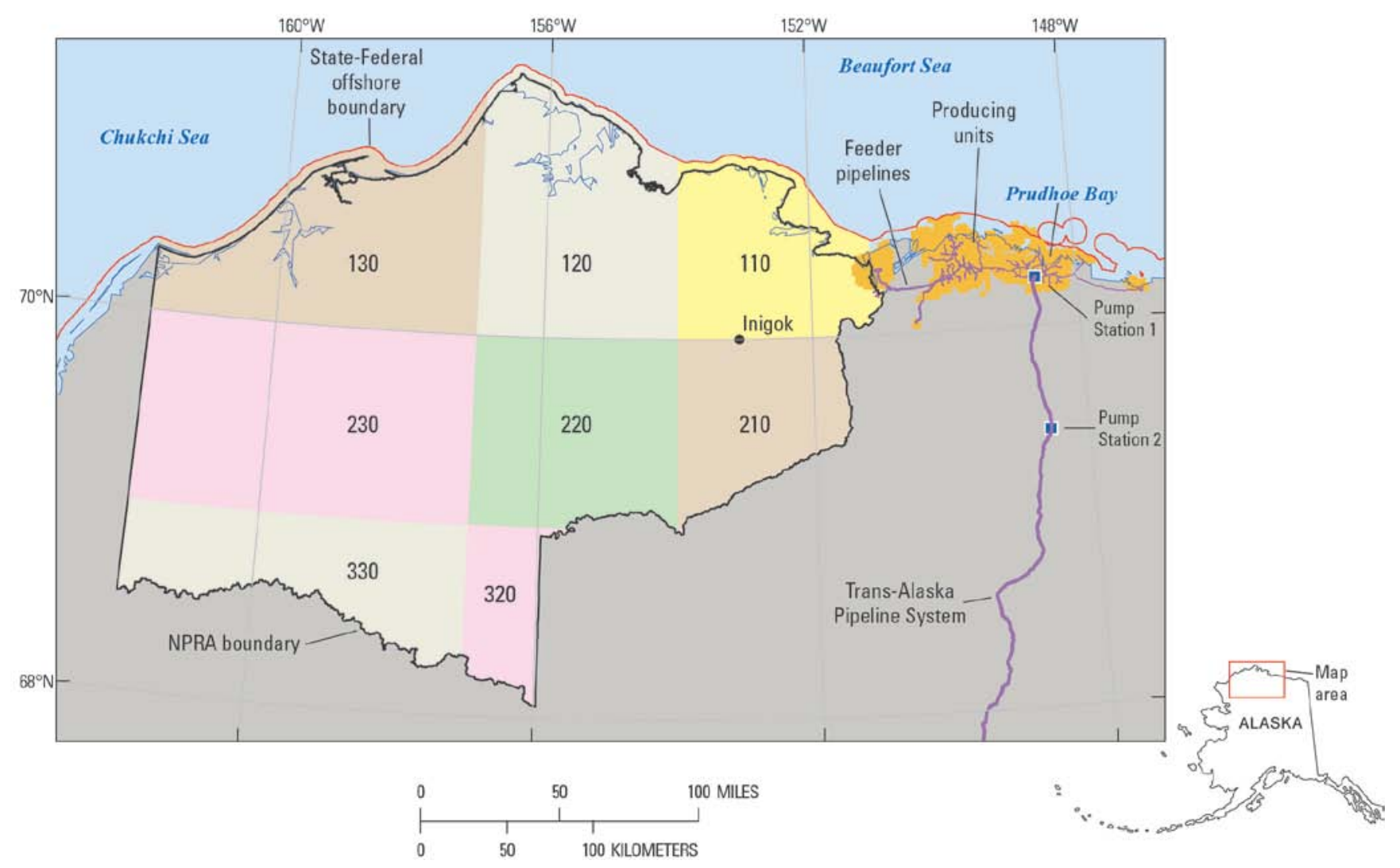

Figure 3. Map showing economic zones of the National Petroleum Reserve in Alaska (NPRA) study area.

\section{Economic Method}

\section{Scope}

Economic models are abstractions that characterize real economic systems and are typically just detailed enough to roughly approximate the outcomes of interactions between economic agents. Only the general direction and the approximate magnitude of the reaction of the system to price or cost change can be modeled. The results of this economic analysis are estimated costs of transforming undiscovered resources into discovered commercially producible volumes of oil and gas. Prices received by the operator must be sufficient to repay all investment expenditures, cover production costs including taxes, and still yield an acceptable return to investment; otherwise, the investment will not be undertaken. Costs include all expenditures incurred in finding, developing, and producing oil and gas resources and transporting them to market. The timing and costs associated with leasing (bonus bids, rentals, preleasing seismic surveys) that must precede exploration drilling are not included. All these engineering parameters are highly uncertain because the posited oil and gas resources are in unknown locations (still undiscovered).

The cost functions reported here are time independent and should not be confused with the firm's supply or market-supply functions that relate marginal cost to production per unit time period. Because of the time-independent nature of the cost functions and the absence of market-demand conditions in the analysis, user costs and the opportunity costs of future resource use are not computed.

At any given price, the oil and gas industry will allocate funds over a number of provinces and worldwide sources of supply in order to meet market demand at lowest costs. Observed market price- 
supply relationships are the culmination of numerous supplier decisions over many projects and regions. Incremental cost functions represent costs that are computed independently of activities in other areas. However, these cost functions and the data that underlie the functions are commonly used as the basis for market-supply models.

\section{Computational Procedure}

A new discovery is commercially developable if the after-tax net present value of its development is greater than zero. Market prices, size, depth, location, regional costs and associated regulations, and coproduct ratios determine whether a discovery will be commercially viable. The algorithm used the assessed size and depth distribution of undiscovered accumulations (at the economic zone level) to compute quantities of resources that can be found and be commercially developed at various prices.

A finding rate model (Attanasi and Bird, 1996) was adjusted for each economic zone's undiscovered oil and gas accumulations and was used to forecast the size and depth distribution of new discoveries from increments of exploration. The results of the forecasts drive the economic development and production processes to establish the expected aggregate value of new discoveries. Specifically, at a given price, the commercial value of developing a representative oil or gas accumulation in a specific size class and depth category is determined by the results of a discounted cash flow (DCF) analysis.

The net after-tax cash flow consists of revenues from the production of oil or gas less the operating costs, capital costs in the year incurred, and all taxes. All new discoveries from a size and depth category are assumed to be developable if the representative accumulation is commercially viable; that is, the after-tax DCF is greater than zero, where the discount rate (12 percent) represents the cost of capital and the industry's required return.

Production is assumed to stop (the economic limit is reached) when operator income declines below the sum of direct operating costs and the operator's production-related taxes. Commercially developable accumulations are summed and represent an estimate of the potential reserves attainable from undiscovered accumulations at a given price and required hurdle rate or minimum rate of return. The results from this procedure do not imply that every accumulation determined to be commercially developable is worth exploring. Some accumulations are discovered by the finding rate model that will only meet the commercially developable threshold and not repay all exploration costs.

Incremental units of exploration, development, and production effort will not be expended unless the revenues expected to be received from eventual production will cover the incremental costs, including a normal return on the incremental investment. Exploration continues until the incremental cost of drilling wildcat wells equals or exceeds the after-tax net present value of the commercial discoveries identified by the last increment of wildcat wells. For the last increment of hydrocarbons produced from a field, operating costs (including production-related taxes) per barrel of oil equivalent are equal to price. This procedure assures that for the commercially developable resources discovered by the last economic increment of wildcat wells, the sum of per-barrel finding, development, and production costs equals the wellhead price (price of oil or gas to the field owner). ${ }^{11}$

When oil and gas accumulations occur in the same depth interval and geographic basin, exploration productivity is determined jointly by the expected oil and gas targets and their economic

\footnotetext{
${ }^{11}$ The marginal finding costs as described here are calculated by dividing the cost of the last increment of wildcat wells (which is approximately equal to the sum of the after-tax net present value of all commercially developable fields discovered in that last increment of exploration) by the amount of economic resources discovered by the last increment of exploration. Marginal development and production cost per barrel (for the economic resources discovered in that last increment of exploration) are calculated by subtracting the marginal finding costs from the wellhead price.
} 
value. If the oil search finds gas and the gas discovery has a positive after-tax net present economic value, the operator might develop the gas or sell the discovery to an operator that will develop the discovery. However, if the gas discovery is of no value, the discovery is reported as a dry hole, with a show of gas. So, when oil and gas accumulations occur in the same exploration area and depth intervals, the expected number of wildcat wells depends on the net present values for both the oil and the nonassociated gas that are found. In such situations, the incremental cost function for oil discoveries depends on the value imputed to the gas finds and the incremental cost function for nonassociated gas depends on the valuation of the oil. This procedure of representing the joint nature of oil and gas exploration with finding rate functions was applied to most U.S. provinces analyzed in the economic component of the 1995 USGS National Oil and Gas Assessment (Attanasi, 1998).

At the margin, or last economic increment of exploration, the surplus of net present value of commercial discoveries (above the required 12-percent after-tax return) must be sufficient to fund exploration. However, if the generation of those funds is delayed for 10 or 20 years because pipelines are not available, the funds must be discounted in order to be compared to current dollars. For gas discoveries, such discounting was assumed to correspond to a delay between the time of discovery (exploration expenditures) and the time of development.

\section{Data}

The geologic assessment data consisted of the play simulations (play realizations) associated with the NPRA study area 95th- and 5th-fractile volume estimates and the average of the play realizations that constituted the mean estimates. The simulation data include accumulation size, depth, reservoir net pay, and other characteristics. The data were partitioned into size and depth categories in order to characterize representative accumulations for the economic evaluation zones.

Major components of oil and gas industry costs, such as drilling and service industry costs, are affected by oil and gas price levels and changes that commonly follow economic cycles. Between early 2005 and early 2011, world-market prices for crude oil have fluctuated between \$34 per barrel and nearly $\$ 150$ per barrel. The oil and gas industry typically faces increasing costs when price increases, particularly if the industry tries to rapidly increase output (see Attanasi and Freeman, 2009).

A recent episode of the rapid rise in oil prices, from 2005 to 2008, produced significant cost escalation through most phases of operations. The amount of the increase from $\$ 34$ per barrel in early 2005 to almost $\$ 150$ per barrel in mid-2008 also drove all costs higher (IHS Inc., 2011a,b). Although a worldwide economic recession had seized most of the world's economies by late 2008 and reduced oil prices by about two-thirds, costs did not decline symmetrically during that period. It is the intent of this economic assessment to estimate resource recovery volumes in relation to cost, based upon the long-run costs of the industries that service the oil and gas sectors.

Some of the engineering and cost relationships used here were drawn from earlier economic studies prepared for the individual study areas (Attanasi and Freeman, 2005, 2009) and sources referred to in these references. Information from James Craig (Minerals Management Service, written commun., 2010) was used in calibrating and updating some costs based on local conditions.

The engineering relationships, equipment configurations, and equipment and installation cost estimates embedded in the IHS QUE\$TOR software (IHS Inc., 2010) were used extensively in this analysis. In particular, a set of generic models of hypothetical oil and gas fields was prepared by using the software's engineering and cost data and modified by economic zone. The data from the constructed models were used to estimate development and production costs for the representative field for each oil and gas accumulation size shown in table 2. These data provided the cost stream for the discounted cash flow analysis described in the section on the computational procedure. The options chosen from those 
available in the QUE\$TOR software were specific to Alaska's North Slope with development under very remote conditions, requiring infrastructure (new gravel pads and in-field roads) and airstrip construction as part of field development. Permanent roads to connect remote fields to the present North Slope road system were not added. A detailed explanation of engineering relationships, cost assumptions, and fiscal relationships is provided in appendixes 3 and 4.

\section{Economic Assumptions}

For this study, it is assumed that industry will not invest in new projects unless the full operating costs, taxes, capital, and cost of capital can be recovered. The costs modeled here include all expenditures (except lease bonus and rental payments) that are estimated to be incurred by the industry in finding, developing, and producing the product and transporting it to market.

Unless otherwise stated, it is assumed that all of the NPRA study area is available for exploration and development for oil and gas. This includes onshore and State offshore waters. The cost functions presented are time independent, and so they are not the same as supply functions, which relate price to quantity per unit time. Because of the time-independent nature of the cost functions and the absence of market-demand conditions in the analysis, user costs or the opportunity costs of future resource use are not computed.

Technology and costs used in this analysis are assumed to represent those prevailing during calendar year 2010. ${ }^{12}$ As discussed above, the industries serving the oil and gas industry face erratic demands on services because of (1) volatile price changes related to shortfalls in production and (2) cost increases that are expected to be sustained despite new capacity that could modernize the service industries. The latter component is the primary basis for the cost assumptions in this economic analysis.

The oil prices evaluated in this economic analysis are based on the landed market prices at the west coast of the conterminous United States, which is the primary destination of oil produced in Alaska. The natural gas prices evaluated are those for gas delivered to Chicago or similar destinations in the northern U.S. Midwest, which, at this time, is the likely market for North Slope gas. All transportation costs are subtracted from the assumed market prices to calculate the wellhead oil and gas prices used for project evaluation. The market prices are assumed to be sustained, rather than an erratic spot price. The market price of natural gas liquids is assumed to be 75 percent of the per-barrel price of crude oil.

A recent study by Black and Veatch (2010) identified the potential regulations and environmental government policies that would lead to sufficiently elevated gas prices in the gas markets in the conterminous United States to permit entry of Alaskan gas into those markets. Also among the factors identified by Black and Veatch is the national policy with respect to carbon dioxide abatement in electricity generation and construction and approval of nuclear electricity generation plants.

The increasing sophistication of international gas markets and growth in demand for gas may lead to export sales of liquefied natural gas (LNG) produced in the conterminous 48 States. Since 2002, in anticipation of a shortfall of natural gas, several LNG receiving terminals have been built along the coasts in the conterminous 48 States, and existing terminals have been expanded. The producers and terminal operators may now perceive U.S. domestic markets as over supplied. There is an expectation that gas prices will remain depressed, relative to price levels that were used to justify the new shale gas production technologies and the LNG terminal construction. Terminal operators are now partnering with domestic gas producers to seek approval from regulators for construction of liquefaction plants, to use

\footnotetext{
${ }^{12} \mathrm{~A}$ primary motivation of this analysis is to capture economic implications of geologic uncertainty. Therefore, the economic variables and engineering relationships used are expressed as point estimates rather than as probability distributions. As noted above, costs were adjusted to represent the stable component.
} 
the facilities to supply LNG to the international market. ${ }^{13}$ The effect of such gas exports could produce a realignment of U.S. domestic gas prices to world market price levels.

The pipeline to transport natural gas to market in the conterminous United States has yet to be built. It is expected that the future gas pipeline will start near Pump Station 1 of the Trans-Alaska Pipeline System (TAPS) and proceed southward along the TAPS right-of-way until it is redirected to the southeast toward the AECO Hub ${ }^{\mathrm{TM}}$ in Alberta, Canada. The gas moving through the Alberta Energy Company (AECO) market could reach U.S. markets through several crossing points on the U.S.-Canada border. Because of the uncertainty regarding the timing and access to shipping capacity of the future gas pipeline, this economic analysis includes data for two scenarios. For scenario 1, the assumption is that pipeline access for new discoveries will occur approximately 10 years from the time of discovery; for scenario 2, the assumption is that access will not occur until 20 years after discovery. The longer delay gives priority access for proven gas reserves in fields near the pipeline origin before new supplies are accepted from new outlying discoveries. For these scenarios, the expected net present values of commercial discoveries are discounted for the lag time between discovery and startup. To simplify the analysis, it is assumed that there is no direct cost to the operation as a result of delays (lease rental, storage, and reserve taxes) during the period between discovery and field development for market sales.

In recent years, market prices for natural gas have been very volatile, ranging mostly from $\$ 3$ per thousand cubic feet (MCF) to $\$ 12$ per MCF and, in some markets, climbing even higher. However, historically, the market valuation of gas relative to crude oil on a calorific heating basis has been discounted. For the gas prices that are used in the valuation of potential gas discoveries, unless otherwise stated, gas is valued at the market at two-thirds the value of oil based on calorific heating value or British thermal units (Btu). Because of the sheer size of the investment required for the gas conditioning plant and construction of a pipeline to Alberta (approximately $\$ 30$ billion), the pipeline owners are likely to require long-term contracts of shippers and buyers, who, in turn, will agree to pay stable shipping fees (tariffs). Associated gas in new oil discoveries is not valued at the market but is assumed to be stripped of liquids and re-injected into the oil accumulation for pressure maintenance. ${ }^{14}$ Therefore, associated gas is not included in the gas cost functions.

During 2010, domestic refiner acquisition cost for crude oil ranged from $\$ 75.07$ to $\$ 85.59$ per barrel (Energy Information Administration, 2011). History has shown that when prices rise substantially and rapidly, it is unrealistic to assume that costs in constant dollars will hold (Kuuskraa and others, 1987). In order to adjust cost to changes in prices, it is assumed that for market prices between $\$ 70$ and $\$ 110$ per barrel, the prevailing 2010 costs are unaffected by price volatility. Above $\$ 110$ per barrel and below $\$ 70$ per barrel, drilling, facilities, and operating costs would rise or decline as a fraction of the percentage price changes. Details of the price-cost adjustment are presented in appendix 3.

Discounted cash flow analysis is specific to an individual project, and tax preference items that might be important from a corporate accounting stance are not considered in this general economic assessment. A minimum 12-percent after-tax required return is applied to all projects that are deemed economic. A one-eighth royalty is assumed to be paid to the owner of the mineral rights. In this study, the assumption is that $\$ 0.25$ per barrel of produced oil is set aside by operators to fund abandonment costs for oil fields, and $\$ 0.05$ per MCF is set aside to fund the abandonment cost of natural gas fields. All pipelines outside the petroleum lease unit are assumed to be operated as common carriers with

\footnotetext{
${ }^{13}$ Cheniere Energy has an application with the Federal Energy Regulatory Commission to construct a liquefaction plant to transform gas into LNG for export (Krauss, 2011).

${ }^{14}$ Associated gas could be recovered for sale when oil is depleted. However, the discounting for decades of delay in sales would reduce its value so much that at the time of discovery, it would not be a significant factor in the decision to develop the oil discovery.
} 
estimated tariffs that must repay annual operating costs, State property tax, State and Federal income taxes, and a 12-percent return to investors.

The Alaska State taxes include a corporate income tax, ad valorem tax (property tax), and petroleum profits tax (called $\mathrm{ACES}^{15}$ ). Although the nominal corporate income tax rate is 9 percent, the effective tax rate is set by a complex formula based on the individual company's production and sales. For planning purposes, State agencies use effective rates between 2 and 4 percent of net income. An effective corporate tax rate of 4 percent is used here. The State's ad valorem tax is an annual charge equivalent to 2 percent of the economic value of equipment, facilities, and pipelines. The State petroleum profits tax (ACES) replaced the severance tax and is described in appendix 4. Federal income tax provisions are as of the end of $2010^{16}$ with an assumed rate of 35 percent of taxable income.

\section{Cost Components}

\section{Transportation, Infrastructure, and Location Assumptions}

Since 1977, oil produced in northern Alaska has been transported by the Trans-Alaska Pipeline System (TAPS) to the Port of Valdez in southern Alaska and then by marine tanker to market. The peak flow for TAPS occurred in 1988 at just above 2.0 million barrels per day. For 2009, the TAPS flow rate averaged 0.67 million barrels per day of oil and natural gas liquids (Alyeska Pipeline Service Company, 2011). Pump capacity for the TAPS has recently been reduced, and so the apparent 1.25 million barrels per day of unused capacity is not currently available. The reduced capacity can be restored in the future if discoveries result in increased North Slope daily production. For this analysis, it is assumed that TAPS will be able to accept any additional supplies in the foreseeable future.

The TAPS tariff rates and marine transport rates to market are projected semiannually by the Alaska Department of Revenue, Tax Division (2010). The marine transport rate represents transport cost weighted by projected sales volumes to various destinations from Valdez to markets that have included the west coast of the conterminous United States, the Far East, and the U.S. Gulf of Mexico region. These rates are projected on an annual basis to 2020. The annual TAPS tariff forecasts by the Alaska Department of Revenue from 2011 through 2020 averaged $\$ 4.79$ per barrel (nominal dollars). Alternatively, if one uses the 2009 rate of $\$ 4.59$ as the basis for projecting required pipeline annual revenues and then divides the annual forecast of North Slope production to 2020, the average tariff is $\$ 5.18$ per barrel. ${ }^{17}$ The State projects an average of $\$ 2.20$ per barrel deflated to constant dollars for marine tanker transport to market, and so the total transport cost for crude oil to market is $\$ 7.38$ per barrel.

For the evaluation of nonassociated natural gas discoveries, it is assumed that gas will be transported from the discovery to a new gas conditioning plant located near Pump Station 1 of TAPS. The calculation of the gasline tariff from the gas conditioning plant to market is based, in part, on the data presented by TransCanada (TransCanada, 2007) in its application to the State of Alaska for a license under the Alaska Gasline Inducement Act. The analysis shows that the maximum transport tariff (including gas conditioning) to the AECO Hub ${ }^{\mathrm{TM}}$ in Alberta is $\$ 2.58$ per million Btu or $\$ 2.88$ per MCF

\footnotetext{
${ }^{15} \mathrm{ACES}$ is an acronym for Alaska's Clear and Equitable Share tax (also see Alaska Department of Revenue, Tax Division, 2007, for State tax explanation).

${ }^{16}$ According to the 1986 Tax Reform Act, 30 percent of development well drilling cost is classified as a tangible cost and, therefore, is capitalized over 7 years. Of the remaining 70 percent of drilling cost (that is, the intangible drilling costs), 30 percent is depreciated over 5 years and the remaining 70 percent is expensed immediately.

${ }^{17}$ The difference between $\$ 4.79$ and the $\$ 5.18$ as a portion of the per-barrel market price of $\$ 75$ per barrel is about a half of 1 percent.
} 
if one uses the conversion factor in TransCanada's application. At the time of the application, rates quoted to transport gas to the U.S. market averaged \$1.06 per MCF (ConocoPhillips, 2007). These sources estimate the overall loss in sales gas volume transported due to fuel use at compressor stations to be about 11.5 percent. The total cost of gas delivered to U.S. markets is then estimated to be $\$ 4.42$ per MCF.

The study area was partitioned into the economic zones shown in figure 3 . These zones were also defined for the NPRA study area in Attanasi (2003). Distances and the corresponding pipeline costs for field feeder lines and regional pipelines to transport oil or nonassociated gas to the Pump Station 1 area of TAPS were computed as levelized tariffs on the basis of the assumption that the lines would be operated as common-carrier pipelines. The assumed regional pipeline capacities, which in large measure determine the pipeline tariff rates from the discovery to the Pump Station 1 area or the inlet of the proposed gas conditioning plant, depend on play resource volumes that are computed with the play percentage allocation (see appendix 2) devised by the assessment geologists.

The play percentage allocations to the various economic zones were based on the play outlines and supplemental information developed by geologists relating to the identification of gas- and oilprone areas within plays. A centroid for oil and a centroid for gas within each subarea were located on the basis of the play data. Transport costs to the Pump Station 1 area were computed by using the distance from each economic zone product centroid to Pump Station 1 or the location of the inlet of the proposed gas conditioning plant. Appendix 3 provides distances and pipeline capacities used for each zone.

\section{Exploration, Development, and Production Costs}

North Slope exploration and field development procedures are designed to accommodate special requirements in the Arctic environment. Wildcat drilling occurs in the winter when temporary ice roads, ice pads, and ice airstrips are constructed to support drilling activities. After the ice melts, there is no sign of the previous winter's activity. Seasonal instability of the permafrost requires construction of permanent gravel pads to support production drilling rigs, well equipment, and facilities. Production wells are drilled directionally from the pads to target depths and lateral locations up to several miles away from the pad. Gravel drilling pads commonly accommodate as many as 40 well collars ${ }^{18}$ spaced at 10 -foot intervals, along with production equipment. Sidetrack and multilateral drilling of two or more wells using a single well collar enables more well completions to be made on individual drilling pads.

The remoteness of the targets, the cold Arctic climate, and the absence of infrastructure result in high initial exploration and development costs compared with development costs of fields of similar sizes at onshore locations in the conterminous United States. With stand-alone field development, produced oil is processed at the field's central processing facility, and the final product is transported from the periphery of the field to TAPS. Because commercial North Slope discoveries have been large relative to onshore fields in other areas, the application of new technology to increase recovery of the percentage of resource in place produces large payoffs in incremental volumes of oil, and so operators typically introduce such technological innovations early in the development cycle. For example, the application of extended-reach drilling has allowed production wells access to distant reaches of the reservoir (commonly up to 4 miles), in places, eliminating the need for additional drilling pads by permitting satellite pool development from existing drilling pads. Because of this technology, it is assumed that any offshore accumulation in State waters can be developed from onshore with extended-

\footnotetext{
${ }^{18}$ The well collar is at the end of the steel well casing that protrudes at the surface of the drilling pad.
} 
reach wells or with an artificial gravel island in shallow waters, which would not increase the costs for stand-alone fields beyond the costs of onshore fields.

Actual field development costs, which include the cost of drilling and completion and the cost of well pads, production equipment, processing facilities, and infrastructure, depend on site-specific characteristics. In developing generic cost functions, a number of simplifying assumptions were made to keep the economic analysis tractable. The simulation data that constituted the assessment were grouped into the size classes shown in table 2 and into 5,000-foot depth intervals. Development costs for a representative accumulation for each size and depth class were estimated and tested against an economic screen. If the representative accumulation was tested to be economic, then all accumulations in that size and depth category were considered commercially developable.

\section{Exploration Costs}

Costs of geologic and geophysical studies to site exploration wells after a lease is acquired are included as part of the costs of wildcat wells. Wildcat well drilling costs were assumed to be twice the cost of drilling and completion of production wells for the particular economic zone. Nondrilling exploration expenditures include geologic and geophysical data collection after lease acquisition, scouting costs, and overhead charges. Nondrilling exploration expenditures, ${ }^{19}$ exclusive of lease bonuses and lease rental, were assumed to amount to 50 percent of the wildcat well drilling costs (Vidas and others, 1993) and were added to wildcat exploration expenditures. ${ }^{20}$ Exploration was evaluated in increments of 20 wildcat wells. Actual exploration and development costs will depend on site-specific characteristics of the prospects. Because play analysis does not provide specific locations, generic costs were used to model expenditures in each economic zone. Exploration costs are discussed further in appendix 3.

\section{Development Costs for Crude Oil Accumulations}

The two principal field development cost categories are (1) drilling and completion costs of production and injection wells and (2) facilities costs. Research on new procedures, materials, and technology target these two categories to reduce cost and (or) increase productivity. The use of horizontal wells for all development at the Alpine field, North Slope, Alaska, for example, was designed to enhance well productivity and enabled the commercial development of an accumulation having a relatively thin pay interval by North Slope standards (Gingrich and others, 2001). Greater well productivity reduces the required number of wells for field development and also reduces the size and (or) number of drilling pads.

Estimates of the number of development wells for a typical prospect were based on the assumption that the conventional well drainage area is 160 acres. Oil well recovery for the accumulation was based on the simulated reservoir attributes (see footnote 5 where the variable for the area of closure, $a c$, is set equal to 160 acres). Details of the vertical well drainage area conversion for field designs with horizontal well configurations along with the procedure for drilling cost estimation are discussed in appendix 3 .

\footnotetext{
${ }^{19}$ For potential prospect identification, the three-dimensional (3D) seismic expense may range from $\$ 750,000$ to $\$ 1$ million per prospect (David Houseknecht, U.S. Geological Survey, written commun., 2005). The 3D seismic surveys would follow lease acquisition and depend on an existing two-dimensional (2D) seismic survey that located the prospect.

${ }^{20}$ For example, a typical vertical development well at a measured depth of 12,500 feet costs $\$ 6$ million. Total costs for a comparable wildcat well where nondrilling costs amount to 50 percent of drilling cost are about $\$ 18$ million; that is, the product of $\$ 6$ million $\times 2$ (wildcat factor) $\times 1.5$ (nondrilling cost factor).
} 
Facilities include drilling pads, flow lines from drilling sites, the central processing unit, and infrastructure required for housing workers and providing storage. Facilities design and costs depend on peak fluid flow rates and ultimately on the field size. Although little information is in the public domain, a version of the Northstar development plan, including development cost estimates, was submitted by British Petroleum Exploration (Alaska) to the State of Alaska for evaluation with its request for relief of profit-sharing provisions of the State lease (British Petroleum Exploration (Alaska), 1996). NPRA study area facilities costs were estimated by applying the corresponding options for a remote region of the North Slope of the QUE\$TOR cost analysis software (IHS Inc., 2010). The (step) cost relationship was calibrated for facilities cost expressed as a per-barrel function of expected field recovery.

As of early 2011, the oil fields developed on a stand-alone basis in northern Alaska were Prudhoe Bay, Kuparuk River, Lisburne, Milne Point, Endicott, Badami, Northstar, Alpine, and Nikaitchuq. Other developed fields and pools have produced fluids (oil, gas, and water) transported to the central processing unit of a nearby stand-alone field for separation. Point McIntyre, Niakuk, North Prudhoe Bay, and West Beach all use the central processing facilities of the Lisburne field. Prudhoe Bay production facilities process production from Midnight Sun, Aurora, Polaris, Borealis, and Orion. The Kuparuk River field facilities also process production from Tabasco, Tarn, Meltwater, and Palm. Oil produced from the Oooguruk unit, operated by independent Pioneer Natural Resources, is processed at the Kuparuk facilities.

The cost reduction from facility sharing depends on physical production configurations and on the relative bargaining strength of the satellite owner in comparison to that of the owner of the central processing facilities. The State of Alaska recognizes the importance of reducing capital barriers to attract entry of additional firms to the North Slope. The State is studying the potential regulatory issues of fair treatment of new entrants (Kaltenbach and others, 2004).

There is a developing literature by those who have considered the spatial clustering of oil and gas accumulations. Data with respect to oil accumulations in major basins in the conterminous United States show by analysis of wildcat well success ratios that oil accumulations tend to cluster spatially (Grace, 1997). With respect to the NPRA study area, the opportunity for joint development of oil accumulation is limited by the small number of assessed accumulations. Joint development was considered only for economic zones 110 and 120. Additional discussion is provided in appendix 3 .

\section{Production Profiles and Operating Costs for Crude Oil Accumulations}

The oil accumulation production profiles assumed in this study are based on historical experience and on information supplied to the State of Alaska Oil and Gas Conservation Commission for support of the operator's development plans for new discoveries. Oil field operating costs include labor, supervision, overhead and administration, communications, catering, supplies, consumables, well service and workovers, facilities maintenance and insurance, and transportation. Annual field operating costs were estimated as a function of hydrocarbon and water fluid volumes and number of operating wells (Craig, 2002). The fluid volumes were projected annually from field production forecasts based on the relationship between water cut and cumulative production (see appendix 3). Water cut is the ratio of water produced compared to total volume of liquids produced. As fields are depleted, the water cut increases, thus increasing the per-barrel cost of oil processed. Operating cost estimates were reconciled with independently derived estimates using the QUE\$TOR software (IHS Inc., 2010).

\section{Development Costs for Gas Accumulations}

Although large natural gas accumulations have been discovered on the North Slope, natural gas has not been developed for commercial export from the North Slope because there is no gas 
transportation system to market. Currently 8 billion cubic feet (BCF) per day is recovered during oil production operations, and $200 \mathrm{BCF}$ per year is used as fuel. When a gas pipeline is constructed (2018 at the earliest according to TransCanada, 2007), most of the gas supplied to fill the pipeline will likely come from Prudhoe Bay and other fields in the central North Slope. Known gas reserves in these fields could supply the pipeline for at least 10 years if the nominal flow rate were 4.5 BCF per day.

Without any direct information about technical relationships or cost for gas development on the North Slope, the cost estimates developed for this study relied on the data generated from the QUE\$TOR software (IHS Inc., 2010) for facilities cost and operating costs. Facilities costs include gas dehydration and, if required, acid removal and a natural gas liquids separation plant. This analysis is based on the assumption that after dehydration and purification, natural gas liquids will be transported with the gas from the field through feeder lines to the regional line. The high-pressure regional lines will transport gas and NGL in a dense phase to the gas processing facility to be constructed near Pump Station 1.

Gas well drilling and completion costs are assumed to be similar to oil drilling costs on a measured depth basis. The number of wells required to produce a new gas discovery was computed by assuming a well drainage area of 640 acres (National Petroleum Council, 1981a,b). It was assumed that the natural gas wells would be vertical or slightly deviated, but not horizontal.

The number of assessed gas accumulations in size classes from $250 \mathrm{BCF}$ to $768 \mathrm{BCF}$ will provide opportunities for joint development. The assessment geologists allocated a minimum of three such accumulations in these size categories to each of the economic zones except the southernmost zones, 320 and 330 (see table A2-3 in appendix 2). The advances in multiphase transport of produced fluids would allow joint development similar to the patterns demonstrated in offshore areas. Appendix 3 describes details of the assumed patterns.

\section{Production Profiles and Operating Costs for Gas Accumulations}

Development of North Slope gas discoveries is assumed to be delayed until the gas is deliverable to market via a pipeline. ${ }^{21}$ In the posited production profiles, peak production rates and their duration are related to gas accumulation size. It was assumed that field production could be held constant until 75 to 80 percent of the field's original reserves was produced. The phase of constant production then would be followed by a rapid decline at a rate of 24 percent per year. Annual production costs relied upon cost estimates developed using the QUE\$TOR software (IHS Inc., 2010). Details are presented in appendix 3.

\section{Economic Analysis Results}

The 2010 reassessment of the undiscovered oil and gas in conventional accumulations in the NPRA study areas has shifted the regional paradigm for economic analysis from an oil- and gas-prone area to a predominantly gas-prone area. Because it is reasonable for firms to expend funds to identify and define assets that are expected to have value at some future date, there may still be some incentive to explore for gas in anticipation of the pipeline construction. In the case of North Slope undiscovered gas, an important question is the timing of construction of a commercial gas pipeline to market. During the nominal 25-year life of a proposed 4.5-BCF-per-day pipeline, more than 41 TCF would be transported to market. If a 35-year useful life is more likely (Thomas and others, 2007), then 57 TCF gas would be transported. Estimates range from 30 to 33 TCF for proven, pipeline quality, recoverable

\footnotetext{
${ }^{21}$ Even if a pipeline were operational by 2018, the earliest date discussed by TransCanada (2007), there might not be capacity for newly discovered gas until 10 years after the start of the gas pipeline's operation.
} 
gas in conventional fields on the North Slope ${ }^{22}$ (Thomas and others, 2007; Nehring Associates, Inc., 2010). Additional discoveries are required to meet even the minimum commercial life of a new pipeline.

Two scenarios are considered with respect to availability of a gas pipeline capacity for the transportation of gas. The resource cost functions to be presented are time independent, and the scenarios considered are static and represent the resource costs at a single instant in time. For scenario 1, it is assumed that the scale and the regulation of the North Slope gas pipeline will allow some newly discovered gas to be transported to market upon completion of the pipeline. However, the current aftertax net present value of a new gas discovery is discounted for the 10-year period for pipeline permitting and construction. Specifically, the analysis shows how the resource cost function appears to an operator who explores in 2010 and must discount the net present value of a find (based on constant cost and the assumed North Slope gas pipeline tariff) for the 10-year lag time between disbursement of exploration cost and projected cash flow. The projected cash flow streams consist of expenses associated with exploration and development and net revenue from production.

Scenario 2 assumes a 20-year delay between discovery and projected cash flow streams, but the development schedule is the same as that in scenario 1 . Scenario 2 recognizes that the delay for development of newly discovered gas fields could lengthen an additional 10 years if proven gas in operating oil fields is given absolute priority for the capacity of the yet-to-be-built North Slope gas pipeline.

The volume of the assessed undiscovered conventional gas in the study area is greater than the conventional gas assessed in any other U.S. onshore province (U.S. Geological Survey, 2011). The overwhelming magnitude of the assessed gas resource relative to the oil argues that most economic incentives for exploration will be derived from the anticipated commercial discovery of natural gas. However, because some plays were assessed to have both oil and gas, undiscovered oil deposits are predicted to be found in the process of gas exploration. These deposits, while perhaps not sufficiently large to drive exploration, could be developed once exploration costs are already expended. In fact, the results of the analysis will show how the shifts of the gas valuation due to gas pipeline delay assumptions affect the economically recoverable oil estimates. ${ }^{23}$

\section{Estimated Economic Gas in Undiscovered Gas Accumulations}

Figure 4 and table 3 show the estimates of undiscovered economically recoverable gas in nonassociated gas accumulations that are based on assumptions of a 10-year delay and also a 20-year delay between disbursement of exploration expenditures and project startup. In particular, the posited scenarios model the current situation where construction of a major gas pipeline from the North Slope is not expected for 10 years. After the pipeline is operational, proven gas reserves at Prudhoe Bay could fill the pipeline for another 10 years, implying a 20-year delay. The economic effects of geologic uncertainty are clear by observing the differences in the cost functions evaluated using the field size distributions associated with the 95th- and 5th-fractile estimates (spanning the 90-percent confidence interval associated with the geologic estimates of technically recoverable resources). Figure 4 shows the associated functions graphically. The dashed vertical lines indicate the assessed volumes of technically

\footnotetext{
${ }^{22}$ The largest accumulations of discovered gas are attributed to Prudhoe Bay and Point Thompson (Thomas and others, 2007). At the current rate of gas usage (200 BCF per year), the gas available to the pipeline should be reduced by 2 TCF.

${ }^{23}$ This analysis does not directly consider effects of cost uncertainty, except via a cost sensitivity analysis. This approach was taken for two reasons. First, the purpose of the economic analysis was to provide an interpretation of the implications of the geologic assessment for policy analysts and decisionmakers and to demonstrate the range of consequences of geologic uncertainty inherent in the assessment. Second, rather than confounding the geologic uncertainty with the formal introduction of cost uncertainty, the cost sensitivity analysis of the properties associated with the mean value estimate is provided in appendix 5 .
} 
recoverable oil at the 95 th fractile, the mean, and the 5 th fractile. The curves typically have a gently sloping portion that then becomes much steeper. However, if sustained higher prices prevail over a period of time, it is expected that operators will make additional investments in improvements in recovery technology that will improve the recovery factor and shift the vertical lines to the right.

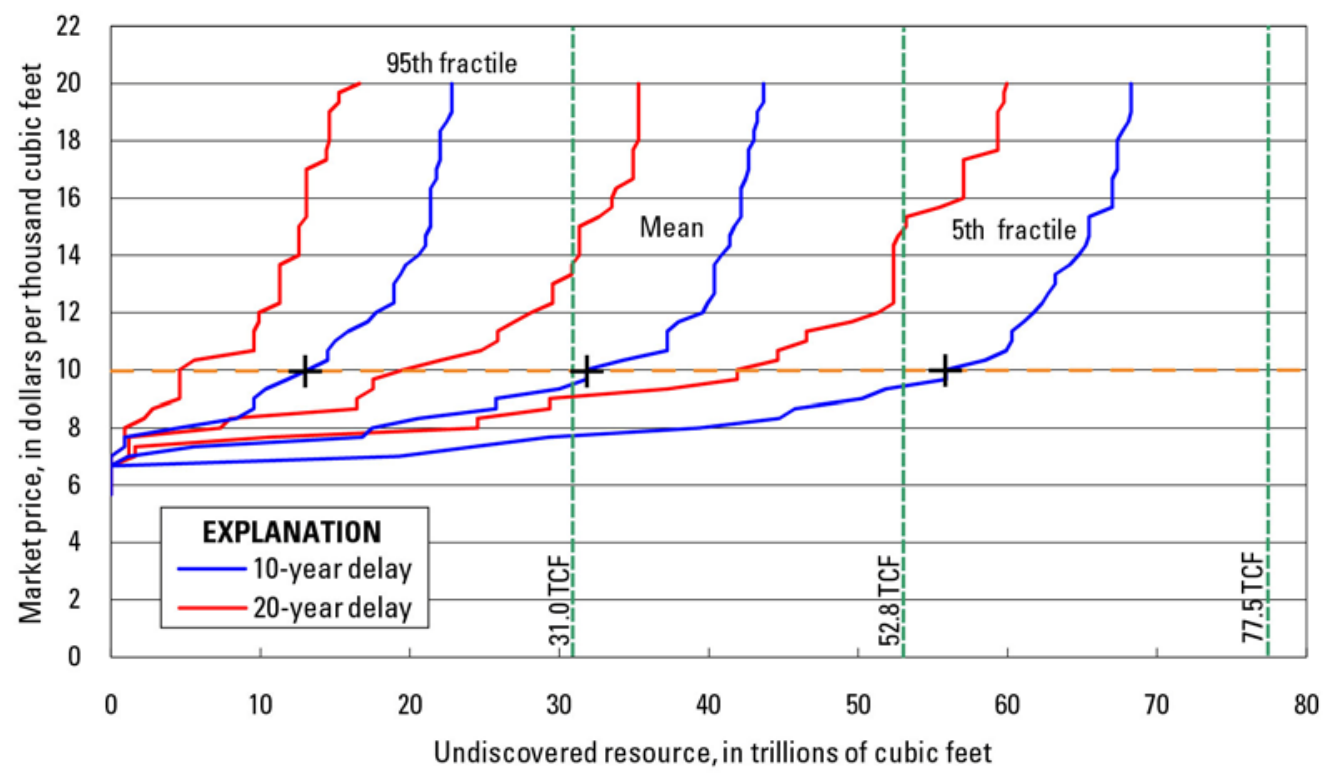

Figure 4. Summary graph of undiscovered economic nonassociated gas resources in the National Petroleum Reserve in Alaska (NPRA) study area. In the economic analysis, gas was valued (in 2010 U.S. dollars) at twothirds the value of oil, and the present value of gas was discounted for delays in pipeline availability of 10 years (blue curves) and 20 years (red curves); the green dashed vertical bars represent the volumes of technically recoverable gas, providing upper limits to the volume of economically recoverable gas. Thus, at a market price of \$10 per thousand cubic feet (orange dashed horizontal line) with a 10-year delay in pipeline availability, at the 95thfractile resource estimate representing a 95-percent occurrence probability of at least 31.0 trillion cubic feet (TCF) of gas, 13.2 TCF is economic, as indicated by the leftmost black cross. Similarly, at the 5th-fractile estimate representing a 5-percent occurrence probability of at least 77.5 TCF of gas, 55.9 TCF is economic (rightmost black cross); at the mean estimate of 52.8 TCF of gas, 31.8 TCF is economic (see table 3.) 
Table 3. Volumes of nonassociated gas and natural gas liquids (NGL) from undiscovered gas accumulations, estimated for the National Petroleum Reserve in Alaska study area, available as a function of specified market prices that offset costs of finding, developing, producing, and transporting the gas to market.

[Volumes represent the 95th-fractile, mean, and 5th-fractile estimates of gas accumulations based on the study area aggregation. Results of computations shown in the table are based on the assumption that sales of gas in gas discoveries are delayed 10 or 20 years. Prices are in 2010 dollars; $\$ / M C F$, dollars per thousand cubic feet; TCF, trillions of cubic feet of gas; BBL, billions of barrels of natural gas liquids]

\begin{tabular}{|c|c|c|c|c|c|c|c|c|c|c|c|c|}
\hline \multirow{3}{*}{$\begin{array}{c}\text { Gas } \\
\text { price } \\
\text { (\$/MCF) }\end{array}$} & \multicolumn{4}{|c|}{ 95th-fractile estimate } & \multicolumn{4}{|c|}{ Mean estimate } & \multicolumn{4}{|c|}{ 5th-fractile estimate } \\
\hline & \multicolumn{2}{|c|}{ 10-year delay } & \multicolumn{2}{|c|}{ 20-year delay } & \multicolumn{2}{|c|}{ 10-year delay } & \multicolumn{2}{|c|}{ 20-year delay } & \multicolumn{2}{|c|}{ 10-year delay } & \multicolumn{2}{|c|}{ 20-year delay } \\
\hline & $\begin{array}{l}\text { Gas } \\
\text { (TCF) }\end{array}$ & $\begin{array}{c}\text { NGL } \\
\text { (BBL) }\end{array}$ & $\begin{array}{c}\text { Gas } \\
\text { (TCF) }\end{array}$ & $\begin{array}{c}\text { NGL } \\
\text { (BBL) }\end{array}$ & $\begin{array}{c}\text { Gas } \\
\text { (TCF) }\end{array}$ & $\begin{array}{c}\text { NGL } \\
\text { (BBL) }\end{array}$ & $\begin{array}{c}\text { Gas } \\
\text { (TCF) }\end{array}$ & $\begin{array}{c}\text { NGL } \\
\text { (BBL) }\end{array}$ & $\begin{array}{l}\text { Gas } \\
\text { (TCF) }\end{array}$ & $\begin{array}{c}\text { NGL } \\
\text { (BBL) }\end{array}$ & $\begin{array}{c}\text { Gas } \\
\text { (TCF) }\end{array}$ & $\begin{array}{c}\text { NGL } \\
\text { (BBL) }\end{array}$ \\
\hline 5.67 & 0.00 & 0.00 & 0.00 & 0.00 & 0.00 & 0.00 & 0.00 & 0.00 & 0.00 & 0.00 & 0.00 & 0.00 \\
\hline 6.00 & 0.00 & 0.00 & 0.00 & 0.00 & 0.00 & 0.00 & 0.00 & 0.00 & 0.00 & 0.00 & 0.00 & 0.00 \\
\hline 6.33 & 0.00 & 0.00 & 0.00 & 0.00 & 0.00 & 0.00 & 0.00 & 0.00 & 0.00 & 0.00 & 0.00 & 0.00 \\
\hline 6.67 & 0.00 & 0.00 & 0.00 & 0.00 & 0.00 & 0.00 & 0.00 & 0.00 & 0.00 & 0.00 & 0.00 & 0.00 \\
\hline 7.00 & 0.00 & 0.00 & 0.00 & 0.00 & 1.18 & 0.01 & 1.18 & 0.01 & 19.26 & 0.38 & 1.60 & 0.02 \\
\hline 7.33 & 0.90 & 0.01 & 0.90 & 0.01 & 5.54 & 0.10 & 1.18 & 0.01 & 24.25 & 0.44 & 1.60 & 0.02 \\
\hline 7.67 & 0.90 & 0.01 & 0.90 & 0.01 & 16.82 & 0.32 & 1.18 & 0.01 & 29.29 & 0.51 & 10.61 & 0.15 \\
\hline 8.00 & 4.48 & 0.07 & 0.90 & 0.01 & 17.48 & 0.32 & 7.32 & 0.11 & 39.35 & 0.66 & 24.54 & 0.41 \\
\hline 8.33 & 8.43 & 0.15 & 2.24 & 0.02 & 20.58 & 0.37 & 7.97 & 0.11 & 44.72 & 0.73 & 24.54 & 0.41 \\
\hline 8.67 & 9.55 & 0.17 & 2.77 & 0.03 & 25.77 & 0.44 & 16.45 & 0.28 & 45.77 & 0.74 & 29.35 & 0.48 \\
\hline 9.00 & 9.55 & 0.17 & 4.59 & 0.06 & 25.77 & 0.44 & 16.45 & 0.28 & 50.26 & 0.79 & 29.35 & 0.48 \\
\hline 9.33 & 10.35 & 0.18 & 4.59 & 0.06 & 30.00 & 0.50 & 17.55 & 0.30 & 51.86 & 0.81 & 37.28 & 0.59 \\
\hline 9.67 & 11.81 & 0.20 & 4.59 & 0.06 & 31.81 & 0.52 & 17.55 & 0.30 & 55.88 & 0.89 & 41.90 & 0.66 \\
\hline 10.00 & 13.19 & 0.22 & 4.59 & 0.06 & 31.81 & 0.52 & 19.59 & 0.33 & 55.89 & 0.89 & 41.90 & 0.66 \\
\hline 10.33 & 14.49 & 0.24 & 5.57 & 0.07 & 34.29 & 0.55 & 22.08 & 0.36 & 58.51 & 0.93 & 44.62 & 0.69 \\
\hline 10.67 & 14.49 & 0.24 & 9.56 & 0.15 & 37.22 & 0.61 & 24.75 & 0.41 & 59.91 & 0.94 & 44.62 & 0.69 \\
\hline 11.00 & 14.99 & 0.24 & 9.56 & 0.15 & 37.22 & 0.61 & 25.87 & 0.42 & 60.29 & 0.95 & 46.54 & 0.72 \\
\hline 11.33 & 15.87 & 0.26 & 9.56 & 0.15 & 37.22 & 0.61 & 25.87 & 0.42 & 60.29 & 0.95 & 46.54 & 0.72 \\
\hline 11.67 & 17.17 & 0.27 & 9.89 & 0.15 & 37.99 & 0.62 & 27.02 & 0.44 & 61.09 & 0.96 & 49.55 & 0.76 \\
\hline 12.00 & 17.74 & 0.28 & 9.89 & 0.15 & 39.61 & 0.64 & 28.13 & 0.46 & 61.72 & 0.96 & 51.35 & 0.79 \\
\hline 12.33 & 18.93 & 0.32 & 11.29 & 0.17 & 39.91 & 0.65 & 29.56 & 0.47 & 62.33 & 0.97 & 52.36 & 0.80 \\
\hline 12.67 & 18.93 & 0.32 & 11.29 & 0.17 & 40.37 & 0.65 & 29.56 & 0.47 & 62.72 & 0.98 & 52.36 & 0.80 \\
\hline 13.00 & 18.93 & 0.32 & 11.29 & 0.17 & 40.37 & 0.65 & 29.56 & 0.47 & 63.18 & 0.98 & 52.36 & 0.80 \\
\hline 13.33 & 19.38 & 0.32 & 11.29 & 0.17 & 40.37 & 0.65 & 30.83 & 0.49 & 63.18 & 0.98 & 52.36 & 0.80 \\
\hline 13.67 & 19.73 & 0.33 & 11.29 & 0.17 & 40.37 & 0.65 & 30.83 & 0.49 & 64.17 & 1.01 & 52.36 & 0.80 \\
\hline 14.00 & 20.56 & 0.34 & 12.58 & 0.20 & 40.86 & 0.66 & 31.34 & 0.49 & 64.74 & 1.01 & 52.36 & 0.80 \\
\hline 14.33 & 21.04 & 0.34 & 12.58 & 0.20 & 41.41 & 0.67 & 31.34 & 0.49 & 65.22 & 1.02 & 52.36 & 0.80 \\
\hline & & & & & & 23 & & & & & & \\
\hline
\end{tabular}


Table 3. Volumes of nonassociated gas and natural gas liquids (NGL) from undiscovered gas accumulations, estimated for the National Petroleum Reserve in Alaska study area, available as a function of specified market prices that offset costs of finding, developing, producing, and transporting the gas to market. - Continued

[Volumes represent the 95th-fractile, mean, and 5th-fractile estimates of gas accumulations based on the study area aggregation. Results of computations shown in the table are based on the assumption that sales of gas in gas discoveries are delayed 10 or 20 years. Prices are in 2010 dollars; $\$ / M C F$, dollars per thousand cubic feet; TCF, trillions of cubic feet of gas; BBL, billions of barrels of natural gas liquids]

\begin{tabular}{|c|c|c|c|c|c|c|c|c|c|c|c|c|}
\hline \multirow{3}{*}{$\begin{array}{c}\text { Gas } \\
\text { price } \\
\text { (\$/MCF) }\end{array}$} & \multicolumn{4}{|c|}{ 95th-fractile estimate } & \multicolumn{4}{|c|}{ Mean estimate } & \multicolumn{4}{|c|}{ 5th-fractile estimate } \\
\hline & \multicolumn{2}{|c|}{ 10-year delay } & \multicolumn{2}{|c|}{ 20-year delay } & \multicolumn{2}{|c|}{ 10-year delay } & \multicolumn{2}{|c|}{ 20-year delay } & \multicolumn{2}{|c|}{ 10-year delay } & \multicolumn{2}{|c|}{ 20-year delay } \\
\hline & $\begin{array}{l}\text { Gas } \\
\text { (TCF) }\end{array}$ & $\begin{array}{l}\text { NGL } \\
\text { (BBL) }\end{array}$ & $\begin{array}{l}\text { Gas } \\
\text { (TCF) }\end{array}$ & $\begin{array}{l}\text { NGL } \\
\text { (BBL) }\end{array}$ & $\begin{array}{l}\text { Gas } \\
\text { (TCF) }\end{array}$ & $\begin{array}{l}\text { NGL } \\
\text { (BBL) }\end{array}$ & $\begin{array}{l}\text { Gas } \\
\text { (TCF) }\end{array}$ & $\begin{array}{l}\text { NGL } \\
\text { (BBL) }\end{array}$ & $\begin{array}{l}\text { Gas } \\
\text { (TCF) }\end{array}$ & $\begin{array}{l}\text { NGL } \\
\text { (BBL) }\end{array}$ & $\begin{array}{l}\text { Gas } \\
\text { (TCF) }\end{array}$ & $\begin{array}{l}\text { NGL } \\
\text { (BBL) }\end{array}$ \\
\hline 14.67 & 21.04 & 0.34 & 12.58 & 0.20 & 41.41 & 0.67 & 31.34 & 0.49 & 65.46 & 1.02 & 52.68 & 0.80 \\
\hline 15.00 & 21.37 & 0.35 & 12.58 & 0.20 & 41.72 & 0.67 & 31.34 & 0.49 & 65.46 & 1.02 & 53.21 & 0.81 \\
\hline 15.33 & 21.37 & 0.35 & 13.07 & 0.20 & 42.15 & 0.68 & 32.65 & 0.51 & 65.46 & 1.02 & 53.21 & 0.81 \\
\hline 15.67 & 21.37 & 0.35 & 13.07 & 0.20 & 42.15 & 0.68 & 33.51 & 0.52 & 67.01 & 1.05 & 55.45 & 0.84 \\
\hline 16.00 & 21.37 & 0.35 & 13.07 & 0.20 & 42.15 & 0.68 & 33.51 & 0.52 & 67.01 & 1.05 & 57.06 & 0.86 \\
\hline 16.33 & 21.37 & 0.35 & 13.07 & 0.20 & 42.15 & 0.68 & 33.78 & 0.52 & 67.01 & 1.05 & 57.06 & 0.86 \\
\hline 16.67 & 21.78 & 0.35 & 13.07 & 0.20 & 42.48 & 0.68 & 34.94 & 0.54 & 67.01 & 1.05 & 57.06 & 0.86 \\
\hline 17.00 & 21.78 & 0.35 & 13.07 & 0.20 & 42.66 & 0.68 & 34.94 & 0.54 & 67.33 & 1.05 & 57.06 & 0.86 \\
\hline 17.33 & 22.03 & 0.35 & 14.40 & 0.22 & 42.66 & 0.68 & 34.94 & 0.54 & 67.33 & 1.05 & 57.06 & 0.86 \\
\hline 17.67 & 22.03 & 0.35 & 14.40 & 0.22 & 42.66 & 0.68 & 34.94 & 0.54 & 67.33 & 1.05 & 59.33 & 0.92 \\
\hline 18.00 & 22.03 & 0.35 & 14.61 & 0.23 & 43.02 & 0.69 & 35.31 & 0.55 & 67.33 & 1.05 & 59.33 & 0.92 \\
\hline 18.33 & 22.03 & 0.35 & 14.61 & 0.23 & 43.02 & 0.69 & 35.31 & 0.55 & 67.69 & 1.06 & 59.33 & 0.92 \\
\hline 18.67 & 22.46 & 0.36 & 14.61 & 0.23 & 43.25 & 0.69 & 35.31 & 0.55 & 68.10 & 1.06 & 59.33 & 0.92 \\
\hline 19.00 & 22.80 & 0.36 & 14.61 & 0.23 & 43.25 & 0.69 & 35.31 & 0.55 & 68.26 & 1.06 & 59.33 & 0.92 \\
\hline 19.33 & 22.80 & 0.36 & 15.24 & 0.23 & 43.66 & 0.70 & 35.31 & 0.55 & 68.26 & 1.06 & 59.75 & 0.92 \\
\hline 19.67 & 22.80 & 0.36 & 15.24 & 0.23 & 43.66 & 0.70 & 35.31 & 0.55 & 68.26 & 1.06 & 59.75 & 0.92 \\
\hline 20.00 & 22.80 & 0.36 & 16.62 & 0.25 & 43.66 & 0.70 & 35.31 & 0.55 & 68.26 & 1.06 & 59.94 & 0.92 \\
\hline
\end{tabular}


At a market price in the conterminous United States of $\$ 8$ per MCF and with the assumption of a 10-year delay, the economic nonassociated gas resources at the 95th-fractile, mean, and 5th-fractile estimates are predicted to be 4.5 TCF, 17.5 TCF, and 39.4 TCF, respectively (table 3). At \$12 per MCF, the economic nonassociated gas resources at the 95th-fractile, mean, and 5th-fractile estimates are predicted to be 17.7 TCF, 39.6 TCF, and 61.7 TCF, respectively.

At the \$8-per-MCF market price and with the assumption of a 10-year delay, the economically recoverable volume at the mean estimate is 33 percent of the assessed volume of $52.8 \mathrm{TCF}$. Similarly, given $\$ 8$ per MCF and the assumption of a 10-year delay at the 95th fractile, only 14 percent of the assessed gas of $31.0 \mathrm{TCF}$ is economic, and at the 5 th fractile, 51 percent of the assessed technically recoverable gas of 77.5 TCF is economic. These differences are directly attributable to the cost characteristics of the field size distributions posited at those estimates by the geologic assessment (see table 2). The average accumulation size (assessed volume divided by the number of accumulations) for the 5th fractile is $900 \mathrm{BCF}$; the average size for the mean estimate is $750 \mathrm{BCF}$; and the average size for the 95th fractile is $600 \mathrm{BCF}$. The data in table 2 show that not only are the accumulations associated with the 5th fractile much larger, but there are approximately 86 undiscovered accumulations compared to approximately 70 at the mean and 51 at the 95 th-fractile estimate.

At $\$ 8$ per MCF, a 20 -year delay reduces the economic nonassociated gas at the mean estimate to 7.3 TCF from 17.5 TCF (a 58-percent reduction). At $\$ 12$ per MCF, a 20-year delay reduces economic gas at the mean estimate to 28.1 TCF from 39.6 TCF (a 29-percent reduction). The results illustrate the importance of access to pipeline capacity for the timely development of new discoveries as an incentive for exploration.

\section{Estimated Economic Oil in Undiscovered Oil Accumulations}

Table 4 and figure 5 show results of the economic analysis of the technically recoverable volumes of oil. As discussed above, the 2010 geologic assessment (Houseknecht and others, 2010) resulted in the reclassification of the study area as primarily gas prone. The exploration for gas in gas accumulations will drive the discoveries of oil as demonstrated by the difference in the computed economic oil based on the availability of the gas pipeline of 10 and 20 years into the future (see table 4). ${ }^{24}$ The figure is based on the assumption that sales of gas in gas discoveries are delayed by 10 years after discovery and that there are no sales of associated gas in oil discoveries.

\footnotetext{
${ }^{24}$ Recall that no commercial value is attached to associated gas. It is typically injected into the formation to maintain reservoir pressures.
} 
Table 4. Volumes of oil and natural gas liquids (NGL) from undiscovered oil accumulations, estimated for the National Petroleum Reserve in Alaska study area, available as a function of specified market prices that offset costs of finding, developing, producing, and transporting the oil to market.

[Volumes represent the 95th-fractile, mean, and 5th-fractile estimates of undiscovered oil accumulations based on the study area aggregation. Because exploration is assumed to be driven by the search for both oil and gas accumulations, the results of computations shown in the table are based on the assumption that sales of gas in gas discoveries are delayed 10 or 20 years. Prices are in 2010 dollars; $\$ / b b l$, dollars per barrel; BBO, billions of barrels of oil; BBL, billions of barrels of natural gas liquids]

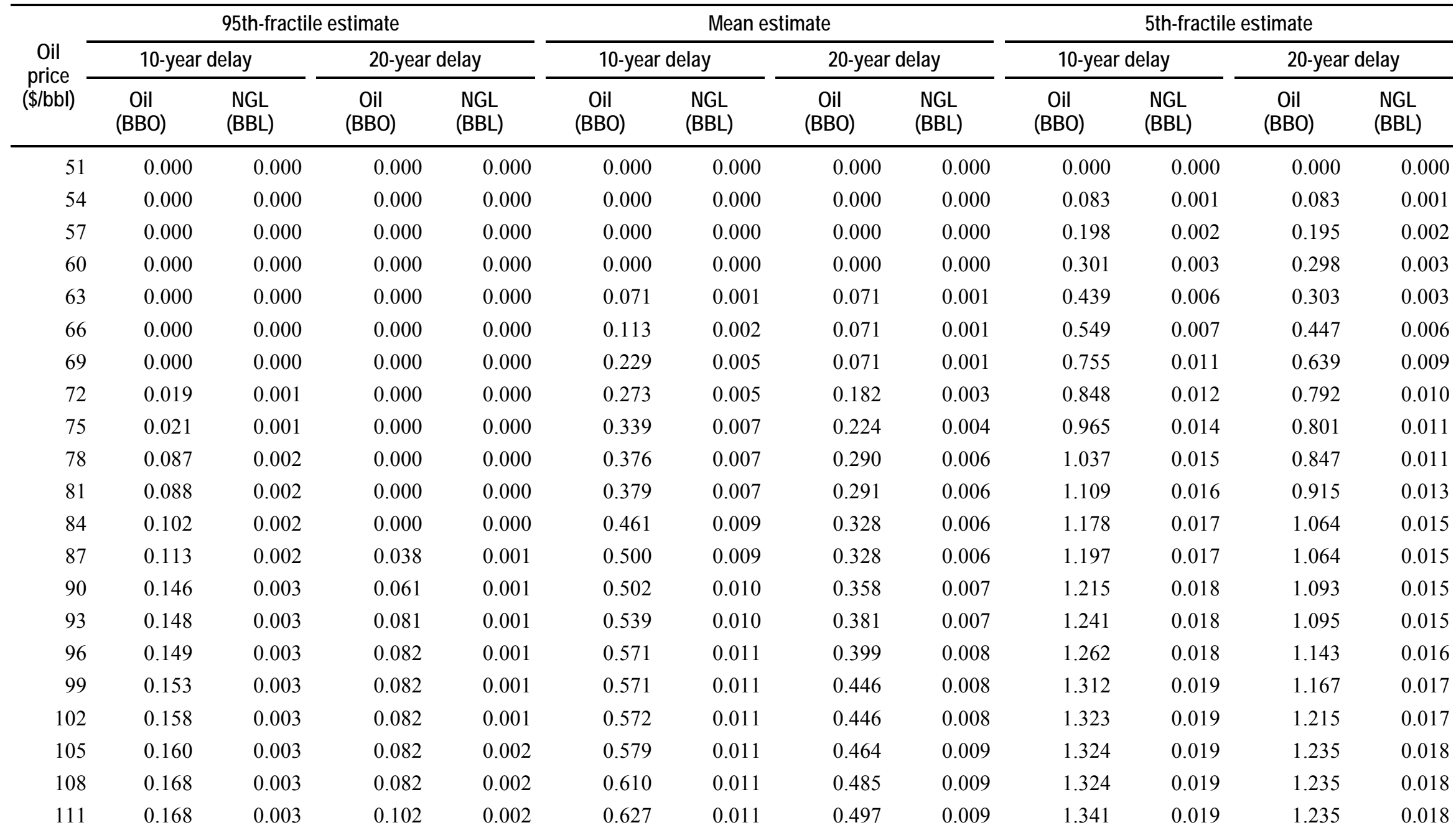


Table 4. Volumes of oil and natural gas liquids (NGL) from undiscovered oil accumulations, estimated for the National Petroleum Reserve in Alaska study area, available as a function of specified market prices that offset costs of finding, developing, producing, and transporting the oil to market.-Continued

\begin{tabular}{|c|c|c|c|c|c|c|c|c|c|c|c|c|}
\hline \multirow{3}{*}{$\begin{array}{c}\text { Oil } \\
\text { price } \\
\text { (\$/bbl) }\end{array}$} & \multicolumn{4}{|c|}{ 95th-fractile estimate } & \multicolumn{4}{|c|}{ Mean estimate } & \multicolumn{4}{|c|}{ 5th-fractile estimate } \\
\hline & \multicolumn{2}{|c|}{ 10-year delay } & \multicolumn{2}{|c|}{ 20-year delay } & \multicolumn{2}{|c|}{ 10-year delay } & \multicolumn{2}{|c|}{ 20-year delay } & \multicolumn{2}{|c|}{ 10-year delay } & \multicolumn{2}{|c|}{ 20-year delay } \\
\hline & $\begin{array}{c}\text { Oil } \\
\text { (BBO) }\end{array}$ & $\begin{array}{c}\text { NGL } \\
\text { (BBL) }\end{array}$ & $\begin{array}{c}\text { Oil } \\
\text { (BBO) }\end{array}$ & $\begin{array}{c}\text { NGL } \\
\text { (BBL) }\end{array}$ & $\begin{array}{c}\text { Oil } \\
\text { (BBO) }\end{array}$ & $\begin{array}{c}\text { NGL } \\
\text { (BBL) }\end{array}$ & $\begin{array}{c}\text { Oil } \\
\text { (BBO) }\end{array}$ & $\begin{array}{c}\text { NGL } \\
\text { (BBL) }\end{array}$ & $\begin{array}{c}\text { Oil } \\
\text { (BBO) }\end{array}$ & $\begin{array}{c}\text { NGL } \\
\text { (BBL) }\end{array}$ & $\begin{array}{c}\text { Oil } \\
\text { (BBO) }\end{array}$ & $\begin{array}{c}\text { NGL } \\
\text { (BBL) }\end{array}$ \\
\hline 114 & 0.176 & 0.003 & 0.117 & 0.002 & 0.638 & 0.012 & 0.497 & 0.009 & 1.365 & 0.020 & 1.235 & 0.018 \\
\hline 117 & 0.189 & 0.003 & 0.117 & 0.002 & 0.638 & 0.012 & 0.497 & 0.009 & 1.365 & 0.020 & 1.250 & 0.018 \\
\hline 120 & 0.193 & 0.003 & 0.117 & 0.002 & 0.638 & 0.012 & 0.512 & 0.010 & 1.365 & 0.020 & 1.268 & 0.018 \\
\hline 129 & 0.198 & 0.004 & 0.125 & 0.002 & 0.650 & 0.012 & 0.528 & 0.010 & 1.398 & 0.020 & 1.269 & 0.018 \\
\hline 132 & 0.201 & 0.004 & 0.125 & 0.002 & 0.650 & 0.012 & 0.528 & 0.010 & 1.398 & 0.020 & 1.269 & 0.018 \\
\hline 135 & 0.201 & 0.004 & 0.137 & 0.002 & 0.659 & 0.012 & 0.528 & 0.010 & 1.398 & 0.020 & 1.286 & 0.018 \\
\hline 138 & 0.201 & 0.004 & 0.142 & 0.003 & 0.667 & 0.012 & 0.553 & 0.010 & 1.411 & 0.020 & 1.316 & 0.019 \\
\hline 141 & 0.201 & 0.004 & 0.142 & 0.003 & 0.667 & 0.012 & 0.567 & 0.010 & 1.413 & 0.020 & 1.333 & 0.019 \\
\hline 156 & 0.211 & 0.004 & 0.153 & 0.003 & 0.687 & 0.012 & 0.592 & 0.011 & 1.432 & 0.021 & 1.347 & 0.019 \\
\hline 159 & 0.211 & 0.004 & 0.153 & 0.003 & 0.687 & 0.012 & 0.592 & 0.011 & 1.432 & 0.021 & 1.347 & 0.019 \\
\hline 162 & 0.211 & 0.004 & 0.153 & 0.003 & 0.693 & 0.013 & 0.604 & 0.011 & 1.432 & 0.021 & 1.347 & 0.019 \\
\hline 165 & 0.211 & 0.004 & 0.153 & 0.003 & 0.693 & 0.013 & 0.604 & 0.011 & 1.435 & 0.021 & 1.357 & 0.019 \\
\hline 168 & 0.213 & 0.004 & 0.153 & 0.003 & 0.700 & 0.013 & 0.604 & 0.011 & 1.449 & 0.021 & 1.357 & 0.019 \\
\hline 171 & 0.213 & 0.004 & 0.153 & 0.003 & 0.700 & 0.013 & 0.604 & 0.011 & 1.449 & 0.021 & 1.370 & 0.020 \\
\hline 174 & 0.213 & 0.004 & 0.165 & 0.003 & 0.704 & 0.013 & 0.604 & 0.011 & 1.449 & 0.021 & 1.370 & 0.020 \\
\hline 177 & 0.213 & 0.004 & 0.165 & 0.003 & 0.704 & 0.013 & 0.604 & 0.011 & 1.469 & 0.021 & 1.370 & 0.020 \\
\hline 180 & 0.213 & 0.004 & 0.165 & 0.003 & 0.704 & 0.013 & 0.604 & 0.011 & 1.469 & 0.021 & 1.373 & 0.020 \\
\hline
\end{tabular}




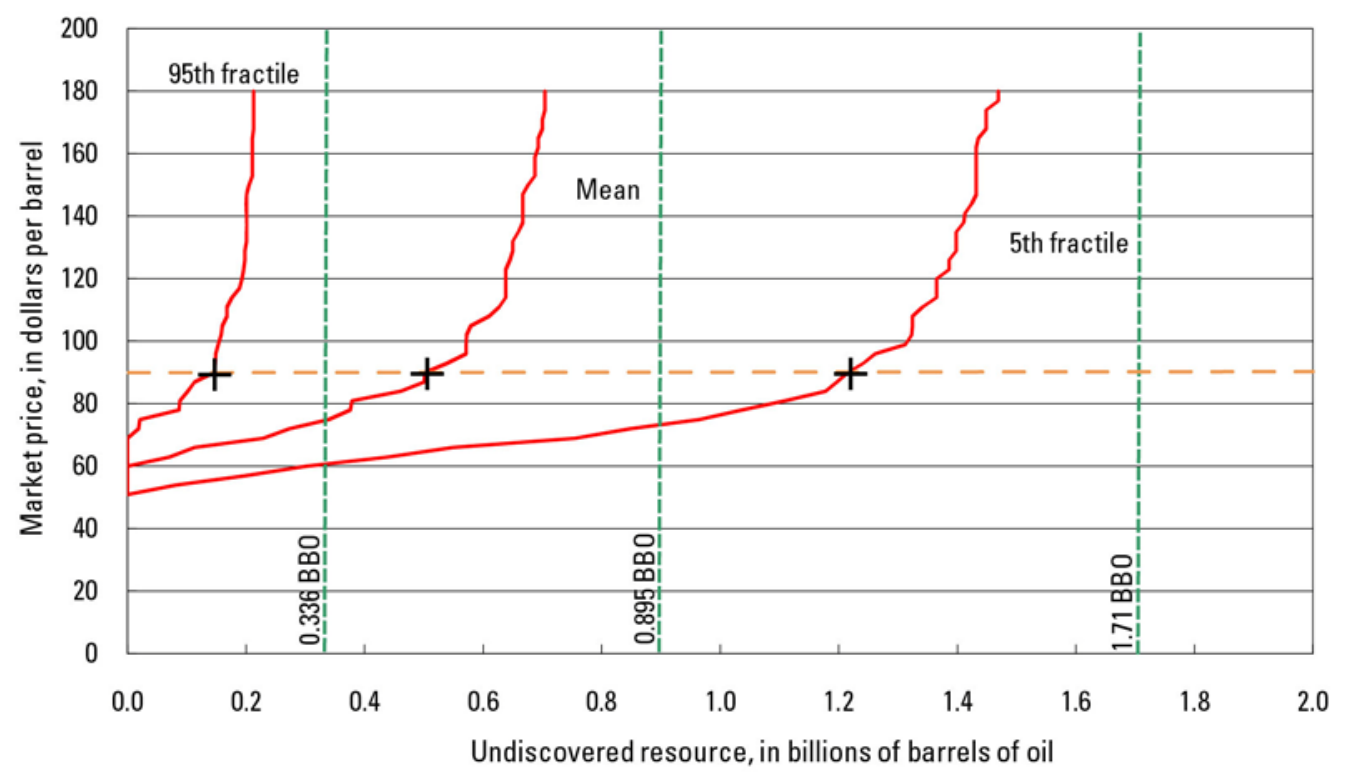

Figure 5. Summary graph of undiscovered economic oil resources in the National Petroleum Reserve in Alaska (NPRA) study area. Each red curve relates the market price (in 2010 U.S. dollars) to the estimated volume of economic resources where gas is valued at two-thirds the value of oil and the present value of gas accumulations is discounted for a 10-year delay; the green dashed vertical bars represent the volumes of technically recoverable oil, providing upper limits to the volume of economically recoverable oil. Thus, at a market price of $\$ 90$ per barrel (orange dashed horizontal line), at the 95th-fractile resource estimate representing a 95-percent occurrence probability of at least 0.336 billion barrels of oil (BBO), $0.146 \mathrm{BBO}$ is economic, as indicated by the leftmost back cross. Similarly, at the 5 th-fractile estimate representing a 5-percent occurrence probability of at least $1.71 \mathrm{BBO}$, $1.22 \mathrm{BBO}$ is economic; at the mean estimate of $0.895 \mathrm{BBO}, 0.502 \mathrm{BBO}$ is economic.

The differences in the curves are attributable to the properties of the assessed distribution shown in table 2. Because of the small number of accumulations and on the basis of the geologists' allocation of plays to the economic zones, it was determined that there would be no opportunity for facility sharing for the discoveries represented at the 95th-fractile estimate. It is obvious from the cost functions that some of the accumulations were determined to be so small or to be located in sufficiently remote areas that even if discovered, they would not be developed. In the case of the mean and 5th-fractile estimates, the allocations of plays to economic zones allow one to infer that facilities sharing would be possible only in economic zones 110 and 120. At $\$ 72$ per barrel for the 10- and 20-year delays, the economically recoverable oil represented 30 and 20 percent, respectively, of the technically recoverable oil.

\section{Conclusions and Limitations}

This economic analysis applied the technically recoverable volumes, size-frequency distributions, and reservoir characteristics from the geologic assessment to develop resource cost relationships for the 2010 assessment of undiscovered technically recoverable oil and gas in conventional accumulations for the NPRA study area prepared by the U.S. Geological Survey (Houseknecht and others, 2010). The results of the new assessment have dramatically changed estimates of the nature and magnitudes of the undiscovered resource. 
The results of the economic analysis are presented as cost functions associated with the mean, 95th-fractile, and 5th-fractile estimates of undiscovered technically recoverable oil and gas. An after-tax 12-percent rate of return, or hurdle rate, was assumed. The calculations used the 2010 costs and technology, and the results of the analysis are stated in constant 2010 dollars. Cost functions include the cost of finding, developing, producing, and transporting the resource to market. Transportation costs from the field to the market were included in the analysis so that the prices and costs are at the market rather than at the wellhead. There is currently a proposed pipeline to take gas produced on Alaska's North Slope to Alberta and then to various markets in the United States. An estimated tariff was used to examine the economics of exploring and eventually developing the assessed natural gas when 10- and 20 -year delays were assumed to exist after discovery before the availability of pipeline capacity to bring the gas to market.

The results of the economic analysis show (1) that substantial volumes of undiscovered natural gas could drive exploration in the NPRA study area, particularly if the gas pipeline project continues to advance, during which process part of the assessed oil will be found and may be developed, (2) that, in terms of current economic valuation of gas, there is a substantial dampening effect from an additional 10-year delay in pipeline capacity availability, and (3) that significant volumes of gas are expected to be present in the study area. The undiscovered gas accumulations could be economically developed at gas market prices above $\$ 8$ per MCF.

In a report prepared for the State of Alaska, Black and Veatch (2010) projected Canadian gas prices at the AECO Hub ${ }^{\mathrm{TM}}$ in Alberta, Canada, and U.S. gas prices at Henry Hub in Erath, Louisiana, by using a North American gas market model. The report identified three price scenarios. Each scenario was tied to a set of energy and environmental policies that would affect gas supplies. These policies related to regulation of shale gas production practices and policies that affect the cost of alternative methods to generate electricity. In particular, policies considered that affect costs include those leading to increases in electricity generated from natural gas, an increase in nuclear power generation, and penalties associated with the use of coal for electricity generation. The policy options examined are considered plausible and now are under active debate. The results of the Black and Veatch (2010) projections (in 2010 dollars) at the mid-price level are Henry Hub prices reaching $\$ 7.50$ by 2020 and $\$ 7.80$ by 2030 and AECO Hub prices reaching $\$ 5.80$ by 2020 and $\$ 7.00$ by 2030 . The high-price projections for Henry Hub were $\$ 8.00$ by 2020 and $\$ 9$ by 2030, and high-price projections for the AECO Hub were $\$ 6.20$ by 2020 and $\$ 8.00$ by 2030. In this report, Black and Veatch did not describe the potential effect on U.S. domestic gas prices from the development of export LNG facilities to export gas.

The March 2011 earthquake, tsunami, and releases of radiation from Japan's nuclear powerplants will have a worldwide effect on the entire electrical power generation industry, potentially moving prices above the Black and Veatch (2010) high-price scenario. Japan's imports of gas will likely bear much of the burden of replacing the power from damaged reactors. However, the health effects of the released radiation will likely have substantial long-term implications for the nuclear power industry as it attempts to replace aging plants. Data in the 2010 BP Statistical Review of World Energy (BP, 2010) were used to estimate that about 2.44 TCF of natural gas per year (6.68 BCF per day) would be required to replace the electricity generated by Japan's nuclear industry with electricity generated from natural gas.

Historical perspective suggests that public reaction to the perceived danger of nuclear power generation will result in opposition to construction of new and replacement plants. The Black and Veatch (2010) analysis did not forecast a decline in nuclear power generation. For the United States, replacement of the nuclear generating capacity with gas would require 7.46 TCF per year $(20.3 \mathrm{BCF}$ per 
day) (BP, 2010). Most of the nuclear plants in the United States are old, having been built before the nuclear accident in 1979 at the Three Mile Island Nuclear Generating Station in Pennsylvania.

Additionally, the United States has yet to address the long-term issue of a permanent site for the disposal of nuclear wastes.

The limitations of this study are evident in the many assumptions that were required to make the analysis tractable. The economic analysis is highly dependent on the geologic assessment. The analysis could not incorporate site-specific information or take into consideration the specific regulations of operating within the Federal part of the NPRA. In addition, the production characteristics of nonassociated gas accumulations are not known for most of the formations having large assessed volumes of gas. Almost all of the gas production on the North Slope has been associated with oil production, and large gas fields (such as Point Thomson) have not been developed for gas production. The cost modeling in this study did not include the improvements in exploration efficiency or technology that can be expected to occur when the exploration and development process progresses.

Finally, appendix 5 provides a summary of a cost sensitivity analysis using market prices of $\$ 8$, \$10, and \$12 per MCF. These prices bracket the Black and Veatch (2010) high-price scenario of projected prices for the conterminous United States in 2030. The analysis focused on the difference in predicted economic gas (see table 3) using the "base case" defined by mean assessment estimates and corresponding cost assumptions described above and the predicted economic gas under assumptions that correspond to increases (reductions) in various cost components by one-third of the "base case costs." The cost sensitivities included (1) drilling and facilities cost, (2) production transportation cost to market, and (3) drilling, facilities, and pipeline cost (within the North Slope). For the market prices of $\$ 8$ and $\$ 10$ per MCF, the economic volumes were quite sensitive to assumptions underlying the costs used in deriving table 3 . The cost increases have the effect of raising the threshold price of gas above $\$ 8$ per MCF for the case where operators expect a 20-year delay between discovery and gas sales pipeline availability. However, at market prices of $\$ 12$ per MCF, the same percentage cost increases will reduce economic volumes by no more than one-third. In summary, at and below \$10 per MCF market prices, overall cost increases can lead to substantial reductions in the projected economic gas, but this effect is substantially dampened with increasing market prices. Spot market natural gas prices at Henry Hub hovered around \$4 per MCF in late March of 2011. Real gas prices would have to grow at a rate of 4.7 percent per annum to reach $\$ 10$ per MCF by 2031. While the Black and Veatch analysis (2010) might have assessed the likelihood for reaching that price as relatively small, recent events in Japan may have changed that assessment.

\section{Acknowledgments}

The authors thank David Houseknecht and Christopher Garrity (both of the U.S. Geological Survey, USGS) and John H. Schuenemeyer (Southwest Statistical Consulting, LLC) for assistance in the assembly and interpretation of the updated NPRA resource analysis. The authors thank James D. Craig (Bureau of Ocean Energy Management, Regulation and Enforcement [formerly the Minerals Management Service]), Keith Long (USGS), and James Coleman (USGS) for reviews and Elizabeth Good (USGS), Anna Glover (USGS), and Cathy Knutson (USGS) for editing and final publication.

\section{References Cited}

Alaska Department of Revenue, Tax Division, 2007, Fall 2007 revenue sources book: Anchorage, Alaska, Alaska Department of Revenue, Tax Division, 126 p. (Also available at http://www.tax.alaska.gov/programs/documentviewer/viewer.aspx?255.) 
Alaska Department of Revenue, Tax Division, 2010, Fall 2010 revenue sources book: Anchorage, Alaska, Alaska Department of Revenue, Tax Division, 102 p. (Also available at http://www.tax.alaska.gov/programs/documentviewer/viewer.aspx?2136f.)

Alyeska Pipeline Service Company, 2011, Pipeline facts-Throughput: Anchorage, Alaska, Alyeska Pipeline Service Company, Web page, accessed March 8, 2011, at http://www.alyeskapipe.com/Pipelinefacts/Throughput.html.

American Petroleum Institute, Independent Petroleum Association of America, and Mid-Continent Oil and Gas Association, 1997-2005, Joint association survey on drilling costs: Washington, D.C., American Petroleum Institute, Statistics Department, pagination varies by year.

ARCO Alaska Inc., Anadarko Petroleum Corp., and Union Texas Petroleum LLC, 1998, Alpine written testimony, Alpine Pool Rules Hearing, Alaska Oil and Gas Conservation Commission, December 3, 1998: Anchorage, Alaska.

Atkinson, Ian, Theuveny, Bertrand, Berard, Michel, Conort, Gilbert, Groves, Joel, Lowe, Trey, McDiarmid, Allan, Mehdizadeh, Parviz, Perciot, Patrick, Pinguet, Bruno, Smith, Gerald, and Williamson, K.J., 2004, A new horizon in multiphase flow measurement: Oilfield Review, v. 16, no. 4, Winter 2004/2005, p. 52-63. (Also available at http://www.slb.com/media/services/resources/oilfieldreview/ors04/win04/05_multiphase_flow.pdf.)

Attanasi, E.D., 1998, Economics and the 1995 national assessment of United States oil and gas resources: U.S. Geological Survey Circular 1145, 35 p. (Also available at http://pubs.usgs.gov/circ/1998/c1145/c1145.html.)

Attanasi, E.D., 2003, Economics of undiscovered oil in Federal lands on the National Petroleum Reserve, Alaska: U.S. Geological Survey Open-File Report 03-44, 63 p., available only online at http://pubs.usgs.gov/of/2003/of03-044/. (Accessed February 27, 2009.)

Attanasi, E.D., and Bird, K.J., 1996, Economics and undiscovered conventional oil and gas accumulations in the 1995 national assessment of U.S. oil and gas resources-Alaska: U.S. Geological Survey Open-File Report 95-75-J, 48 p., accessed February 27, 2009, at http://pubs.er.usgs.gov/usgspubs/ofr/ofr9575J.

Attanasi, E.D., and Freeman, P.A., 2005, Economics of undiscovered oil and gas in the central North Slope, Alaska: U.S. Geological Survey Open-File Report 2005-1276, 39 p. (Version 1.1 was released January 13, 2006, and is available at http://pubs.usgs.gov/of/2005/1276/.) (Accessed February 27, 2009.)

Attanasi, E.D., and Freeman, P.A., 2009, Economics of undiscovered oil and gas in the North Slope of Alaska; Economic update and synthesis: U.S. Geological Survey Open-File Report 2009-1112, 59 p., available only at http://pubs.usgs.gov/of/2009/1112/.

Baker, R.A., Gehman, H.M., James, W.R., and White, D.A., 1984, Geologic field number and size assessments of oil and gas plays: American Association of Petroleum Geologists Bulletin, v. 68, no. 4, p. 426-432.

Bird, K.J., and Houseknecht, D.W., 2002, U.S. Geological Survey 2002 petroleum resource assessment of the National Petroleum Reserve in Alaska (NPRA): U.S. Geological Survey Fact Sheet 045-02, 6 p., available at http://pubs.usgs.gov/fs/2002/fs045-02/. (Accessed February 27, 2009.)

Black and Veatch, 2010, Growing shale resources-Understanding implications for North American natural gas prices; Prepared for the State of Alaska, November 2010: 106 p., available at http://www.dog.dnr.alaska.gov/oil/agia/newsroom/Presentations/BV\%20AK\%20LT\%20Prices\%20Re port\%2011232010.pdf.

BP, 2010, Statistical review of world energy, June 2010: London, BP, 50 p., accessed March 28, 2011, at http://www.bp.com/statisticalreview/. 
British Petroleum Exploration (Alaska), 1996, Northstar Development Project - Conceptual engineering report, report submitted for evaluation to the Alaska Department of Natural Resources: Anchorage, Alaska.

ConocoPhillips, 2007, ANS natural gas pipeline-Proposal to the State of Alaska, November 30, 2007 : [Houston,] ConocoPhillips, 115 p. (Available from the Alaska Department of Natural Resources, Anchorage, Alaska.)

Corbett, K.T., Bowen, R.R., and Petersen, C.W., 2003, High strength steel pipeline economics, in v. 4 of Ayer, Raghavan, Langen, Ivar, Knapp, R.H., and Chung, J.S., eds., Proceedings of the Thirteenth International Offshore and Polar Engineering Conference, 25-30th May 2003, Honolulu, Hawaii: Cupertino, Calif., International Society of Offshore and Polar Engineers, p. 105-112.

Craig, J.D., 2002, Economic analysis of the development alternatives for the Liberty prospect, Beaufort Sea, Alaska, app. D-1 in v. IV, Appendices, of Liberty development and production plan; Final environmental impact statement: Minerals Management Service [Report] OCS EIS/EA 2002-019, p. D1-1 to D1-22, available at http://www.mms.gov/alaska/ref/EIS\%20EA/libertyfeis/Documents/Liberty\%20FEIS\%20Vol\%204.pdf. (Accessed April 8, 2009.)

Energy Information Administration, 2011, March 2011 petroleum marketing monthly with data for December 2010: Energy Information Administration Web site at http://www.eia.gov/oil_gas/petroleum/data_publications/petroleum_marketing_monthly/pmm.html. (Accessed March 15, 2011.)

Gao, Haiyu, Zhuoheng, Chen, Osadetz, K.G., Hannigan, Peter, and Watson, Cameron, 2000, A poolbased model of the spatial distribution of undiscovered petroleum resources: Mathematical Geology, v. 32, no. 6, p. 725-749, doi:10.1023/A:1007594423172.

Garrity, C.P., Houseknecht, D.W., and Bird, K.J., 2002, U.S. Geological Survey 2002 petroleum resource assessment of the National Petroleum Reserve in Alaska (NPRA) - GIS play maps: U.S. Geological Survey Open-File Report 02-439, available only at http://pubs.usgs.gov/of/2002/of02439/. (Accessed February 27, 2009.)

Garrity, C.P., Houseknecht, D.W., and Bird, K.J., 2011, 2010 petroleum resource assessment of the National Petroleum Reserve in Alaska (NPRA) - GIS play maps: U.S. Geological Survey Open-File Report 2011-1099, available only at http://pubs.usgs.gov/of/2011/1099/. (Supersedes U.S. Geological Survey Open-File Report 02-439.)

Gingrich, Dean, Knock, Doug, and Masters, Ron, 2001, Geophysical interpretation methods applied at Alpine oil field, North Slope Alaska: The Leading Edge, v. 20, no. 7 (July), p. 730-738.

Grace, J.D., 1997, Resource data provide insights into U.S. exploration risk: Oil and Gas Journal, v. 95, no. 17 (April 28, 1997), p. 84-88.

Houseknecht, D.W., Bird, K.J., Schuenemeyer, J.H., Attanasi, E.D., Garrity, C.P., Schenk, C.J., Charpentier, R.R., Pollastro, R.M., Cook, T.A., and Klett, T.R., 2010, 2010 updated assessment of undiscovered oil and gas resources of the National Petroleum Reserve in Alaska (NPRA): U.S. Geological Survey Fact Sheet 2010-3102, 4 p., available at http://pubs.usgs.gov/fs/2010/3102/. (Accessed March 10, 2011.)

IHS Inc., 2010, QUE\$TOR petroleum field development and production cost database, v. 10.3: Englewood, Colo., IHS Inc.

IHS Inc., 2011a, IHS CERA Upstream Capital Costs Index (through Q3 2010): Cambridge, Mass., IHS Inc., accessed March 25, 2011, at http://www.ihsindexes.com/.

IHS Inc., 2011b, IHS CERA Upstream Operating Costs Index (through Q3 2010): Cambridge, Mass., IHS Inc., accessed March 25, 2011, at http://www.ihsindexes.com/. 
Joshi, S.D., 1991a, Drainage areas and well spacing, in Fritz, R.D., Horn, M.K., and Joshi, S.D., eds., Geological aspects of horizontal drilling: American Association of Petroleum Geologists Continuing Education Course Note Series 33, p. 65-78.

Joshi, S.D., 1991b, Factor influencing productivity, in Fritz, R.D., Horn, M.K., and Joshi, S.D., eds., Geological aspects of horizontal drilling: American Association of Petroleum Geologists Continuing Education Course Note Series 33, p. 80-90.

Kaltenbach, Bob, Walsh, Chantal, Foerster, Cathy, Walsh, Tom, MacDonald, Jan, Stokes, Pete, Livesey, Chris, and Nebesky, Will, 2004, North Slope of Alaska facility sharing study, prepared for Division of Oil and Gas, Alaska Department of Natural Resources, by Petrotechnical Resources of Alaska: 62 p., available at http://www.dog.dnr.state.ak.us/oil/products/publications/otherreports/nsfacility/share.htm. (Accessed February 27, 2009.)

Krauss, Clifford, 2011, U.S. company, in reversal, wants to export natural gas: New York Times, January 27, 2011, accessed March 10, 2011, at http://www.nytimes.com/2011/01/28/business/economy/28gas.html.

Kuuskraa, V.A., Morra, F., Jr., and Godec, M.L., 1987, Importance of cost/price relationships for leastcost oil and gas resources, in Proceedings of 1987 Hydrocarbon Economics and Evaluation Symposium, Dallas, Texas: Richardson, Tex., Society of Petroleum Engineers, SPE Paper 16290, p. 25-42.

National Petroleum Council, 1981a, U.S. Arctic oil and gas: Washington D.C., National Petroleum Council, December 1981, 286 p.

National Petroleum Council, 1981b, Working papers of the Production Task Group of the National Petroleum Council's Committee on Arctic Oil and Gas Resources: Washington, D.C., National Petroleum Council, $372 \mathrm{p}$.

National Petroleum Council, 2003, Balancing natural gas policy_Fueling the demands of a growing economy, v. IV, Supply Task Force Report: Washington, D.C., National Petroleum Council, 456 p.

Nehring Associates, Inc., 2010, Significant oil and gas fields of the United States database [includes data current as of December 31, 2008]: Colorado Springs, Colo., Nehring Associates, Inc.

Nelson, Kristen, 2004, Alternatives to Alpine satellite project proposed: Anchorage, Alaska, Petroleum News, January 28, 2004, p. 1, 12-13.

Redman, R.S., 2002, Horizontal miscible water alternating gas development of the Alpine field, Alaska, in Society of Petroleum Engineers Western Regional/AAPG Pacific Section Joint Meeting, 20-22nd May 2002, Anchorage, Alaska: Richardson, Tex., Society of Petroleum Engineers, SPE Paper 76819, 8 p.

Schuenemeyer, J.H., 2003, Methodology and results for the assessment of oil and gas resources, National Petroleum Reserve, Alaska: U.S. Geological Survey Open-File Report 03-118, 201 p., accessed February 27, 2009, at http://geopubs.wr.usgs.gov/open-file/of03-118/.

Thomas, C.P., Doughty, T.C., Faulder, D.D., Harrison, W.E., Irving, J.S., Jamison, H.C., and White, G.J., 1991, Alaska oil and gas; Energy wealth or vanishing opportunity?: Idaho Falls, Idaho, E.G. and G, Idaho, Inc., DOE/ID/01570-H1, 279 p.

Thomas, C.P., Faulder, D.D., Doughty, T.C., Hite, D.M., and White, G.J., 2007, Alaska North Slope oil and gas-A promising future or an area in decline? (full report): National Energy Technology Laboratory [Report] DOE/NETL-2007/1279, 479 p., available at http://www.netl.doe.gov/technologies/oilgas/publications/EPreports/ANSFullReportFinalAugust2007.pdf. (Accessed April 9, 2009.) 
TransCanada, 2007, Application for license-Alaska Gasline Inducement Act, Public application and appendices: Calgary, Alberta, Canada, TransCanada Pipelines Limited, accessed September 30, 2008, at $h t t p: / / w w w . g o v . s t a t e . a k . u s / a g i a /$.

U.S. Geological Survey, 2011, National oil and gas assessment: U.S. Geological Survey Web site at http://energy.cr.usgs.gov/oilgas/noga/. (Accessed March 15, 2011.)

Vidas, E.H., Hugman, R.H., and Haverkamp, D.S., 1993, Guide to the hydrocarbon supply model1993 update: Arlington, Va., Energy and Environmental Analysis, Inc., prepared for the Gas Research Institute, $272 \mathrm{p}$.

Young, J.H., and Hauser, W.S., 1986, Economics of oil and gas production from the Arctic Refuge (ANWR): Anchorage, Alaska, U.S. Bureau of Land Management, Alaska State Office, $101 \mathrm{p}$. 


\section{Appendix 1. Play Maps and Mean Estimates of Undiscovered Technically Recoverable Volumes of Oil, Gas, and Natural Gas Liquids for Each Play in the NPRA Study Area}

Table A1-1 provides the volumes of undiscovered technically recoverable oil and gas resources associated with the mean estimates for each play in the National Petroleum Reserve in Alaska (NPRA) study area assessed by the U.S. Geological Survey in 2010. Data for text table 1 and table A1-1 in this appendix are from unpublished play simulations from John H. Schuenemeyer (written commun., 2010). The minor differences in the mean estimates from Houseknecht and others (2010) are due to rounding and slightly different simulation realizations. The generation of the simulated plays is described in the text discussion of the "Geologic Assessment Procedures."

Figure A1-1 shows the play boundary maps used in the 2010 assessment. The play maps are from Garrity and others (2011) and are updated from the maps used in the 2002 assessment (Garrity and others, 2002). Of the 24 plays originally assessed in the 2002 NPRA assessment (Bird and Houseknecht, 2002), 9 plays were assessed as having the same volumes, 11 plays had assessment volumes revised, and 4 plays were dropped for insufficient reservoir quality in the 2010 updated NPRA assessment (Houseknecht and others, 2010). 
Table A1-1. Mean estimates by the U.S. Geological Survey in 2010 of undiscovered technically recoverable volumes of conventional oil and gas by play for the National Petroleum Reserve in Alaska study area.

[Asc. gas, associated gas; Nonasc. gas, nonassociated gas; MMBO, millions of barrels of oil; BCF, billions of cubic feet of gas; MMBL, millions of barrels of natural gas liquids (NGL). Because of rounding, some totals may differ slightly from the sum of estimates shown. Data source: John H. Schuenemeyer, written communication of unpublished data, 2010]

\begin{tabular}{|c|c|c|c|c|c|}
\hline \multirow[b]{2}{*}{ Play } & \multicolumn{3}{|c|}{ Oil accumulations } & \multicolumn{2}{|c|}{ Gas accumulations } \\
\hline & $\begin{array}{c}\text { Oil } \\
\text { (MMBO) }\end{array}$ & $\begin{array}{c}\text { Asc. gas } \\
\text { (BCF) }\end{array}$ & $\begin{array}{c}\text { NGL } \\
\text { (MMBL) }\end{array}$ & $\begin{array}{l}\text { Nonasc. gas } \\
\text { (BCF) }\end{array}$ & $\begin{array}{c}\text { NGL } \\
\text { (MMBL) }\end{array}$ \\
\hline Brookian Topset $^{1}$ & 117 & 73 & 0.8 & 386 & 4 \\
\hline Brookian Clinoform North ${ }^{1}$ & 265 & 233 & 3.0 & 1,004 & 9 \\
\hline 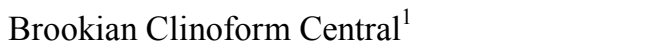 & 129 & 194 & 4.4 & 2,215 & 29 \\
\hline Brookian Clinoform South-Shallow ${ }^{1}$ & 127 & 191 & 4.3 & 2,253 & 29 \\
\hline Brookian Clinoform South-Deep & 0 & 0 & 0.0 & 3,788 & 111 \\
\hline Beaufortian Cretaceous Topset North ${ }^{1}$ & 8 & 6 & 0.1 & 670 & 7 \\
\hline Beaufortian Upper Jurassic Topset Northeast ${ }^{1}$ & 33 & 34 & 0.4 & 2,638 & 25 \\
\hline Beaufortian Upper Jurassic Topset Northwest $^{1}$ & 0 & 0 & 0.0 & 1,047 & 13 \\
\hline Beaufortian Lower Jurassic Topset ${ }^{1}$ & 0 & 0 & 0.0 & 4,552 & 44 \\
\hline Ellesmerian Ivishak ${ }^{1}$ & 21 & 14 & 0.3 & 416 & 5 \\
\hline Ellesmerian Echooka North & 7 & 5 & 0.2 & 7 & 0 \\
\hline Ellesmerian Echooka South & 0 & 0 & 0.0 & 505 & 14 \\
\hline Ellesmerian Lisburne North ${ }^{1}$ & 8 & 6 & 0.1 & 146 & 2 \\
\hline Ellesmerian Lisburne South & 0 & 0 & 0.0 & 646 & 19 \\
\hline Ellesmerian Endicott North & 3 & 2 & 0.0 & 1 & 0 \\
\hline Ellesmerian Endicott South ${ }^{1}$ & 0 & 0 & 0.0 & ${ }^{2} 522$ & 7 \\
\hline Brookian Topset Structural & 137 & 60 & 1.4 & 10,606 & 118 \\
\hline Torok Structural & 35 & 19 & 0.5 & ${ }^{3} 17,907$ & 264 \\
\hline Ellesmerian Structural & 0 & 0 & 0.0 & 1,990 & 78 \\
\hline Thrust Belt & 6 & 4 & 0.1 & 1,521 & 49 \\
\hline Total & ${ }^{4} 895$ & 840 & 15.7 & 52,821 & 826 \\
\hline
\end{tabular}

${ }^{1}$ Play assessment volumes were revised by the U.S. Geological Survey in 2010 from the volumes in the 2002 assessment by the USGS (Bird and Houseknecht, 2002).

${ }^{2}$ Houseknecht and others (2010) show a mean volume of nonassociated gas for the Ellesmerian Endicott South play of 544 $\mathrm{BCF}$; this table has a mean volume of $522 \mathrm{BCF}$, which is probably the result of a different play simulation by J.H.

Schuenemeyer (written commun., 2010). The 4-percent difference is well within statistical variability.

${ }^{3}$ The volumes for the Torok Structural play were not changed in 2010; this table has a mean volume of nonassociated gas of 17,907 BCF, which matches the value in Schuenemeyer, 2003, table 21f; Houseknecht and others (2010) use 17,905 BCF, which matches the value in Schuenemeyer, 2003, table 21e. The insignificant difference is probably due to rounding of data from different simulations.

${ }^{4}$ Houseknecht and others (2010) show a total mean oil volume of 896 million barrels, which is the sum if each play mean is rounded to an integer. The mean estimate of 895 million barrels used in this report represents the sum of the actual unrounded (decimal-valued) play estimates. 

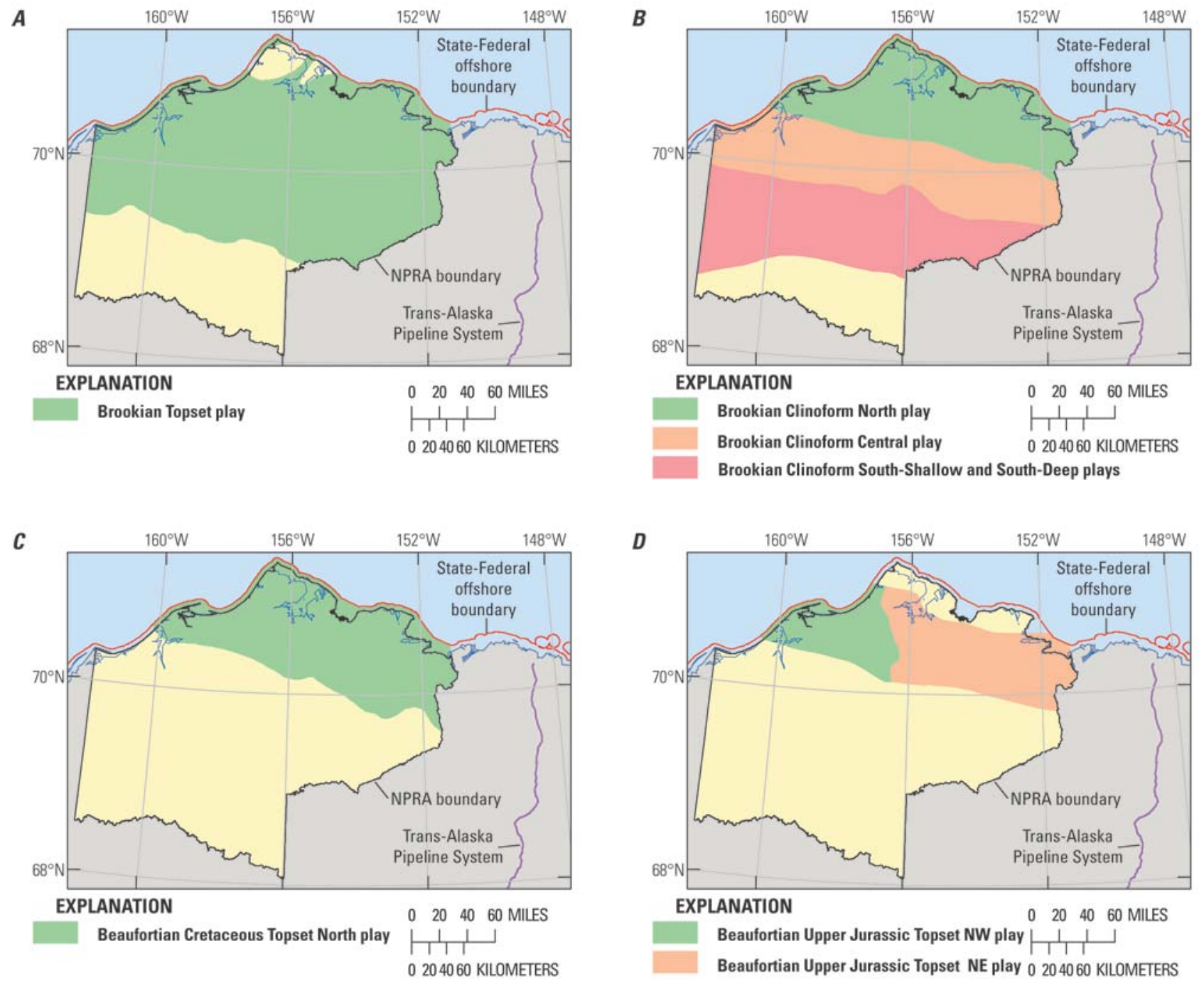

Figure A1-1. Play boundary maps for the 20 plays in the 2010 assessment (Houseknecht and others, 2010) showing the National Petroleum Reserve in Alaska (NPRA, light yellow), the coastline (blue line), and play extents (see explanation below each map.) Data are from Garrity and others (2011). 

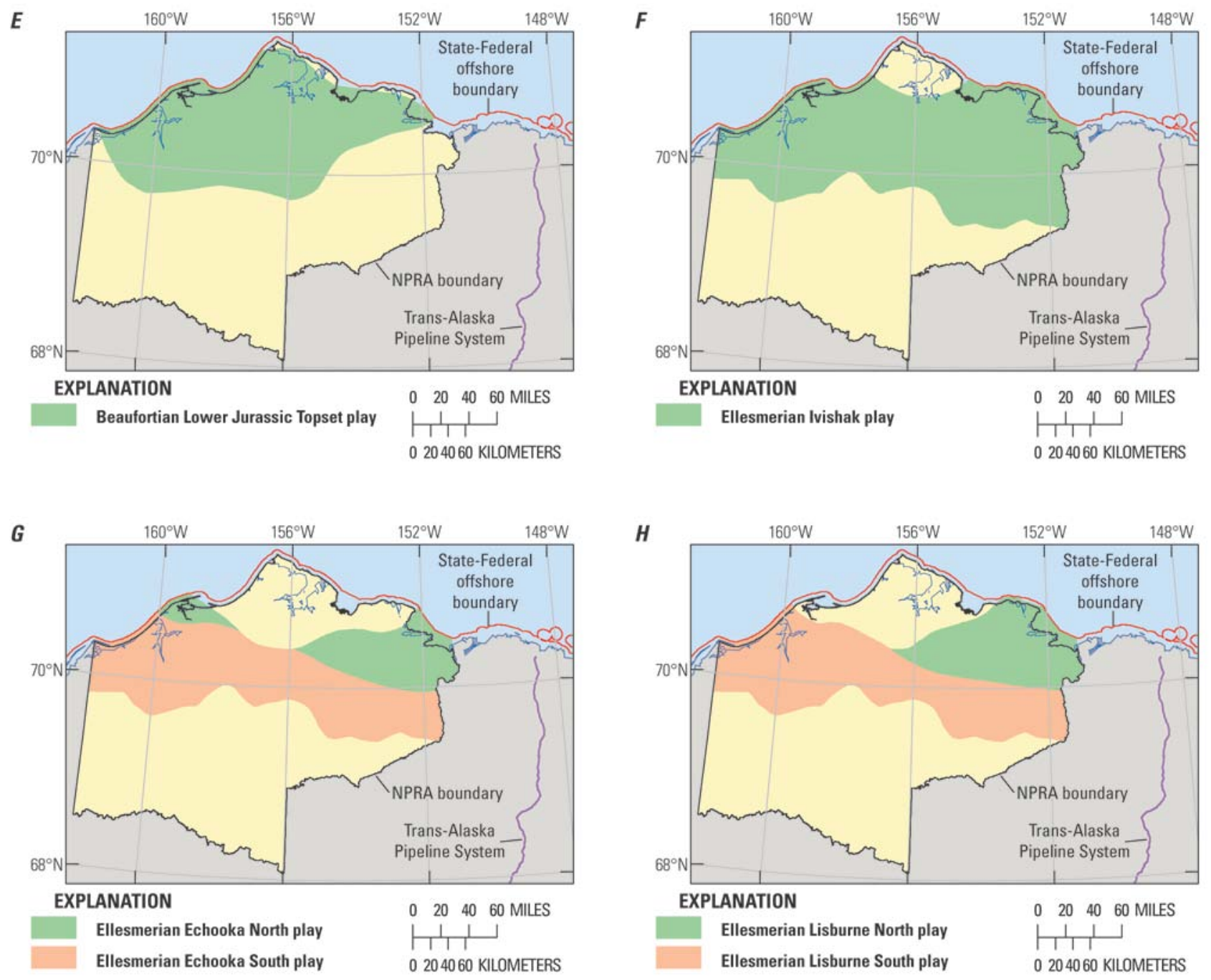

Figure A1-1. Continued 

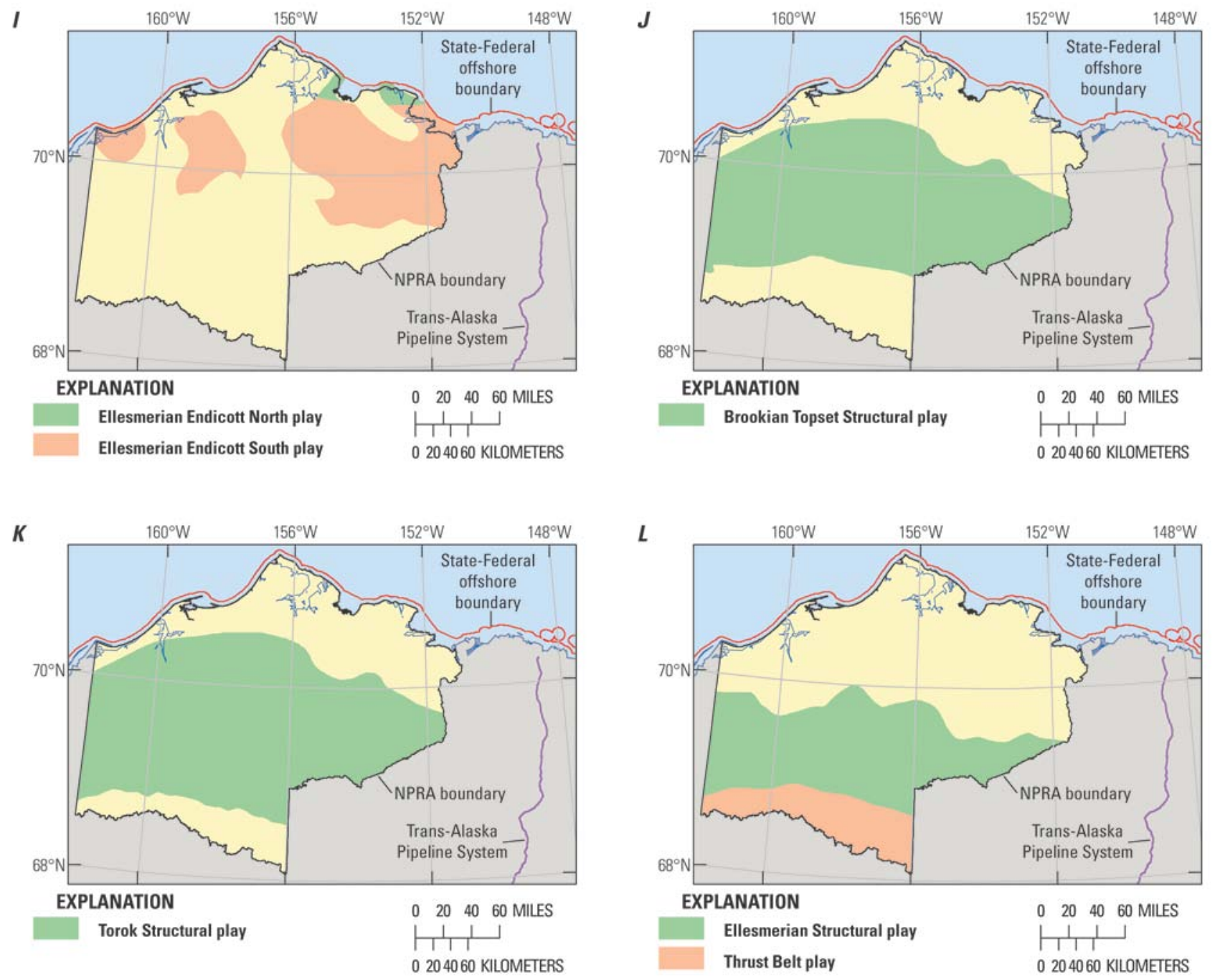

Figure A1-1. Continued 


\section{Appendix 2. Allocation of Play Resources to Economic Zones}

The procedure for the allocation of play resources to economic zones begins with the play boundaries of the National Petroleum Reserve in Alaska (NPRA) study area (Garrity and others, 2002, 2011). The economic zones encompass onshore Federal, State, and Native lands and State waters on the landward side of the State-Federal offshore boundary. Text figure 3 shows the economic zones for the NPRA study area; the zones were the same in the 2002 (Attanasi, 2003) and 2010 assessments by the U.S. Geological Survey. The economic zones are of a sufficient size to be served by a gathering hub. The allocations of total play volumes by primary product (oil and nonassociated gas resources) were expressed as percentages and were made by the assessment geologists. The same percentages were used to allocate resources at the 95th-fractile, the mean, and the 5th-fractile estimates. For an individual play, accumulation size class allocations were the same percentages as the primary product volume allocations. However, inasmuch as each economic zone has a different mix of plays, the size-frequency distribution for undiscovered accumulations is different across zones of the same study subarea.

The NPRA study area was divided into eight economic zones. For the 2010 assessment, geologists considered 20 plays. Table A2-1 shows the percentage of total oil resources and the percentage of nonassociated natural gas resources allocated to each of the eight economic zones. Table A2-2 shows the assessed volumes for each of the estimates by economic zone. Table A2-3 shows numbers of accumulations and volumes by size class that correspond to the assessment mean estimate by economic zone. 
Table A2-1. Percentage allocations to economic zones of undiscovered technically recoverable oil in oil accumulations and gas in gas accumulations for plays of the National Petroleum Reserve in Alaska study area.

[Economic zones are identified in text figure 3]

\begin{tabular}{|c|c|c|c|c|c|c|c|c|}
\hline \multirow{2}{*}{ Play } & \multicolumn{8}{|c|}{ Economic zone } \\
\hline & 110 & 120 & 130 & 210 & 220 & 230 & 320 & 330 \\
\hline \multicolumn{9}{|c|}{ Oil in oil accumulations } \\
\hline Brookian Topset & 27 & 25 & 20 & 15 & 8 & 5 & 0 & 0 \\
\hline Brookian Clinoform North & 43 & 43 & 12 & 2 & 0 & 0 & 0 & 0 \\
\hline Brookian Clinoform Central & 3 & 14 & 8 & 40 & 30 & 5 & 0 & 0 \\
\hline Brookian Clinoform South-Shallow & 0 & 0 & 0 & 20 & 54 & 23 & 1 & 2 \\
\hline Brookian Clinoform South-Deep & 0 & 0 & 0 & 0 & 0 & 0 & 0 & 0 \\
\hline Beaufortian Cretaceous Topset North & 80 & 15 & 5 & 0 & 0 & 0 & 0 & 0 \\
\hline Beaufortian Upper Jurassic Topset Northeast & 100 & 0 & 0 & 0 & 0 & 0 & 0 & 0 \\
\hline Beaufortian Upper Jurassic Topset Northwest & 0 & 0 & 0 & 0 & 0 & 0 & 0 & 0 \\
\hline Beaufortian Lower Jurassic Topset & 0 & 0 & 0 & 0 & 0 & 0 & 0 & 0 \\
\hline Ellesmerian Ivishak & 65 & 30 & 5 & 0 & 0 & 0 & 0 & 0 \\
\hline Ellesmerian Echooka North & 79 & 15 & 6 & 0 & 0 & 0 & 0 & 0 \\
\hline Ellesmerian Echooka South & 0 & 0 & 0 & 0 & 0 & 0 & 0 & 0 \\
\hline Ellesmerian Lisburne North & 80 & 20 & 0 & 0 & 0 & 0 & 0 & 0 \\
\hline Ellesmerian Lisburne South & 0 & 0 & 0 & 0 & 0 & 0 & 0 & 0 \\
\hline Ellesmerian Endicott North & 60 & 40 & 0 & 0 & 0 & 0 & 0 & 0 \\
\hline Ellesmerian Endicott South & 0 & 0 & 0 & 0 & 0 & 0 & 0 & 0 \\
\hline Brookian Topset Structural & 2 & 12 & 17 & 17 & 27 & 23 & 1 & 1 \\
\hline Torok Structural & 1 & 3 & 7 & 14 & 28 & 45 & 1 & 1 \\
\hline Ellesmerian Structural & 0 & 0 & 0 & 0 & 0 & 0 & 0 & 0 \\
\hline Thrust Belt & 0 & 0 & 0 & 0 & 0 & 0 & 25 & 75 \\
\hline \multicolumn{9}{|c|}{ Gas in gas accumulations } \\
\hline Brookian Topset & 0 & 10 & 15 & 25 & 25 & 25 & 0 & 0 \\
\hline Brookian Clinoform North & 18 & 45 & 35 & 2 & 0 & 0 & 0 & 0 \\
\hline Brookian Clinoform Central & 2 & 12 & 16 & 20 & 30 & 20 & 0 & 0 \\
\hline Brookian Clinoform South-Shallow & 0 & 0 & 0 & 7 & 30 & 60 & 1 & 2 \\
\hline Brookian Clinoform South-Deep & 0 & 0 & 0 & 7 & 30 & 60 & 1 & 2 \\
\hline Beaufortian Cretaceous Topset North & 20 & 35 & 40 & 5 & 0 & 0 & 0 & 0 \\
\hline Beaufortian Upper Jurassic Topset Northeast & 65 & 35 & 0 & 0 & 0 & 0 & 0 & 0 \\
\hline Beaufortian Upper Jurassic Topset Northwest & 0 & 20 & 80 & 0 & 0 & 0 & 0 & 0 \\
\hline Beaufortian Lower Jurassic Topset & 10 & 45 & 45 & 0 & 0 & 0 & 0 & 0 \\
\hline Ellesmerian Ivishak & 49 & 29 & 19 & 1 & 1 & 1 & 0 & 0 \\
\hline Ellesmerian Echooka North & 79 & 15 & 6 & 0 & 0 & 0 & 0 & 0 \\
\hline Ellesmerian Echooka South & 0 & 15 & 40 & 25 & 10 & 10 & 0 & 0 \\
\hline Ellesmerian Lisburne North & 65 & 35 & 0 & 0 & 0 & 0 & 0 & 0 \\
\hline Ellesmerian Lisburne South & 0 & 20 & 30 & 25 & 20 & 5 & 0 & 0 \\
\hline Ellesmerian Endicott North & 60 & 40 & 0 & 0 & 0 & 0 & 0 & 0 \\
\hline Ellesmerian Endicott South & 30 & 25 & 15 & 15 & 10 & 5 & 0 & 0 \\
\hline Brookian Topset Structural & 2 & 12 & 17 & 17 & 27 & 23 & 1 & 1 \\
\hline Torok Structural & 1 & 3 & 7 & 12 & 24 & 40 & 4 & 9 \\
\hline Ellesmerian Structural & 0 & 0 & 0 & 12 & 25 & 50 & 4 & 9 \\
\hline Thrust Belt & 0 & 0 & 0 & 0 & 0 & 0 & 25 & 75 \\
\hline
\end{tabular}


Table A2-2. Volume of the aggregated undiscovered technically recoverable oil, gas, and natural gas liquids (NGL) related to the mean, 95th-fractile, and 5th-fractile estimates by the U.S. Geological Survey in 2010 of oil and nonassociated gas, associated gas byproduct volume and concomitant resource volumes, that is nonassociated gas volumes corresponding to the oil fractile estimates and concomitant oil volumes corresponding to the nonassociated gas fractile estimates, respectively, for each economic zone of the National Petroleum Reserve in Alaska (NPRA) study area.

[Economic zones are identified in text figure 3. Because of rounding, some totals may differ slightly from the sum of estimates shown. MMBO, millions of barrels of oil; BCF, billions of cubic feet of gas; MMBL, millions of barrels of liquids]

\begin{tabular}{|c|c|c|c|c|c|}
\hline \multirow[b]{2}{*}{ Economic zone } & \multicolumn{3}{|c|}{ Oil accumulations } & \multicolumn{2}{|c|}{ Gas accumulations } \\
\hline & $\begin{array}{c}\text { Oil } \\
\text { (MMBO) }\end{array}$ & $\begin{array}{c}\text { Associated gas } \\
\text { (BCF) }\end{array}$ & $\begin{array}{c}\text { NGL } \\
\text { (MMBL) }\end{array}$ & $\begin{array}{l}\text { Nonassociated gas } \\
\text { (BCF) }\end{array}$ & $\begin{array}{c}\text { NGL } \\
\text { (MMBL) }\end{array}$ \\
\hline \multicolumn{6}{|c|}{ Mean value estimate } \\
\hline 110 & 219 & 184 & 2.6 & 3,382 & 35 \\
\hline 120 & 190 & 161 & 2.5 & 6,491 & 73 \\
\hline 130 & 93 & 71 & 1.2 & 7,528 & 93 \\
\hline 210 & 128 & 144 & 3.1 & 5,577 & 87 \\
\hline 220 & 164 & 189 & 4.2 & 10,468 & 172 \\
\hline 230 & 89 & 80 & 1.8 & 14,875 & 266 \\
\hline 320 & 4 & 4 & 0.1 & 1,343 & 29 \\
\hline 330 & 9 & 8 & 0.2 & 3,158 & 72 \\
\hline Total & 895 & 840 & 15.7 & 52,821 & 826 \\
\hline \multicolumn{6}{|c|}{ 95th-fractile oil estimate for study area } \\
\hline 110 & 102 & 89 & 1.2 & 2,845 & 29 \\
\hline 120 & 69 & 60 & 0.9 & 4,820 & 55 \\
\hline 130 & 31 & 26 & 0.4 & 5,708 & 73 \\
\hline 210 & 46 & 57 & 1.2 & 4,581 & 75 \\
\hline 220 & 59 & 80 & 1.8 & 8,513 & 146 \\
\hline 230 & 27 & 32 & 0.7 & 12,304 & 231 \\
\hline 320 & 1 & 1 & 0.0 & 1,258 & 29 \\
\hline 330 & 1 & 2 & 0.1 & 3,014 & 75 \\
\hline Total & 336 & 348 & 6.3 & 43,042 & 712 \\
\hline \multicolumn{6}{|c|}{ 5th-fractile oil estimate for study area } \\
\hline 110 & 291 & 244 & 3.4 & 3,310 & 35 \\
\hline 120 & 327 & 250 & 3.9 & 6,738 & 75 \\
\hline 130 & 214 & 128 & 2.3 & 8,164 & 99 \\
\hline 210 & 253 & 218 & 4.7 & 6,878 & 106 \\
\hline 220 & 361 & 314 & 7.2 & 13,113 & 213 \\
\hline 230 & 236 & 154 & 3.6 & 18,757 & 330 \\
\hline 320 & 11 & 7 & 0.2 & 1,530 & 32 \\
\hline 330 & 15 & 11 & 0.3 & 3,496 & 77 \\
\hline Total & 1,707 & 1,327 & 25.4 & 61,985 & 966 \\
\hline
\end{tabular}


Table A2-2. Volume of the aggregated undiscovered technically recoverable oil, gas, and natural gas liquids (NGL) related to the mean, 95th-fractile, and 5th-fractile estimates by the U.S. Geological Survey in 2010 of oil and nonassociated gas, associated gas byproduct volume and concomitant resource volumes, that is nonassociated gas volumes corresponding to the oil fractile estimates and concomitant oil volumes corresponding to the nonassociated gas fractile estimates, respectively, for each economic zone of the National Petroleum Reserve in Alaska (NPRA) study area._-Continued

[Economic zones are identified in text figure 3. Because of rounding, some totals may differ slightly from the sum of estimates shown. MMBO, millions of barrels of oil; BCF, billions of cubic feet of gas; MMBL, millions of barrels of liquids]

\begin{tabular}{|c|c|c|c|c|c|}
\hline \multirow[b]{2}{*}{ Economic zone } & \multicolumn{3}{|c|}{ Oil accumulations } & \multicolumn{2}{|c|}{ Gas accumulations } \\
\hline & $\begin{array}{c}\text { Oil } \\
\text { (MMBO) }\end{array}$ & $\begin{array}{l}\text { Associated gas } \\
\text { (BCF) }\end{array}$ & $\begin{array}{c}\text { NGL } \\
\text { (MMBL) }\end{array}$ & $\begin{array}{l}\text { Nonassociated gas } \\
\text { (BCF) }\end{array}$ & $\begin{array}{c}\text { NGL } \\
\text { (MMBL) }\end{array}$ \\
\hline \multicolumn{6}{|c|}{ 95th-fractile gas estimate for study area } \\
\hline 110 & 184 & 152 & 2.5 & 2,652 & 27 \\
\hline 120 & 133 & 114 & 1.8 & 4,220 & 48 \\
\hline 130 & 59 & 46 & 0.8 & 4,639 & 57 \\
\hline 210 & 86 & 103 & 2.2 & 3,142 & 47 \\
\hline 220 & 113 & 142 & 3.1 & 5,775 & 92 \\
\hline 230 & 51 & 54 & 1.2 & 7,773 & 137 \\
\hline 320 & 4 & 4 & 0.1 & 800 & 19 \\
\hline 330 & 10 & 10 & 0.3 & 1,982 & 51 \\
\hline Total & 640 & 625 & 12.0 & 30,984 & 478 \\
\hline \multicolumn{6}{|c|}{ 5th-fractile gas estimate for study area } \\
\hline 110 & 234 & 196 & 2.9 & 4,380 & 46 \\
\hline 120 & 209 & 173 & 2.7 & 9,015 & 101 \\
\hline 130 & 108 & 75 & 1.3 & 10,667 & 130 \\
\hline 210 & 141 & 143 & 3.0 & 8,277 & 127 \\
\hline 220 & 182 & 188 & 4.2 & 15,757 & 254 \\
\hline 230 & 114 & 85 & 2.0 & 22,876 & 395 \\
\hline 320 & 4 & 3 & 0.1 & 1,986 & 39 \\
\hline 330 & 5 & 5 & 0.1 & 4,555 & 93 \\
\hline Total & 995 & 868 & 16.1 & 77,513 & 1,186 \\
\hline
\end{tabular}


Table A2-3. Distribution of mean estimates of undiscovered technically recoverable oil in oil accumulations and nonassociated gas in gas accumulations by size class for each economic zone in the National Petroleum Reserve in Alaska study area.

[Economic zones are identified in text figure 3. MMBO, millions of barrels of oil; BCF, billions of cubic feet of gas. The number of accumulations may round down to 0.00 , yet have a small volume of oil or gas; entries of " 0 " indicate zero amount]

\begin{tabular}{|c|c|c|c|c|c|}
\hline \multicolumn{3}{|c|}{ Oil } & \multicolumn{3}{|c|}{ Nonassociated gas } \\
\hline $\begin{array}{l}\text { Size class } \\
\text { (MMBO) }\end{array}$ & $\begin{array}{c}\text { Number of } \\
\text { accumulations }\end{array}$ & $\begin{array}{c}\text { Oil in } \\
\text { class } \\
\text { (MMBO) }\end{array}$ & $\begin{array}{l}\text { Size class } \\
\text { (BCF) }\end{array}$ & $\begin{array}{c}\text { Number of } \\
\text { accumulations }\end{array}$ & $\begin{array}{l}\text { Gas in } \\
\text { class } \\
\text { (BCF) } \\
\end{array}$ \\
\hline \multicolumn{6}{|c|}{ Zone 110} \\
\hline $4,096-8,192$ & 0 & 0 & $24,576-49,152$ & 0 & 0 \\
\hline $2,048-4,096$ & 0.00 & 0.04 & $12,288-24,576$ & 0.00 & 4 \\
\hline $1,024-2,048$ & 0.00 & 0.3 & $6,144-12,288$ & 0.00 & 30 \\
\hline $512-1,024$ & 0.00 & 1.0 & $3,072-6,144$ & 0.03 & 110 \\
\hline $256-512$ & 0.01 & 4.4 & $1,536-3,072$ & 0.12 & 238 \\
\hline $128-256$ & 0.14 & 23.7 & $768-1,536$ & 0.38 & 396 \\
\hline $64-128$ & 0.62 & 54.1 & $384-768$ & 2.06 & 1,015 \\
\hline $32-64$ & 1.50 & 66.3 & $250-384$ & 5.26 & 1,590 \\
\hline $16-32$ & 2.98 & 68.9 & & & \\
\hline \multicolumn{6}{|c|}{ Zone 120} \\
\hline $4,096-8,192$ & 0 & 0 & $24,576-49,152$ & 0 & 0 \\
\hline $2,048-4,096$ & 0.00 & 0.2 & $12,288-24,576$ & 0.00 & 11 \\
\hline $1,024-2,048$ & 0.00 & 2.1 & $6,144-12,288$ & 0.01 & 86 \\
\hline $512-1,024$ & 0.01 & 4.1 & $3,072-6,144$ & 0.08 & 305 \\
\hline $256-512$ & 0.02 & 7.0 & $1,536-3,072$ & 0.41 & 824 \\
\hline $128-256$ & 0.16 & 25.6 & $768-1,536$ & 1.43 & 1,493 \\
\hline $64-128$ & 0.64 & 55.9 & $384-768$ & 3.83 & 1,997 \\
\hline $32-64$ & 1.35 & 60.3 & $250-384$ & 5.83 & 1,775 \\
\hline $16-32$ & 1.43 & 34.5 & & & \\
\hline \multicolumn{6}{|c|}{ Zone 130} \\
\hline $4,096-8,192$ & 0 & 0 & $24,576-49,152$ & 0 & 0 \\
\hline $2,048-4,096$ & 0.00 & 0.3 & $12,288-24,576$ & 0.00 & 26 \\
\hline $1,024-2,048$ & 0.00 & 3.0 & $6,144-12,288$ & 0.02 & 182 \\
\hline $512-1,024$ & 0.01 & 5.9 & $3,072-6,144$ & 0.13 & 521 \\
\hline $256-512$ & 0.02 & 7.8 & $1,536-3,072$ & 0.54 & 1,116 \\
\hline $128-256$ & 0.07 & 12.3 & $768-1,536$ & 1.71 & 1,800 \\
\hline $64-128$ & 0.24 & 20.6 & $384-768$ & 4.13 & 2,172 \\
\hline $32-64$ & 0.57 & 25.3 & $250-384$ & 5.61 & 1,711 \\
\hline $16-32$ & 0.75 & 17.9 & & & \\
\hline
\end{tabular}


Table A2-3. Distribution of mean estimates of undiscovered technically recoverable oil in oil accumulations and nonassociated gas in gas accumulations by size class for each economic zone in the National Petroleum Reserve in Alaska study area. - Continued

[Economic zones are identified in text figure 3. MMBO, millions of barrels of oil; BCF, billions of cubic feet of gas. The number of accumulations may round down to 0.00 , yet have a small volume of oil or gas; entries of " 0 " indicate zero amount]

\begin{tabular}{|c|c|c|c|c|c|}
\hline \multicolumn{3}{|c|}{ Oil } & \multicolumn{3}{|c|}{ Nonassociated gas } \\
\hline $\begin{array}{l}\text { Size class } \\
\text { (MMBO) }\end{array}$ & $\begin{array}{c}\text { Number of } \\
\text { accumulations }\end{array}$ & $\begin{array}{c}\text { Oil in } \\
\text { class } \\
\text { (MMBO) }\end{array}$ & $\begin{array}{l}\text { Size class } \\
\text { (BCF) }\end{array}$ & $\begin{array}{c}\text { Number of } \\
\text { accumulations }\end{array}$ & $\begin{array}{l}\text { Gas in } \\
\text { class } \\
\text { (BCF) } \\
\end{array}$ \\
\hline \multicolumn{6}{|c|}{ Zone 210} \\
\hline $4,096-8,192$ & 0 & 0 & $24,576-49,152$ & 0 & 0 \\
\hline $2,048-4,096$ & 0.00 & 0.3 & $12,288-24,576$ & 0.00 & 44 \\
\hline $1,024-2,048$ & 0.00 & 3.0 & $6,144-12,288$ & 0.04 & 298 \\
\hline $512-1,024$ & 0.01 & 6.3 & $3,072-6,144$ & 0.18 & 744 \\
\hline $256-512$ & 0.03 & 10.3 & $1,536-3,072$ & 0.57 & 1,182 \\
\hline $128-256$ & 0.13 & 22.6 & $768-1,536$ & 1.35 & 1,441 \\
\hline $64-128$ & 0.40 & 35.2 & $384-768$ & 2.27 & 1,231 \\
\hline $32-64$ & 0.73 & 33.0 & $250-384$ & 2.07 & 637 \\
\hline $16-32$ & 0.72 & 17.4 & & & \\
\hline \multicolumn{6}{|c|}{ Zone 220} \\
\hline $4,096-8,192$ & 0 & 0 & $24,576-49,152$ & 0 & 0 \\
\hline $2,048-4,096$ & 0.00 & 0.5 & $12,288-24,576$ & 0.01 & 87 \\
\hline $1,024-2,048$ & 0.00 & 4.7 & $6,144-12,288$ & 0.07 & 587 \\
\hline $512-1,024$ & 0.02 & 10.3 & $3,072-6,144$ & 0.34 & 1,413 \\
\hline $256-512$ & 0.05 & 16.4 & $1,536-3,072$ & 1.08 & 2,254 \\
\hline $128-256$ & 0.19 & 32.2 & $768-1,536$ & 2.66 & 2,828 \\
\hline $64-128$ & 0.52 & 46.2 & $384-768$ & 4.26 & 2,324 \\
\hline $32-64$ & 0.82 & 37.5 & $250-384$ & 3.14 & 975 \\
\hline $16-32$ & 0.64 & 15.7 & & & \\
\hline \multicolumn{6}{|c|}{ Zone 230} \\
\hline $4,096-8,192$ & 0 & 0 & $24,576-49,152$ & 0 & 0 \\
\hline $2,048-4,096$ & 0.00 & 0.4 & $12,288-24,576$ & 0.01 & 145 \\
\hline $1,024-2,048$ & 0.00 & 4.1 & $6,144-12,288$ & 0.12 & 958 \\
\hline $512-1,024$ & 0.02 & 10.0 & $3,072-6,144$ & 0.53 & 2,165 \\
\hline $256-512$ & 0.04 & 14.3 & $1,536-3,072$ & 1.55 & 3,250 \\
\hline $128-256$ & 0.10 & 18.0 & $768-1,536$ & 3.71 & 3,956 \\
\hline $64-128$ & 0.22 & 19.6 & $384-768$ & 5.78 & 3,160 \\
\hline $32-64$ & 0.34 & 15.3 & $250-384$ & 3.98 & 1,240 \\
\hline $16-32$ & 0.29 & 7.1 & & & \\
\hline
\end{tabular}


Table A2-3. Distribution of mean estimates of undiscovered technically recoverable oil in oil accumulations and nonassociated gas in gas accumulations by size class for each economic zone in the National Petroleum Reserve in Alaska study area. - Continued

[Economic zones are identified in text figure 3. MMBO, millions of barrels of oil; BCF, billions of cubic feet of gas. The number of accumulations may round down to 0.00 , yet have a small volume of oil or gas; entries of " 0 " indicate zero amount]

\begin{tabular}{|c|c|c|c|c|c|}
\hline \multicolumn{3}{|c|}{ Oil } & \multicolumn{3}{|c|}{ Nonassociated gas } \\
\hline $\begin{array}{l}\text { Size class } \\
\text { (MMBO) }\end{array}$ & $\begin{array}{c}\text { Number of } \\
\text { accumulations }\end{array}$ & $\begin{array}{c}\text { Oil in } \\
\text { class } \\
\text { (MMBO) }\end{array}$ & $\begin{array}{l}\text { Size class } \\
\text { (BCF) }\end{array}$ & $\begin{array}{c}\text { Number of } \\
\text { accumulations }\end{array}$ & $\begin{array}{l}\text { Gas in } \\
\text { class } \\
\text { (BCF) }\end{array}$ \\
\hline \multicolumn{6}{|c|}{ Zone 320} \\
\hline $4,096-8,192$ & 0 & 0 & $24,576-49,152$ & 0 & 0 \\
\hline $2,048-4,096$ & 0.00 & 0.02 & $12,288-24,576$ & 0.00 & 14 \\
\hline $1,024-2,048$ & 0.00 & 0.2 & $6,144-12,288$ & 0.01 & 95 \\
\hline $512-1,024$ & 0.00 & 0.4 & $3,072-6,144$ & 0.05 & 209 \\
\hline $256-512$ & 0.00 & 0.5 & $1,536-3,072$ & 0.13 & 267 \\
\hline $128-256$ & 0.01 & 0.9 & $768-1,536$ & 0.30 & 318 \\
\hline $64-128$ & 0.01 & 1.2 & $384-768$ & 0.55 & 293 \\
\hline $32-64$ & 0.02 & 0.9 & $250-384$ & 0.47 & 147 \\
\hline $16-32$ & 0.02 & 0.4 & & & \\
\hline \multicolumn{6}{|c|}{ Zone 330} \\
\hline $4,096-8,192$ & 0 & 0 & $24,576-49,152$ & 0 & 0 \\
\hline $2,048-4,096$ & 0.00 & 0.02 & $12,288-24,576$ & 0.00 & 32 \\
\hline $1,024-2,048$ & 0.00 & 0.2 & $6,144-12,288$ & 0.03 & 212 \\
\hline $512-1,024$ & 0.00 & 0.4 & $3,072-6,144$ & 0.11 & 465 \\
\hline $256-512$ & 0.00 & 0.6 & $1,536-3,072$ & 0.28 & 591 \\
\hline $128-256$ & 0.01 & 1.7 & $768-1,536$ & 0.70 & 745 \\
\hline $64-128$ & 0.03 & 2.7 & $384-768$ & 1.38 & 730 \\
\hline $32-64$ & 0.04 & 2.0 & $250-384$ & 1.24 & 382 \\
\hline $16-32$ & 0.04 & 0.9 & & & \\
\hline
\end{tabular}




\section{Appendix 3. Documentation of Cost Estimates}

\section{Transportation Costs}

\section{Costs from North Slope to Market}

The text discussion explains the rationale for the assumptions relating to the dominant cost transportation component, that is, the cost component from North Slope collection points, either Pump Station 1 or the proposed gas conditioning plant, to the respective market. To review, the assumed Trans-Alaska Pipeline System (TAPS) tariff is \$5.18 per barrel from Pump Station 1 to Valdez. In addition to this cost, there is a cost of $\$ 2.20$ per barrel to transport oil from Valdez to the market. There is an estimated cost of $\$ 4.42$ per MCF for natural gas conditioning and pipeline shipment to the U.S. Midwest market.

The assessment results implied that oil discovery sizes will be very small and that gas discovery sizes will be only modest by Arctic standards (less than $3 \mathrm{TCF}$ ). At the mean estimate, the technically recoverable resources are expected to be contained in 16 oil accumulations and 70 nonassociated gas accumulations (text table 2). The economic zones provide a basis for transportation cost sharing of overland pipelines from the economic zone to TAPS or the proposed gas conditioning plant. Table A21 lists the play allocations of oil and nonassociated gas accumulations to the NPRA study area economic zones. Individual discoveries are required to bear the full cost of construction and operation of the feeder pipeline from the field to a zone hub, which connects to a regional pipeline. These pipeline costs are recovered by a tariff charged by the feeder pipeline owner. Both feeder and regional pipelines are operated as common carriers.

\section{Feeder and Regional Pipeline Assumptions}

A hypothetical transportation system moves oil and gas to the locations of TAPS and a proposed natural gas conditioning plant. This system consists of feeder lines from the fields to an economic zone hub and a regional pipeline. For each discovery size class, the peak or plateau annual production volume was computed for the representative oil and gas discovery. The required diameter for the feeder lines from individual discoveries to the regional pipeline was calculated to accommodate the peak or plateau flow rates. The investment costs of the individual feeder lines depend on the pipeline's diameter and length, that is, the average distance from the field to a regional pipeline. The tariff, ${ }^{25}$ or charge, for transporting the oil from the outlying discovery to a regional pipeline hub was computed as if the feeder pipeline were operated as a regulated common carrier and permitted a 12-percent after-tax rate of return on investment cost. The calculated tariff includes the after-tax rate of return, operating costs, taxes, and recovery of the initial investment during the nominal life of the field.

The size of the crude oil or gas product pipeline from the field to the regional pipeline was calculated such that its capacity (regulated by its diameter) would be sufficient to move the discovery's peak annual plateau production to the regional line. The oil and conventional gas pipeline cost data were generated with the QUE\$TOR software (IHS Inc., 2010). The investment costs were estimated and expressed in dollars per inch-diameter per mile. The costs include the installed pipe, the right-of-way, and the initial pump system. The base cost is $\$ 175,000$ per inch-diameter per mile for crude oil and $\$ 188,000$ per inch-diameter per mile for a conventional gas line.

\footnotetext{
${ }^{25}$ The term "tariff," as used in this report, is the charge by a publicly regulated entity, in this case a regulated common carrier.
} 
Base costs were scaled up to include all pipelines and utilities bundled together and installed in the overland pipeline corridor. To estimate costs of these additions for all feeder lines and in some cases for the regional oil pipelines, diameters were increased to account for the additional bundling of utility lines and water lines (for waterflood of oil discoveries) ${ }^{26}$ to the operating field. These lines may use the same vertical support members and right-of-way as the pipeline transporting produced oil and gas to the regional pipeline. To account for this extra cost, the initial investment cost per inch-diameter per mile was increased by 100 percent for oil accumulations requiring import of injection water and 25 percent per inch-diameter per mile for gas discoveries.

Booster pump or compression stations were added to the oil and natural gas pipelines at intervals of 120 miles from the source. Data from studies prepared with the QUE\$TOR software (IHS Inc., 2010) indicated that the booster pump station investment cost was equivalent to about 15 percent of the investment costs required for each 100 miles of pipeline length.

The sizing (diameter) for the regional oil and gas pipelines was based on the total assessed resources allocated to each economic zone. The regional pipeline sizing rule was conservative to allow for differences in the timing of discoveries, development rates, and production rates of different fields in the zone. Typically, the maximum regional pipeline capacity chosen for this study allows only 3 percent of the total assessed resource in the economic unit to be transported in a single year. If greater volumes of oil and gas resources are found and developed, then higher volume regional lines could be installed, and this installation would probably result in a slightly reduced regional pipeline tariff.

Regional gas pipelines from the economic zones are directed to a hypothetical hub at Inigok (text fig. 3); from there, a 3-BCF-per-day high-pressure line would take gas to the future gas conditioning plant near Pump Station 1. It is assumed that this pipeline is a high-pressure pipeline that could transport both gas and natural gas liquids in a dense phase (Corbett and others, 2003). The gas feeder lines from the fields to the economic zone hub were assumed to be low-pressure lines, as these will be much shorter than the regional lines and require less capacity. The regional pipelines from the hubs in zones $110,120,130$, and 210 to Inigok were also assumed to be conventional. The procedures for computing the tariffs for the regional gas pipelines and the feeder lines from the outlying fields were similar to the procedures used to calculate tariffs for the crude oil pipeline.

Annual operating costs for both oil and gas pipelines were estimated to be 2 percent of the initial pipeline investment including any additional booster pumping stations. Tariffs were estimated to recover operating costs, property taxes, State and Federal income taxes, original investment, and an after-tax rate of return of 12 percent.

Table A3-1 shows the feeder and regional pipeline specifications assumed for each of the economic zones (see also fig. 3 in the text). The volume of oil assessed in the southernmost economic zones labeled 320 and 330 is so small that a regional oil pipeline was not considered.

\footnotetext{
${ }^{26}$ In oil accumulations, a waterflood is used in pressure maintenance and to displace residual oil from the reservoir rock to the production well. In the North Slope, seawater has been used for this purpose. Nearly all of the assessed undiscovered oil accumulations were in plays located in the northern part of the NPRA, reasonably close to the coast.
} 
Table A3-1. Distances and regional pipeline capacity by economic zone of a hypothetical pipeline system for the National Petroleum Reserve in Alaska study area.

[Economic zones are identified in text figure 3. MBO/D, thousands of barrels of oil per day; MMCF/D, millions of cubic feet of gas per day]

\begin{tabular}{llccc}
\hline $\begin{array}{c}\text { Economic } \\
\text { zone }\end{array}$ & Commodity & $\begin{array}{c}\text { Length of feeder pipeline } \\
\text { (miles) }\end{array}$ & $\begin{array}{c}\text { Length of regional pipeline }{ }^{1} \\
\text { (miles) }\end{array}$ & $\begin{array}{c}\text { Regional pipeline capacity } \\
\text { (MBO/D or MMCF/D) }\end{array}$ \\
\hline 110 & Oil & 10 & 94 & 21 \\
& Gas & 10 & 20 & 320 \\
120 & Oil & 15 & 169 & 18 \\
& Gas & 15 & 70 & 610 \\
130 & Oil & 12 & 244 & 9 \\
& Gas & 12 & 137 & 710 \\
210 & Oil & 10 & 115 & 13 \\
& Gas & 10 & 20 & 530 \\
220 & Oil & 15 & 180 & 16 \\
& Gas & 15 & 70 & 990 \\
320 & Oil & 17.5 & 275 & 9 \\
& Gas & 70 & 180 & 1,400 \\
& Oil & 200 & $\left({ }^{2}\right)$ & $\left(^{2}\right)$ \\
& Gas & 10 & 120 & 130 \\
& Oil & 300 & $\left({ }^{2}\right)$ & $\left({ }^{2}\right)$ \\
& Gas & 15 & 180 & 300 \\
\hline
\end{tabular}

\footnotetext{
${ }^{1}$ Gas flows to Inigok; from there, a hypothetical, 110-mile, high-pressure trunk line transports gas with entrained natural gas liquids to a gas conditioning facility before entry into an export gas pipeline to the conterminous 48 States.

${ }^{2}$ Because of small oil volumes in economic zones 320 and 330, only feeder lines were hypothesized for transportation to a transshipment point at Pump Station 1 of the Trans-Alaska Pipeline System.
}

\section{Field Development Costs}

Field development costs include well drilling and completion costs and the cost of facilities. The development cost estimates are generalized because actual field development costs will depend on sitespecific characteristics of prospects that are undefined today. In the process of developing generic cost functions, a number of simplifying assumptions were made to keep the economic analysis manageable. The simulated accumulations were first grouped into field size categories and into 5,000-foot subsurface depth intervals. The analysis also included the costs of vertical delineation wells for each accumulation evaluated. Development costs were estimated for a representative accumulation for each size and depth class and tested against an economic screen to determine whether the accumulations in the size and depth category were commercially developable.

With the exception of economic zone 110, distances were computed from a coastal staging area to the centroid of each economic zone. For economic zone 110, the distance was measured from the central North Slope infrastructure. The distances were used to calculate the additional costs that result from moving equipment to the project site. The options chosen from the QUE\$TOR software represented the highest level of remoteness available. This included basic infrastructure cost, an airstrip, and any temporary structures during construction and drilling operations. The following rule was applied to capture the additional costs of getting equipment to the site: costs above the QUE\$TOR estimates were increased 4 percent for each 50 miles from the staging area. In the absence of data from actual gas investment and operations on the North Slope, the QUE\$TOR cost estimates were taken. 


\section{Oil Field Design}

Oil accumulation size (SzO) was computed from the simulated reservoir attributes and reported in millions of barrels of oil (MMBO):

$$
s z o=7.758(t)(h p s)(f)\left(r f_{o}\right)(a c) /\left(f v f_{o}\right),
$$

where $h p s=p\left(1-S_{W}\right)$ and where for each field simulated, the reservoir attribute values are (1) net reservoir thickness, $t$, in feet, (2) porosity, $p$, as a decimal fraction, (3) hydrocarbon pore space, $h p s$, as a function of $p$ and $S_{W}$, where $S_{W}$ is water saturation as a decimal fraction, (4) trapfill, $f$, as decimal fraction, (5) oil recovery factor, $r f_{o}$, as a decimal fraction, (6) area of closure $(a c)$ in thousands of acres, and (7) the oil formation volume factor, $f v f_{o}$. The assessors provided estimates of the recovery factor (fraction of the in-place resource that is recoverable with the assumed technology), which is denoted $r f_{o}$. The oil formation volume factor, $f v f_{o}$, was calculated as a function of reservoir depth (Schuenemeyer, 2003). For each size and depth category, an average accumulation size was computed and used as the representative field size.

Vertical wells were assumed to have drainage areas of 160 acres (Young and Hauser, 1986). Development well productivity for oil (wpo) per producing well for a given individual accumulation was calculated by the following equation:

$$
w p o=7.758(t)(h p s)(f)\left(r f_{o}\right)(0.16) /\left(f v f_{o}\right),
$$

where the reservoir attributes are the same as those defined for szo above. A volume-weighted average well recovery for each accumulation size class was calculated by using the play simulation data. Within a given play, the average well productivity tends to increase as accumulation size increases. The average well productivity for each size category across plays in the study area is shown in table A3-2. The required number of production wells for the representative accumulation was calculated by dividing the recoverable accumulation volume of oil by the estimated well productivity. For conventional wells, each set of 10 producing wells required 4 injection wells (National Petroleum Council, 1981a; Young and Hauser, 1986).

Table A3-2. Estimated recovery per production well, in millions of barrels of oil (MMBO), for oil accumulations in any economic zone of the National Petroleum Reserve in Alaska study area.

\begin{tabular}{lc}
\hline $\begin{array}{c}\text { Discovery size class } \\
\text { (MMBO) }\end{array}$ & $\begin{array}{c}\text { Recovery per well } \\
\text { (MMBO) }\end{array}$ \\
\hline $16-32$ & 0.9 \\
$32-64$ & 1.2 \\
$64-128$ & 1.7 \\
$128-256$ & 2.4 \\
$256-512$ & 3.1 \\
$512-1,024$ & 5.0 \\
$1,024-2,048$ & 7.3 \\
$2,048-4,096$ & 7.3 \\
\hline
\end{tabular}

Application of horizontal well technology is attractive because it can reduce the number of production wells required to drain a pool and reduce the number of drilling pads and their sizes. It also tends to increase the proportion of the in-place oil that is recoverable and to increase the flow rates from individual wells. The drainage area and, thus, well productivity assigned to a horizontal production well depend on the natural drainage area of vertical wells and the length of the horizontal section of the well 
bore that is in contact with the formation. If a vertical well has a circular drainage area of 160 acres, then a horizontal well having a horizontal section of 3,000 feet would theoretically increase the drainage area to 365 acres (Joshi, 1991a,b). ${ }^{27}$ Each producing horizontal oil well is assumed to require a horizontal injection well. This is the case in the Alpine field (Redman, 2002) near the NPRA. This reconnaissance analysis cannot capture all the trade-offs in applying horizontal technologies, such as an increase in recoverable in-place oil and a reduction in pad costs, and so the cost estimates presented here may be higher than costs based on an analysis using site data. According to the assessment geologists, the low permeability in the oil-prone plays in economic zones 110 and 120 will require well stimulation as part of the completion process. The extra cost of well stimulation, approximately $\$ 1$ million per production well, is added to the oil production well costs for discoveries in those zones.

\section{Gas Field Design}

Gas accumulation size ( $\mathrm{szg}$ ) was computed with the simulated reservoir attributes and reported in billions of cubic feet $(\mathrm{BCF})$ :

$$
s z g=4.356(t)(h p s)(f)\left(r f_{g}\right)(a c)\left(f v f_{g}\right) \times 10^{-8},
$$

where $h p s=p\left(1-S_{W}\right)$ and where for each field simulated, the reservoir attribute values are (1) net reservoir thickness, $t$, in feet, (2) porosity, $p$, as a decimal fraction, (3) hydrocarbon pore space, $h p s$, as a function of $p$ and $S_{W}$, where $S_{W}$ is water saturation as a decimal fraction, (4) trapfill, $f$, as a decimal fraction, (5) gas recovery factor, $r f_{g}$, as a decimal fraction, (6) area of closure (ac) in thousands of acres, and (7) the gas formation volume factor, $f v f_{g}$. The assessors provided estimates of the recovery factor (fraction of the in-place resource that is recoverable with the assumed technology), which is denoted $r f_{g}$. The gas formation volume factor, $f v f_{g}$, was calculated as a function of reservoir depth. For each size and depth category, the size of the representative discovery was the average of the discoveries in that category.

A 1981 National Petroleum Council study (1981a,b) on Arctic oil and gas development based its representative field designs on the assumption that the typical gas well drainage area would be 1 square mile (640 acres). Development well productivity for gas (wpg), in billions of cubic feet per producing well, for an individual accumulation was calculated by the following equation:

$$
w p g=4.356(t)(h p s)(f)\left(r f_{g}\right)(0.640)\left(f v f_{g}\right) \times 10^{-8}
$$

where the reservoir attributes are that same as those defined for szg as above. A volume-weighted average for well recovery was computed for each accumulation size class by using the play simulation data. Production well productivity by size class for the study area is shown in table A3-3.

Nonassociated gas has not been produced for export on the North Slope, and so there are few reliable data to predict the gas well performance. The required number of production wells for the representative accumulation was calculated by dividing the recoverable accumulation volume of gas by the estimated gas well productivity. Gas accumulations do not require water injection wells. Horizontal drilling was not applied to gas field development.

\footnotetext{
${ }^{27}$ If a vertical well drains 160 acres, its expected drainage radius is 1,489 feet. The horizontal extension of the well of 3,000 feet adds 205 acres, $(3,000 \mathrm{ft} \times 2 \times 1,489 \mathrm{ft}) /\left(43,250 \mathrm{ft}^{2} /\right.$ acre $)$, to the original 160-acre drainage area. This method of computing the drainage area follows Joshi (1991a). It is based on the assumption that the vertical permeability is at least equal to the horizontal permeability.
} 
Table A3-3. Estimated recovery per production well, in billions of cubic feet of gas (BCF), for gas accumulations in any economic zone of the National Petroleum Reserve in Alaska study area.

\begin{tabular}{lc}
\hline $\begin{array}{c}\text { Discovery size class } \\
\text { (BCF) }\end{array}$ & $\begin{array}{c}\text { Recovery per well } \\
\text { (BCF) }\end{array}$ \\
\hline $250-384$ & 24.6 \\
$384-768$ & 31.5 \\
$768-1,536$ & 43.1 \\
$1,536-3,072$ & 61.5 \\
$3,072-6,144$ & 78.5 \\
$6,144-12,288$ & 108.0 \\
$12,288-24,576$ & 125.9 \\
\hline
\end{tabular}

\section{Drilling Costs}

Total development well costs were computed as the product of the number of wells required for field delineation and development and of the sum of drilling, completion, and nondrilling well costs. Development well drilling and completion cost data were compiled from several sources, including industry reports (Gingrich and others, 2001; Redman, 2002; National Petroleum Council, 2003) and historical costs for Alaska oil wells reported in the "Joint Association Survey on Drilling Costs" (American Petroleum Institute and others, 1997-2005). ${ }^{28}$ Costs were estimated for representative wells within the following vertical intervals: as much as 5,000 feet, from 5,000 feet to 10,000 feet, from 10,000 feet to 15,000 feet, and greater than 15,000 feet.

The following example illustrates the cost estimation procedure for horizontal wells. Production wells at North Slope fields are typically drilled from gravel pads that accommodate as many as 40 well collars. The well collars may be spaced as close as 10 feet apart along with production equipment. Most conventional production wells are deviated or drilled directionally to reach target locations that are horizontally offset from the drilling pad. It is assumed that the directional component adds an average of 30 percent to measured depth for drilling that is beyond the vertical depth for wells drilled with true vertical depths to 10,000 feet. For target vertical depths of 10,000 feet and greater, the directional component requires an additional 20 percent of the vertical depth to reach target depth. At the target depth, a lateral extension of 3,000 feet is drilled and completed as a horizontal extension. If the average per-foot drilling and completion cost of $\$ 600$ is assumed, then the following equation is used to estimate horizontal development well drilling and completion costs for targets at a vertical depth of 10,000 feet (James Craig, Minerals Management Service, written commun., 2005):

$$
(10,000 \mathrm{ft}[\text { vertical }] \times 1.2 \times \$ 600 / \mathrm{ft})+(3,000 \mathrm{ft}[\text { horizontal }] \times \$ 600 / \mathrm{ft})=\$ 9.0 \text { million per well }
$$

In this example, the horizontal well adds 25 percent to the costs of drilling and completing a conventional development well, but the horizontal wells reduce the required number of producing wells by more than half; that is, productivity per producing well is more than doubled. Because each horizontal well is assumed to have one horizontal injector and the conventional well is assumed to require only 4 injection wells per set of 10 producers, the overall drilling investment per barrel recovered in the example for horizontal wells is about 89 percent of the per-barrel drilling cost compared to the standard well investment. To compensate for extra costs associated with drilling wells extending beyond 15,000 feet, it is assumed that costs increase 1 percent for each 500 -foot increment in

\footnotetext{
${ }^{28}$ In some years, the number of wells drilled in Alaska far exceeded the number of wells reported in the "Joint Association Survey on Drilling Costs." Further, data appear to be presented in vertical depth intervals, whereas most North Slope production wells have a significant directional component, and so actual footage drilled is greater than vertical depth.
} 
measured depth beyond 15,000 feet (James Craig, Minerals Management Service, written commun., 2008).

Estimated costs, in 2010 dollars, by 5,000-foot depth interval for conventional wells in the accessible central North Slope area are $\$ 2.9$ million (with vertical depth 5,000 ft), \$3.8 million $(7,500$ $\mathrm{ft}), \$ 6.0$ million $(12,500 \mathrm{ft})$, and $\$ 8.7$ million $(17,500 \mathrm{ft})$. Estimated costs, in 2010 dollars, of corresponding horizontal wells with 3,000-ft lateral extensions are \$4.2 million, \$4.9 million, \$7.2 million, and $\$ 10.0$ million. These estimates represent average costs for drilling programs. Drilling costs are expected to be higher than the average for early drilling operations and lower than the average for later drilling operations in each project. Estimates of drilling costs for wells of the various NPRA study area economic zones were escalated from those cited above to include costs of mobilization and demobilization, which vary with distance from a port or other infrastructure center.

\section{Facilities Costs-Oil and Gas Development}

Production facilities include drilling pads, flow lines from drilling sites, the central processing unit, and infrastructure required for housing workers, including amenities. Facilities design and cost estimates are scaled to peak production rates and field size. As of the beginning of 2011, there were nine stand-alone fields operating in northern Alaska. These fields are Prudhoe Bay, Kuparuk River, Lisburne, Milne Point, Endicott, Badami, Northstar, Alpine, and Nikaitchuq. The Liberty field, formerly Tern Island, was in the final planning stages for commercial development.

There is little detailed information in the public domain about costs of facilities. The Minerals Management Service (MMS) published the Liberty environmental impact statement (EIS) (Craig, 2002). A step-function cost relationship that specified investment cost per barrel as a function of field size for a representative remote North Slope location was calibrated from data obtained with the QUE\$TOR software (IHS Inc., 2010). Table A3-4 shows estimates of oil facilities investment costs by accumulation size class (including cost of permitted infrastructure) assumed for economic zone 110 (text fig. 3). Initial investment costs in facilities were escalated as a function of the distance from the economic zone to a staging area for transporting equipment to the field.

Table A3-4. Estimates of oil field facilities investment costs per barrel of oil recovered by accumulation size class for facilities located in economic zone 110 of the National Petroleum Reserve in Alaska study area.

[MMBO, millions of barrels of oil; \$/bbl, 2010 dollars per barrel of oil]

\begin{tabular}{lr}
\hline $\begin{array}{c}\text { Discovery size class } \\
\text { (MMBO) }\end{array}$ & $\begin{array}{c}\text { Cost } \\
\text { (\$/bbl) }\end{array}$ \\
\hline $16-32$ & 6.59 \\
$32-64$ & 4.94 \\
$64-128$ & 3.38 \\
$128-256$ & 2.61 \\
$256-512$ & 2.04 \\
$512-1,024$ & 1.62 \\
$1,024-2,048$ & 1.33 \\
$2,048-4,096$ & 1.18 \\
\hline
\end{tabular}

Since the mid-1980s, a number of newly discovered accumulations have been developed as satellite units, where production fluids are processed at a nearby facility serving a larger field. The Point McIntyre and Niakuk accumulations share the central processing facilities at the Lisburne field. Prudhoe Bay production includes the following satellites: Midnight Sun, Aurora, Polaris, Borealis, and Orion. 
Kuparuk River production includes the following satellites: Tobasco, Tarn, Meltwater, and Palm. Thus far, nearly all of the satellite and parent fields have common ownership. The cost reduction from facility sharing depends on a number of factors, namely the composition of fluids, processing capacity of the central facility, and the relative bargaining strengths of the satellite owner and the central processing facilities owner.

Recent examples demonstrate the relationships between main field facilities and satellite development opportunities. The central processing facility at the North Slope Alpine field currently processes the produced fluid mixtures (oil, gas, and water) of wells belonging to several satellite fields located up to 25 miles away (Nelson, 2004). For gas production, the Snohvit field in the Barents Sea, offshore Norway, utilizes an 88-mile multiphase pipeline from the field to an onshore processing facility. Elsewhere in the world in deepwater offshore areas, small accumulations, even under different ownership, are produced using subsea well completion technology, and their production fluids are processed at a common production platform or facility many miles away. The advances in multiphase flow pipeline management and measurement of produced fluids have enabled these cluster and satellite production systems to monitor production in different environments and under a variety of ownership situations (Atkinson and others, 2004). Furthermore, there is strong evidence for the occurrence of spatial clustering for both conventional oil (Grace, 1997) and conventional gas accumulations (Gao and others, 2000).

The small oil field sizes posited and the small numbers of posited oil accumulations restrict the opportunities for joint development of oil discoveries in the 110 and 120 economic zones. ${ }^{29}$ It is assumed that the small number of accumulations (with sizes smaller the 100 million barrels) will be clustered spatially, so that infrastructure and facilities can be shared through joint development so that facilities and operating costs will be equivalent to those of a field in the size class from 32 million to 64 million barrels.

Gas field facilities include pads, in-field pipelines, and other infrastructure. For gas discoveries, processing equipment costs are typically a smaller proportion of the total development investment because fluid handling and processing equipment is much less elaborate than equipment needed for oil. Processing equipment is used for gas dehydration and removal of contaminants. Table A3-5 shows the unit investment cost estimates by gas field size class. The gas size distributions allocated for each of the fractile estimates when allocated to the economic zones indicated that joint development opportunities for gas accumulations of less than 384 BCF were possible in all zones except 320 and 330. It is assumed that the joint development with sharing of infrastructure and facilities would enable operators to achieve facilities and operating costs comparable to costs for a field in the size class from 384 BCF to 768 BCF.

\footnotetext{
${ }^{29}$ Joint development might be achievable given the oil accumulation size distribution corresponding to all three fractiles for economic zone 110, but for economic zone 120, it is not achievable with the accumulation size distribution corresponding to the 95th-fractile estimate.
} 
Table A3-5. Estimates of gas field facilities investment costs per thousand cubic feet of gas recovered by accumulation size class for facilities located in economic zone 110 of the National Petroleum Reserve in Alaska study area.

[BCF, billion cubic feet of gas; \$/MCF, 2010 dollars per thousand cubic feet]

\begin{tabular}{lc}
\hline $\begin{array}{c}\text { Discovery size class } \\
\text { (BCF) }\end{array}$ & $\begin{array}{c}\text { Cost } \\
\text { (\$/MCF) }\end{array}$ \\
\hline $250-384$ & 0.58 \\
$384-768$ & 0.40 \\
$768-1,536$ & 0.36 \\
$1,536-3,072$ & 0.31 \\
$3,072-6,144$ & 0.26 \\
$6,144-12,288$ & 0.24 \\
$12,288-24,576$ & 0.23 \\
\hline
\end{tabular}

\section{Production Profile}

\section{Oil Discoveries}

Future discoveries are assumed to attain peak annual rates of production equal to a percentage of the accumulation's ultimate oil recovery. Table A3-6 lists the assumptions relating to the representative oil accumulation production profiles. Peak production is maintained for several years (see table A3-6); thereafter, annual production declines 12 percent per year.

Table A3-6. Oil discovery production profiles used in the economic analysis.

[MMBO, millions of barrels of oil]

\begin{tabular}{lccc}
\hline $\begin{array}{c}\text { Discovery size class } \\
\text { (MMBO) }\end{array}$ & $\begin{array}{c}\text { Year reaches } \\
\text { peak }\end{array}$ & $\begin{array}{c}\text { Peak as percent } \\
\text { of recoverable }\end{array}$ & $\begin{array}{c}\text { Years of peak } \\
\text { production }\end{array}$ \\
\hline $16-32$ & 1 & 11 & 3 \\
$32-64$ & 1 & 11 & 3 \\
$64-128$ & 2 & 10.5 & 3 \\
$128-256$ & 2 & 10 & 3 \\
$256-512$ & 2 & 10 & 3 \\
$512-1,024$ & 3 & 9.75 & 3 \\
$1,024-2,048$ & 3 & 9 & 4 \\
$2,048-4,096$ & 3 & 8.25 & 5 \\
\hline
\end{tabular}

At first glance, the 12-percent field production decline rate appears unduly steep. Observed field decline rates are typically more subdued because of the early application of enhanced recovery techniques to prolong field life. However, the appropriate enhanced recovery application and its success often depend on site-specific conditions. Costs and production streams for oil discoveries calculated in this analysis include primary recovery and the application of waterflood.

The volume of produced water was projected by using typical field production profiles for oil, the degree of field depletion, and the water-cut functions presented by Thomas and others (1991). Figure A3-1 shows the percentage of water expected in oil production with depletion of the field with a Kuparuk-type production, and figure A3-2 shows the production characteristics for an Alpine-type 
field. The Alpine-type water-cut profile was applied to discoveries in economic zone 110, and the Kuparuk-type water-cut profile was applied elsewhere. Produced volumes of natural gas and natural gas liquids were projected by using annual oil production, the expected values of the gas-to-oil ratio, and NGL-to-gas ratios associated with the representative field's size and depth classification.

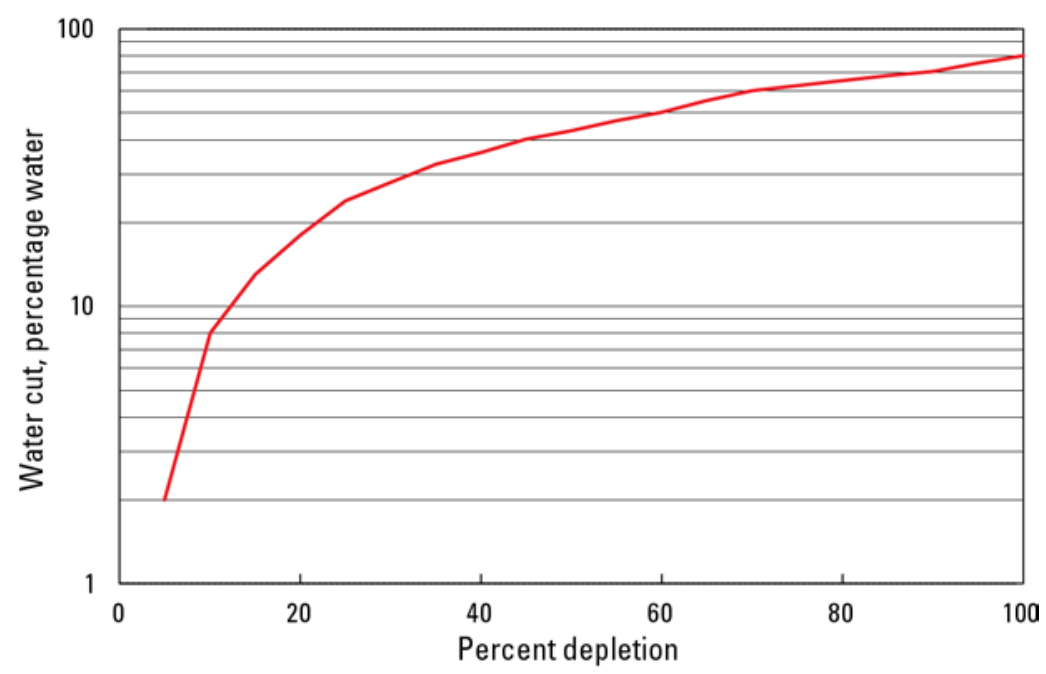

Figure A3-1. Graph showing percentage of water in oil production stream as a function of reservoir depletion for Kuparuk-type reservoirs; data are from Thomas and others (1991).

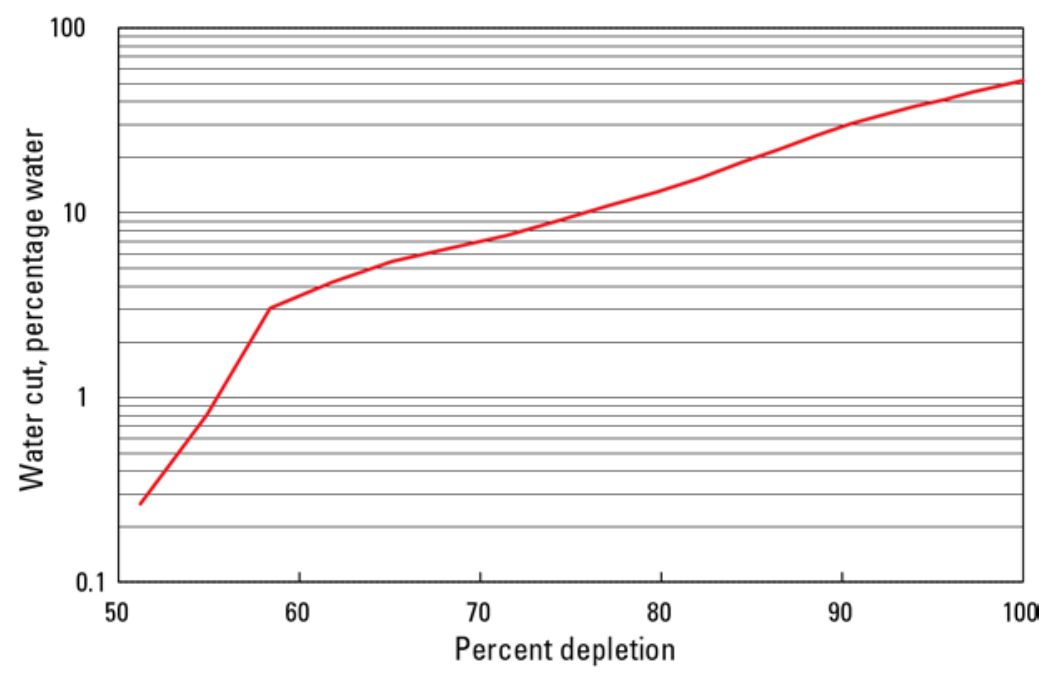

Figure A3-2. Graph showing percentage of water in oil production stream as a function of reservoir depletion for Alpine-type reservoirs in the National Petroleum Reserve in Alaska; data are from ARCO Alaska Inc. and others (1998).

\section{Gas Discoveries}

Representative gas field production profiles were originally developed by using data from the production patterns of accumulations of similar sizes in other areas. The production histories were analyzed to determine the relationship between peak field production and their known recoverable gas partitioned into field size categories. With these peak production rates as a function of estimated field size, it was assumed that field production could be held constant until 75 to 80 percent of the field's 
original reserve was produced. Increasingly, production technology has allowed the operator to control production profiles of gas fields. The period of constant production is then followed by a rapid decline at a rate of 24 percent per year. Table A3-7 lists the gas production parameters assumed for this study.

Table A3-7. Gas discovery production profiles used in the economic analysis.

[BCF, billion cubic feet of gas]

\begin{tabular}{llll}
\hline $\begin{array}{c}\text { Discovery size class } \\
\text { (BCF) }\end{array}$ & $\begin{array}{c}\text { Year reaches } \\
\text { peak }\end{array}$ & $\begin{array}{c}\text { Peak as percent of } \\
\text { recoverable }\end{array}$ & $\begin{array}{c}\text { Years of peak } \\
\text { production }\end{array}$ \\
\hline $250-384$ & 1 & 7 & 12 \\
$384-768$ & 2 & 6.75 & 12 \\
$768-1,536$ & 2 & 6.3 & 13 \\
$1,536-3,072$ & 2 & 6.2 & 13 \\
$3,072-6,144$ & 2 & 6 & 13 \\
$6,144-12,288$ & 3 & 6 & 13 \\
$12,288-24,576$ & 3 & 6 & 13 \\
\hline
\end{tabular}

\section{Operating Costs}

Annual operating costs include labor, supervision, overhead and administration, communications, catering, supplies, consumables, well service and workovers, facilities maintenance and insurance, and transportation. Some of these costs, such as well workover and labor costs, have declined dramatically during the last decade due to the introduction of coiled tubing technology and the introduction of automation in field operations.

\section{Oil Fields}

Annual operating costs, on a per-barrel-of-crude-oil basis, were estimated as a function of fluid volumes and number of operating wells (Craig, 2002). In particular, the annual oil discovery operating cost is estimated to be the sum of \$2 per barrel of annual fluid flow and \$2 million per production well per year. The produced fluids, consisting primarily of oil and water volumes, were projected annually using field production forecasts and water-cut functions (see figs. A3-1 and A3-2) from Thomas and others (1991) and ARCO Alaska Inc. and others (1998), so that per-barrel costs of produced oil increased as the water cut increased and the field approached depletion. Water production is initially very small. Operating cost estimates were cross checked with estimates from the initial year cost predictions from the QUE\$TOR software (IHS Inc., 2010).

\section{Gas Fields}

There are no commercially operating gas discoveries that export natural gas outside the North Slope, and so estimates of operating costs relied on data from studies based on the QUE\$TOR software (IHS Inc., 2010). The estimates for operating costs for gas discoveries for the NPRA are presented in table A3-8. 
Table A3-8. Gas field unit production cost used in the economic analysis.

[BCF, billions of cubic feet of gas; \$MCF, 2010 dollars per thousand cubic feet]

\begin{tabular}{lc}
\hline $\begin{array}{c}\text { Discovery size class } \\
\text { (BCF) }\end{array}$ & $\begin{array}{c}\text { Cost } \\
\text { (\$/MCF) }\end{array}$ \\
\hline $250-384$ & 1.35 \\
$384-768$ & 0.90 \\
$768-1,536$ & 0.61 \\
$1,536-3,072$ & 0.39 \\
$3,072-6,144$ & 0.28 \\
$6,144-12,288$ & 0.22 \\
$12,288-24,576$ & 0.18 \\
\hline
\end{tabular}

\section{Linkage Between Costs and Prices}

The range of prices considered is very wide, and there is evidence that increased oil prices tend to increase costs. QUE\$TOR costs are as of the third quarter of 2010 when oil prices were $\$ 82$ to $\$ 84$ per barrel. We assume at prices between $\$ 70$ and $\$ 110$ per barrel that costs are unchanged. However, for prices that exceeded $\$ 110$ per barrel, costs would increase only a fraction of the percentage increase on price. The respective decimal fractions are 0.15 for equipment, 0.2 for drilling, and 0.25 for operating costs. For example, $\$ 150$ per barrel represents a 26.7 percentage increase above $\$ 110$ per barrel. Operating costs are then assumed to increase by 25 percent of the 26.7 percent or about 6.7 percent. For the prices below $\$ 70$, the fractional reductions (of the percent reduced costs) for equipment are 0.1 ; for drilling, 0.15; and for operations, 0.2. These factors may appear to be modest, but since the 1970s, oil price spikes have triggered economic recessions in the United States, which have tended to reduce oil demand, leading to reduced oil prices and further reducing oil-related activities and costs. Also, when oil prices go beyond the range of historical experience, operators tend to introduce new technology to enhance recovery. If significant improvements in recovery technology are made, the 2010 geologic assessment of technically recoverable undiscovered resources may be conservative. 


\section{Appendix 4. Federal and Alaska Taxes}

\section{Royalties}

Royalties are payments to the resource owner. The National Petroleum Reserve in Alaska study area included areas where mineral rights were owned by the Federal Government, the Alaska State Government, and Native corporations. Actual royalty rates for State and Native lands can vary substantially for different parcels and periods, depending on the economic conditions in the oil and gas industry. To simplify the analysis, it was assumed that each oil or gas project bore a 12.5-percent royalty payment of the gross value received at the wellhead to the owner of the mineral rights. This cost was modeled by assuming that royalty was paid in kind to the owner.

\section{Alaska State Taxes}

\section{Alaska's Clear and Equitable Share Tax}

In 2007, Alaska's Clear and Equitable Share Tax (ACES) replaced the Petroleum Profits Tax (PPT). The PPT had replaced the State severance tax in 2006. The ACES and PPT taxes are on the net income of the producer. Because the ACES tax is calculated from a corporate accounting stance, certain simplifications were needed to apply it to economic analysis of a new discovery (project analysis.) The tax applies to oil, gas, and natural gas liquids. The tax rates are expressed in terms of barrels of oil equivalent, and so these commodities were converted to barrels of oil equivalent. The tax described here is specific to North Slope producers.

\section{Procedure}

The tax liability is calculated on the basis of the petroleum production value (PPV) that is taxable and the tax rate. The taxable barrels exclude the royalty-rate barrels. The corporate PPV is the product of the net wellhead price and taxable barrels (barrels net of royalty) minus operating costs (including property taxes) and capital expenditures taken that year. If the PPV is not positive, the tax liability is 4 percent of the product of the wellhead price and taxable barrels.

The tax rate escalates with increases in the PPV per barrel. When the PPV is positive but does not exceed $\$ 30$ per barrel, the tax rate is 25 percent. From $\$ 30$ per barrel to $\$ 92.50$ per barrel, the tax rate increases 0.4 percent per dollar for each dollar the PPV is greater than $\$ 30$ per barrel. At a PPV of $\$ 92.50$ per barrel, the tax rate is 50 percent. The tax rate increases to a maximum rate of 75 percent from 50 percent in steps of 0.1 percent per dollar for each dollar the PPV is greater than $\$ 92.50$.

The tax liability is the product of the tax rate and the PPV for the company. Once the tax liability is computed, tax credits can offset part of the taxes owed. If previous years had negative PPVs, then 25 percent of those losses can be carried forward to later years as a tax credit. The qualified capital expenditures (QCE) tax credit amounts to 20 percent of the capital expenditures. The accounting calculation for the tax rate, tax liability, and credits is done on a corporate basis. Tax credits may be monetized by being sold to other North Slope operators. Corporate-wide North Slope capital expenditures not only reduce the current year's tax rate by reducing the PPV per barrel, but the 20percent QCE credit reduces the actual net tax liability (Greg Bidwell, Alaska Department of Natural Resources, written commun., 2008). 


\section{Application to Project Analysis}

This analysis applied the following simplified version of the tax to the project level. During production, the PPV, tax rates, and tax liability were computed for the single project. Initial capital for expenditures for field delineation and development prior to production were totaled. Twenty percent of this total became a tax credit against future ACES tax liability. In addition, 25 percent of the annual losses incurred before the start of production were carried forward as a tax credit to offset ACES tax liability. It was assumed that 10 percent of the annual operating costs were expenditures that qualified as capital expenditures (well workover and some replacement machinery).

\section{Ad Valorem Tax}

Alaska's ad valorem tax is 2 percent of the economic value of pipelines, facilities, and equipment. For pipelines, a 20-year life was assumed. For tangible well costs, oil field equipment costs, and facilities costs, depreciation of the asset was based on the unit-of-production method. ${ }^{30}$

\section{State Income Tax}

For planning amounts of State income tax expected, the Alaska State agencies use 2 to 4 percent of net income. The rate used here was 4 percent of net income. Depreciation of capital assets associated with oil field development is permitted on a unit-of-production basis. For other capital, depreciation depends on the economic life of the equipment.

\section{State Conservation Tax}

The State conservation surcharge tax was assumed to be set at $\$ 0.05$ per barrel of oil.

\section{Federal Income Taxes}

A Federal income tax rate of 35 percent of taxable income was assumed. According to the 1986 Tax Reform Act, 30 percent of development well drilling costs is classified as tangible cost and therefore, capitalized over 7 years. Of the remaining 70 percent of drilling cost (that is, the intangible drilling costs), 30 percent is depreciated over 5 years, and the remaining 70 percent is expensed immediately.

\footnotetext{
${ }^{30}$ As a practical matter, as long as the asset is operating, the basis for the tax will not be smaller than 25 percent of either the initial investment or the asset's estimated replacement value (Greg Bidwell, Alaska Department of Natural Resources, written commun., 2008).
} 


\section{Appendix 5. Cost Sensitivity Analysis}

An analysis of the sensitivity of the predicted economic resources to the variations in costs provides a cautionary note on the interpretation of the overall analysis. This discussion of the results focuses on sensitivity of predicted economic volumes at the three market prices of $\$ 8, \$ 10$, and $\$ 12$ per MCF. These prices bracket the Black and Veatch (2010) high-price scenario of forecasted prices for the conterminous United States in 2030. Figures A5-1, A5-2, and A5-3 show the response in terms of percentage change in the economic volume of gas in undiscovered gas accumulations based on the mean estimate for the NPRA study area with changes in drilling and facilities costs, changes in gas transportation costs, and changes in investment cost of drilling, facilities, and North Slope pipelines. The so-called "base case economic volumes" are shown in table 3 in the text and correspond to the mean estimates of the study area assessment (Houseknecht and others, 2010).
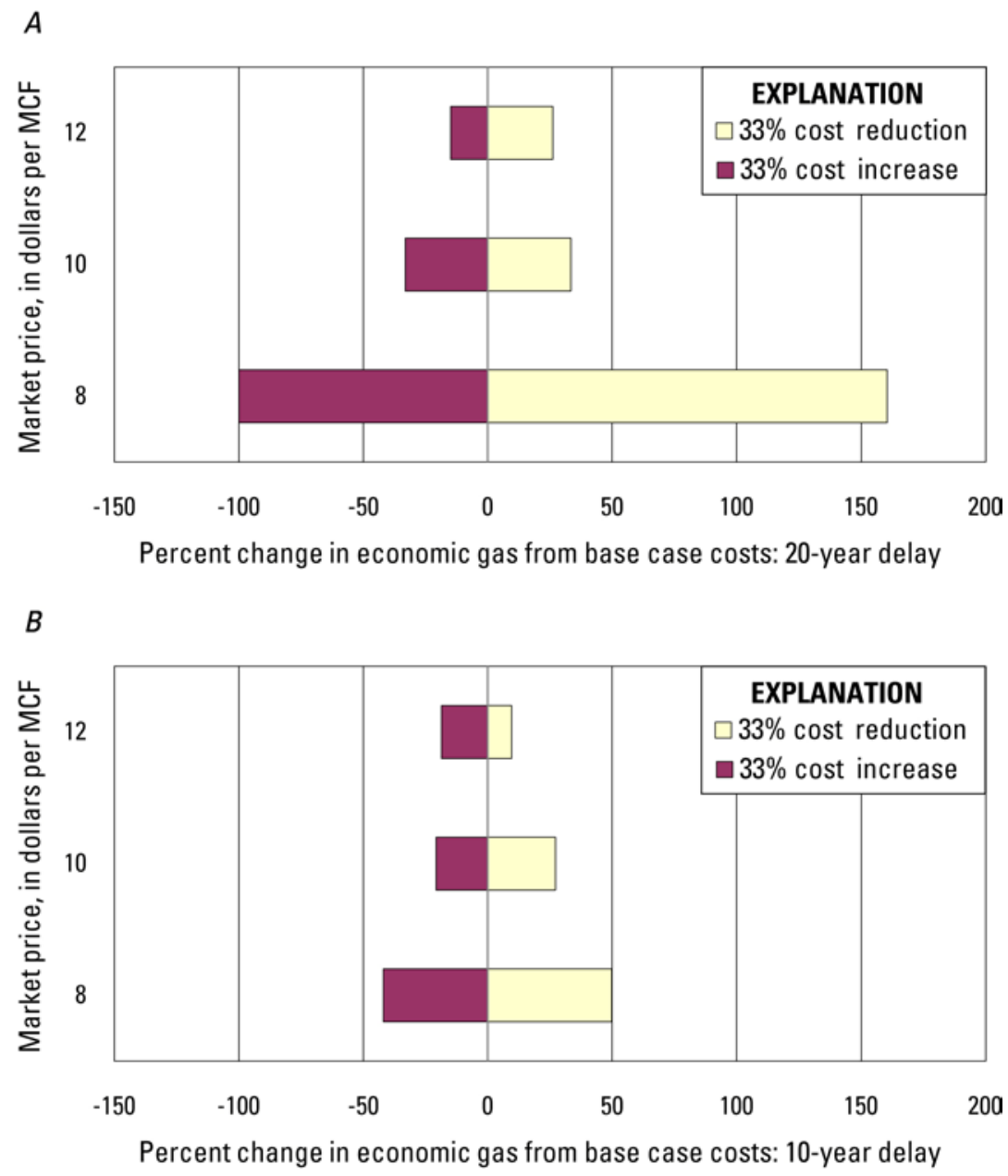

Figure A5-1. Graphs showing percentage changes in economic volumes of gas in undiscovered gas accumulations at different market prices (in dollars per thousand cubic feet, MCF) based on the mean estimate for the NPRA study area with either a 33-percent increase or a 33-percent reduction in investment costs of drilling and facilities from the base case and with either $(A)$ a 20-year delay or $(B)$ a 10-year delay between discovery and availability of an export pipeline to market. 


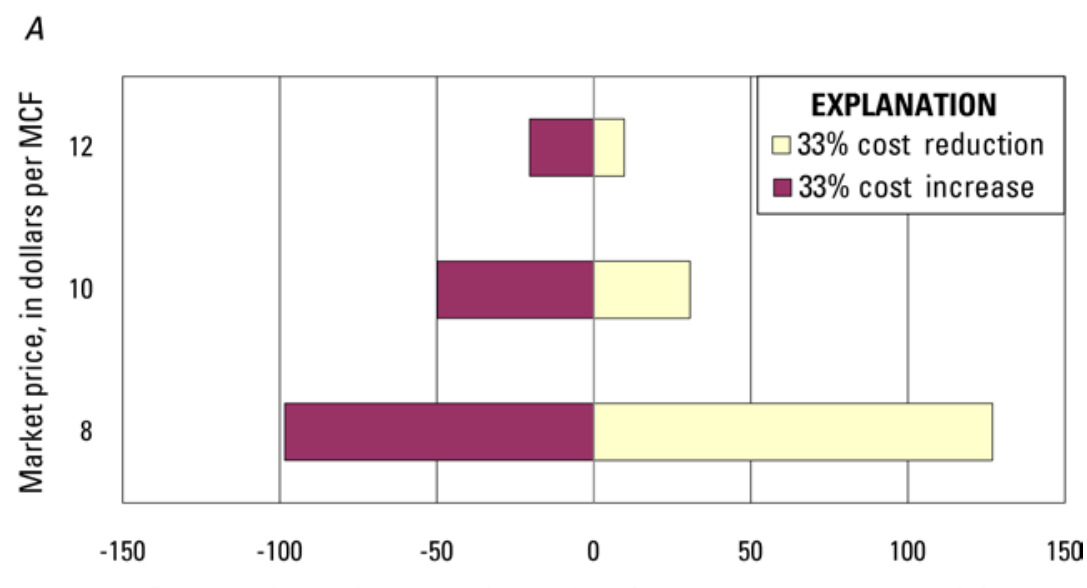

Percent change in economic gas from base case costs: 20 -year delay

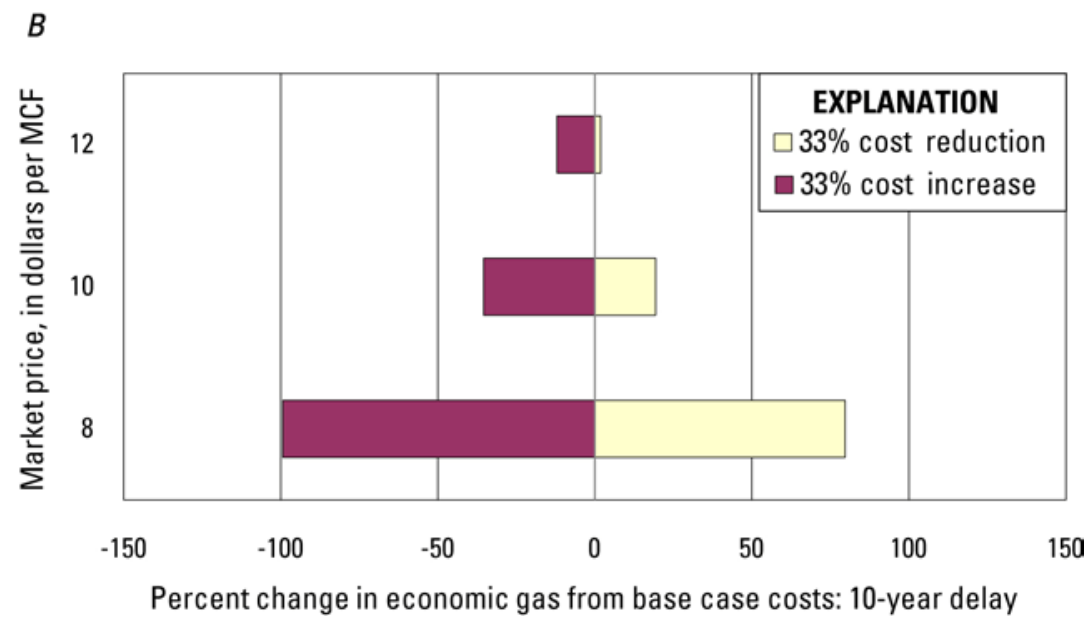

Figure A5-2. Graphs showing percentage changes in economic volumes of gas in undiscovered gas accumulations at different market prices (in dollars per thousand cubic feet, MCF) based on the mean estimate for the NPRA study area with either a 33-percent increase or a 33-percent reduction in transportation costs from the base case and with either $(A)$ a 20-year delay or $(B)$ a 10-year delay between discovery and availability of an export pipeline to market. Transportation costs include the cost of pipelines internal to the North Slope and the cost of assumed tariffs to gas and crude oil export markets. 

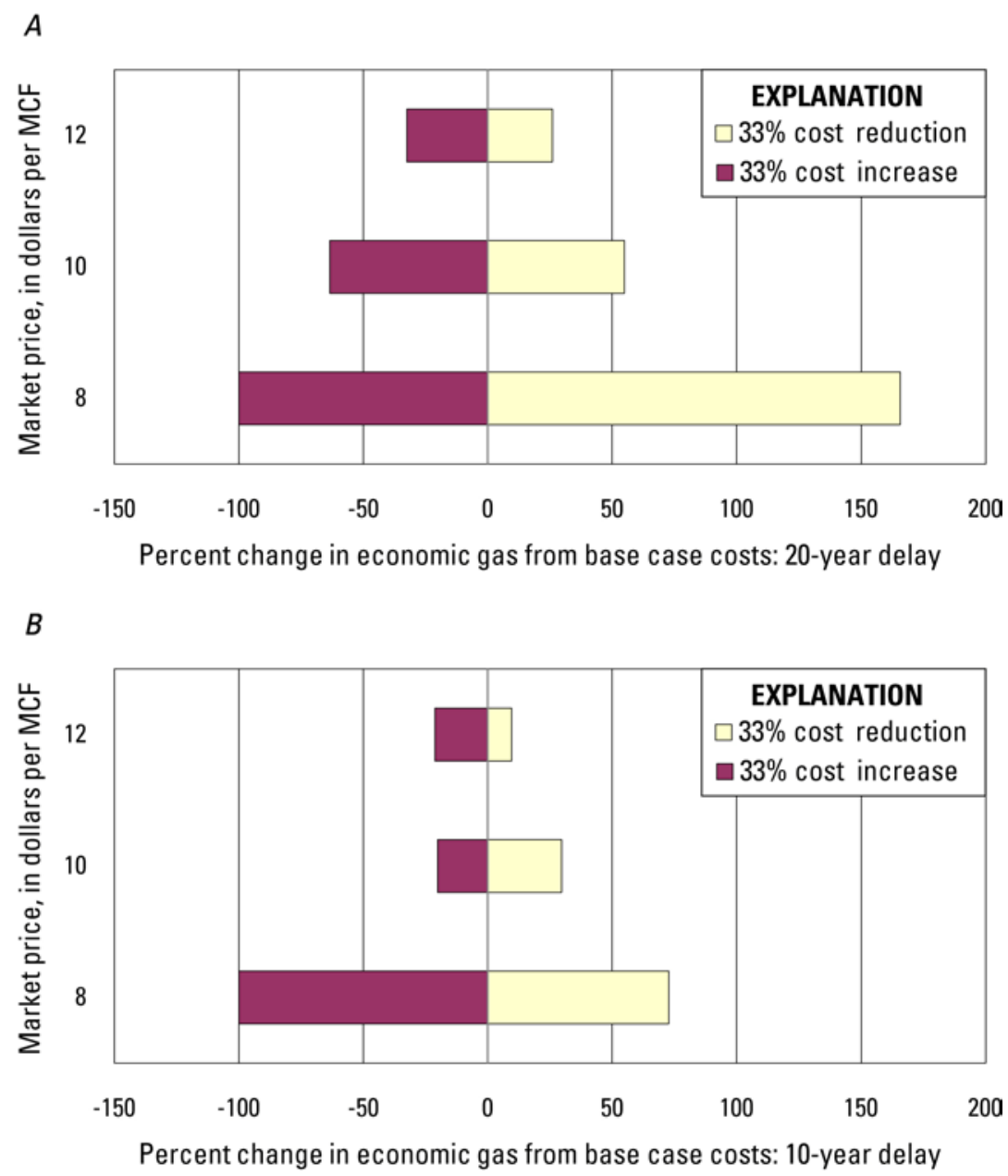

Figure A5-3. Graphs showing percentage changes in economic volumes of gas in undiscovered gas accumulations at different market prices (in dollars per thousand cubic feet, MCF) based on the mean estimate for the NPRA study area with either a 33-percent increase or a 33-percent reduction in investment costs of drilling, facilities, and pipelines (within the North Slope) from the base case and with either $(A)$ a 20 -year delay or $(B)$ a 10 year delay between discovery and availability of an export pipeline to market.

Figure A5-1A shows that, at the three market price levels of $\$ 8, \$ 10$, and $\$ 12$ per MCF, increasing investment costs of drilling and facilities by one-third (33 percent) will reduce economic volumes by 100 percent, 33 percent, and 15 percent, respectively, when a 20-year delay is assumed to exist between discovery and export pipeline capacity availability. Alternatively, reducing these costs by one-third will increase economic gas by 160 percent, 33 percent, and 26 percent for the three price levels.

Figure A5-2A shows that increasing product transportation costs (North Slope pipeline and oil and gas line export tariffs) by one-third will reduce economic gas from the base case for the three price levels $(\$ 8, \$ 10$, and $\$ 12$ per MCF) by 98 percent, 50 percent, and 20 percent when a 20 -year delay is assumed to exist. Alternatively, reducing those costs by one-third will increase the economically recoverable gas by 127 percent, 31 percent, and 10 percent for the market price levels of $\$ 8, \$ 10$, and $\$ 12$ per MCF. 
Figure A5-3A shows that, at the three price levels, the economic gas will decline by 100 percent, 64 percent, and 33 percent if investment costs of drilling, facilities, and pipelines within the North Slope increase by one-third and if a 20-year delay in export pipeline availability is assumed. If those costs are reduced by one-third, the economic gas will increase by 166 percent, 55 percent, and 26 percent at the three price levels. Figures A5-1B, A5-2B, and A5-3B show the corresponding sensitivity results for a 10-year delay between discovery and export pipeline availability.

For the market prices considered, the sensitivity analysis shows economic volumes to be quite sensitive to the cost assumptions used in text table 3 at market prices up to $\$ 10$ per MCF. As prices go beyond $\$ 10$ per MCF, the percentage differences in economic volumes induced by alternative cost assumptions are substantially dampened. Supplemental sensitivity studies showed that the economic values are somewhat more sensitive to drilling costs because drilling not only affects development but also affects the quantity of economic exploration. Comparing results for the 20-year delay with results for the 10-year delay, at the prices examined, shows that the predicted economic volumes associated with the 20-year delay are much more sensitive to cost increases and reductions than the economic volumes associated with the 10-year delay.

The other results worth mentioning relate to breaking down drilling and facilities costs; economic gas is more driven by a change in drilling cost than by a similar percentage change in facilities cost because drilling costs directly determine how much exploration will take place. An increase of one-third for exploration costs will reduce economic gas (from the base case at $\$ 8, \$ 10$, and $\$ 12$ per MCF) by 84 percent, 20 percent, and 15 percent. Reducing exploration costs by one-third will increase economic gas at the three price levels by 44 percent, 20 percent, and 14 percent for the 20 -year delay assumption. 